\title{
Untersuchung zur Rolle des
}

stressinduzierten Proteins Cysteine-rich

angiogenic inducer 61 als Biomarker für

die Früherkennung von

Mammakarzinomen

\author{
INAUGURAL-DISSERTATION \\ zur Erlangung des Doktorgrades \\ der Medizinischen Fakultät der
}

Georg-August-Universität zu Göttingen

vorgelegt von

Isabel Heidrich, geb. Pantel

aus

Dachau

Göttingen 2020 
Die vorliegende Dissertation wurde in Hamburg im Zeitraum von Juni 2017 bis Oktober 2018 in der Arbeitsgruppe von Dr. rer. nat. K. Bartkowiak unter der Betreuung von Prof. Dr. S. Johnsen $(\mathrm{PhD})$ angefertigt.

Dekan:

\section{Betreuungsausschuss}

Betreuer/in

Ko-Betreuer/in:

\section{Prüfungskommission}

Referent/in

Prof. Dr. S. Johnsen (PhD)

Ko-Referent/in:

Prof. Dr. C. Gründker

Drittreferent/in:

Prof. Dr. M. Oppermann

Datum der mündlichen Prüfung: 24.11.2020 
Hiermit erkläre ich, die Dissertation mit dem Titel "Untersuchung zur Rolle des stressinduzierten Proteins Cysteine-rich angiogenic inducer 61 als Biomarker für die Früherkennung von Mammakarzinomen" eigenständig angefertigt und keine anderen als die von mir angegebenen Quellen und Hilfsmittel verwendet zu haben.

Göttingen, den ..............

(Unterschrift) 


\section{Inhaltsverzeichnis}

Abbildungsverzeichnis .......................................................................................... I

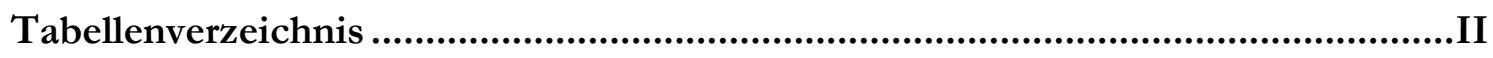

Abkürzungsverzeichnis................................................................................. III

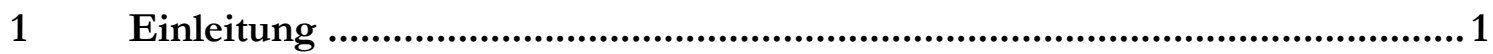

1.1 Inzidenz, Mortalität und Früherkennung des Mammakarzinoms ...............................................1

1.2 Gewebediagnostik und ihre Limitationen beim Mammakarzinom..............................................

1.3 Biologie der Tumorzelldisseminierung und Metastasierung........................................................

1.4 Cystein-rich angiogenic protein 61 (CYR61) als potenzieller Biomarker für die

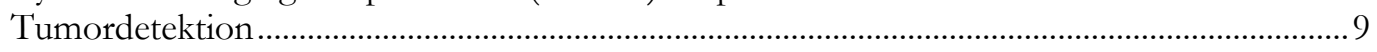

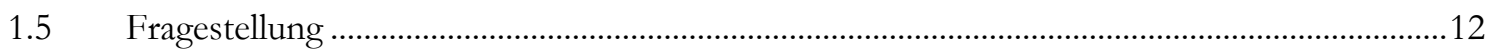

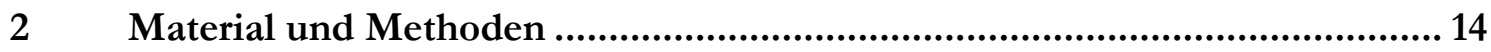

$2.1 \quad$ Liste der Geräte, Materialien und Chemikalien .......................................................................14

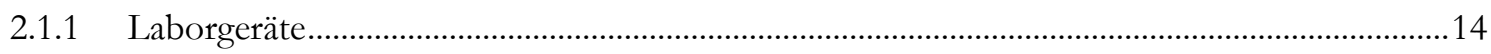

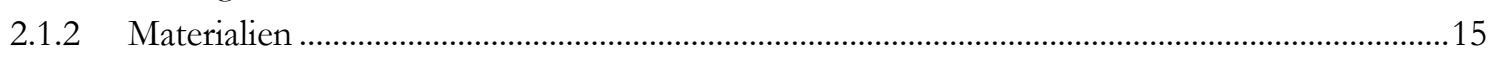

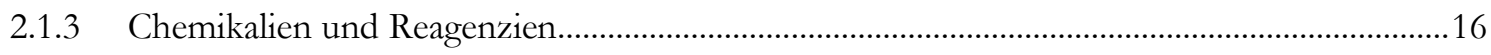

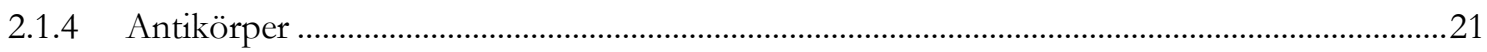

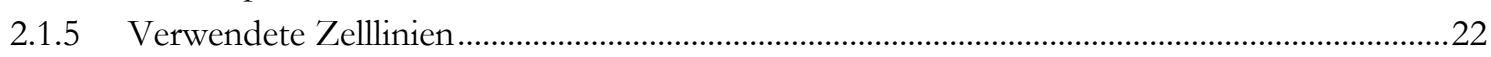

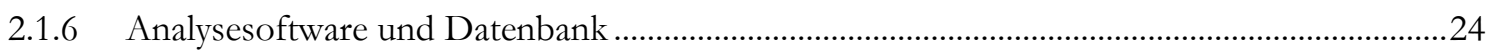

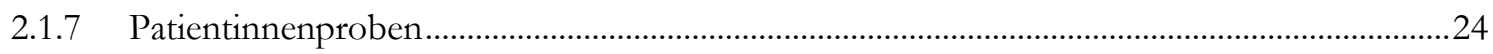

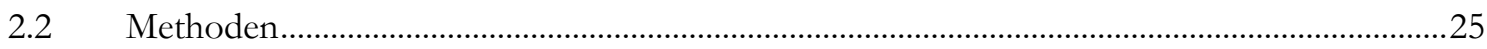

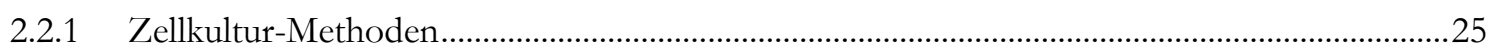

2.2.2 Herstellung von Proteinextrakten und BCA-Proteinmengenbestimmung ...............................26

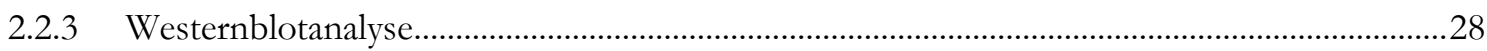

2.2.4 Vorbereitung der Proben für eine quantitative Proteinbestimmung mittels Sandwich-

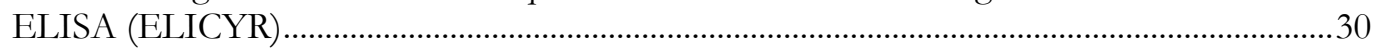

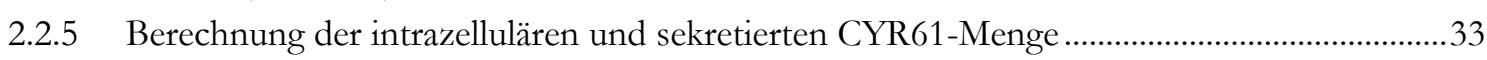

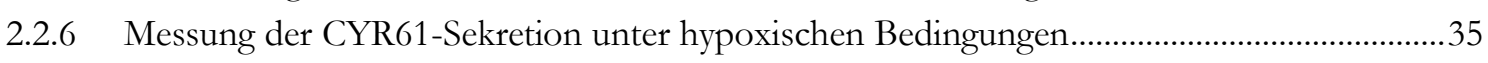

2.2.7 Messung der intra- und extrazellulären CYR61-Konzentration unter EGF-Stimulation.......35

2.2.8 Sandwich-ELISA (ELICYR) mit Plasmaproben von Patientinnen mit

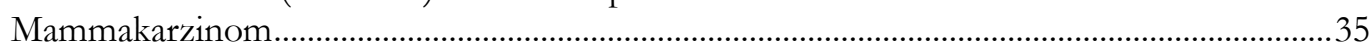

2.2.9 Datenerfassung und statistische Auswertung der Sandwich-ELISA-Messungen von Blutproben in Bezug auf die Menge an CYR61 im Plasma der Patientinnen ...........................36

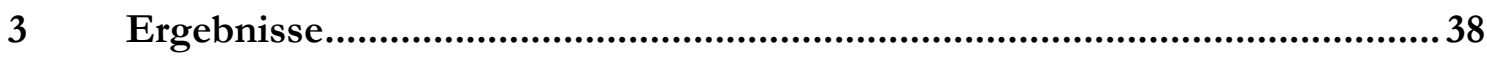

3.1 Zelltypabhängige Differenzen in der Expression von CYR61 ………….................................39

3.2 Gesamtmenge des zytoplasmatischen und sekretierten CYR61-Proteins in

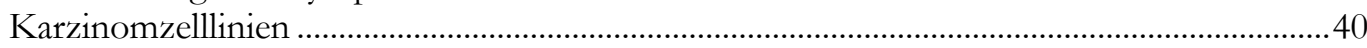

3.3 Expression von CYR61 in Karzinomzellen unter hypoxischen Bedingungen.........................45

3.4 Expression von CYR61 in Karzinomzellen unter EGF-Stimulation .......................................48 
3.5 Definition von Patientinnen- und Kontrollgruppen und Erhebung klinischer Daten der Mammakarzinompatientinnen.

3.6 Sandwich-ELISA-basierte Messung von CYR61-Proteinkonzentrationen im Blutplasma von Mammakarzinompatientinnen und gesunden Frauen...

3.7 Statistische Auswertung: Korrelation der krankheitsbezogenen Daten zu den CYR61Konzentrationen im Blutplasma ...............................................................................................56

3.8 Analyse der Assoziation des CYR61-Spiegels im Blutplasma von Mammakarzinompatientinnen mit klinisch-pathologischen Eigenschaften ...............................60

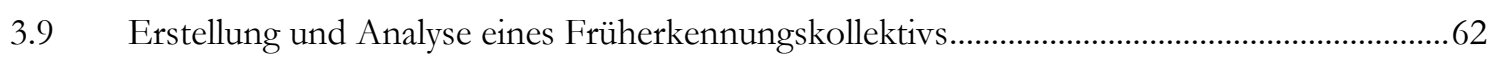

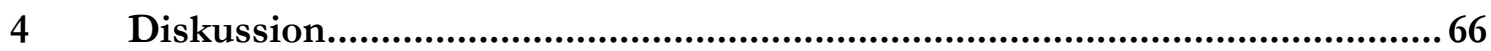

4.1 Zelltypabhängige Differenzen in der Expression von CYR61 ……………………………....66

4.2 Expression von CYR61 in Mammakarzinomzellen unter hypoxischen Bedingungen

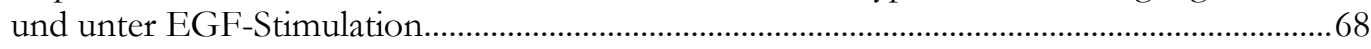

4.3 Eignung von CYR61 als neuer Tumormarker in der Mammakarzinomfrüherkennung .......72

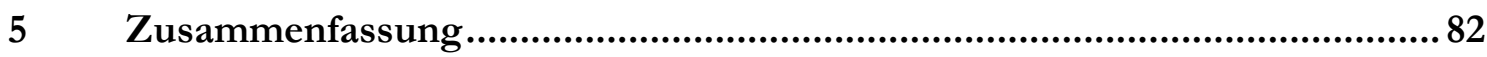

6 Anhang.

Diagramme über die CYR61-Proteinmengen und CYR61-Konzentrationen pro Tumorzelle und Zelllinien.

Ethikvotum der Universität Hamburg................................................................................... 87

7 Literaturverzeichnis 


\section{Abbildungsverzeichnis}

Abbildung 1: Absolute Zahl der Neuerkrankungen am Mammakarzinom und Sterbefälle in Deutschland von 1999-2014/2015.

Abbildung 2: Tumorzellen und zirkulierende Tumor-DNA als Flüssigbiospie...................................6

Abbildung 3: Tumorzelldissemination und Tumorzellplastizität.................................................... 8

Abbildung 4: Modelhafte Darstellung des Aufbaus von CCN1-Proteinen: CYR61...........................10

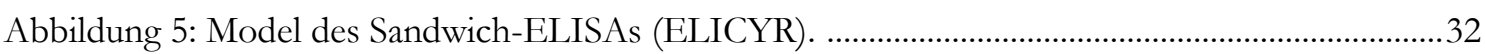

Abbildung 6: Westernblotanalyse von CYR61 in elf Mammakarzinomzelllinien. ............................39

Abbildung 7: Gesamtmenge an rekombinantem CYR61 [in ng] im Zelllysat. ....................................41

Abbildung 8: Gesamtmenge an rekombinantem CYR61 [in ng] im Überstand. ................................42

Abbildung 9: Bestimmung der CYR61-Molekülanzahl pro Tumorzelle im Lysat in neun

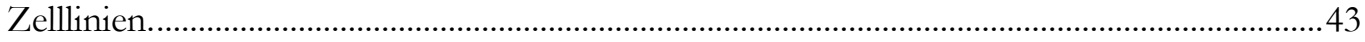

Abbildung 10: Bestimmung der CYR61-Molekülanzahl pro Tumorzelle im Überstand in neun Zelllinien.

Abbildung 11: Messung der CYR61-Sekretion von hypoxisch und atmosphärisch kultivierter MDA-MB-231-Zellen

Abbildung 12: Messung der CYR61-Sekretion von hypoxisch und atmosphärisch kultivierter MDA-468-Zellen.

Abbildung 13: Westernblotanalyse über die Expression von EGFR, ErvB-2, AKT und pho$\mathrm{AKT}(\mathrm{S} 743)$.

Abbildung 14: Westernblotanalyse bei EGF-Stimulation im Vergleich zu nicht stimulierten Kontrollen der Zelllinie MDA-MB-231-BO2.

Abbildung 15:Westernblotanalyse bei EGF-Stimulation im Vergleich zu nicht stimulierten Kontrollen der Zelllinie MDA-MB-231.

Abbildung 16: Veränderung der Konzentrationen von sekretiertem CYR61-Protein in Mammakarzinomzelllinien nach EGFR-Stimulation

Abbildung 17: Veränderung der Konzentrationen von sekretiertem CYR61-Protein in Mammakarzinomzelllinien nach EGFR-Stimulation............................................................54

Abbildung 18: Reproduzierbarkeit des CYR61-Sandwich-ELISAs in Plasmaproben von Mammakarzinompatientinnen.

Abbildung 19: CYR61-Konzentration im Blutplasma von Mammakarzinompatientinnen und gesunden Frauen.M

Abbildung 20: ROC-Kurve zur diagnostischen Wertigkeit der CYR61-Konzentration im Blut für alle analysierten Mammakarzinomfälle im Vergleich zu gesunden Frauen

Abbildung 21: ROC-Kurve zur diagnostischen Wertigkeit der CYR61-Konzentration im Blut von Mammakarzinompatientinnen (DCIS und Tumorstadium T1) ....................................58

Abbildung 22: ROC-Kurve zur diagnostischen Wertigkeit der CYR61-Konzentration im Blut von Mammakarzinompatientinnen (Tumorstadien T2-T4)

Abbildung 23: ROC-Kurve für alle analysierten Mammakarzinomfälle des Früherkennungskollektivs ( $\mathrm{n}=443)$ im Vergleich zu gesunden Frauen $(\mathrm{n}=324)$

Abbildung 24: ROC-Kurve zur diagnostischen Wertigkeit der CYR61-Konzentration im Blut von Mammakarzinompatientinnen (DCIS und Tumorstadium T1) des Früherkennungskollektivs.

Abbildung 25: ROC-Kurve zur diagnostischen Wertigkeit der CYR61-Konzentration im Blut von Mammakarzinompatientinnen (Tumorstadium T2) des Früherkennungs-

kollektivs. 


\section{Tabellenverzeichnis}

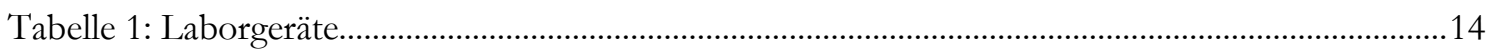

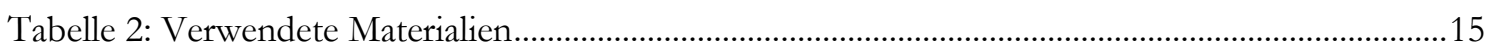

Tabelle 3: Verwendete Chemikalien, Reagenzien und Puffersubstanzen.............................................16

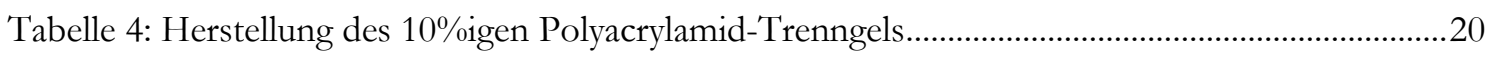

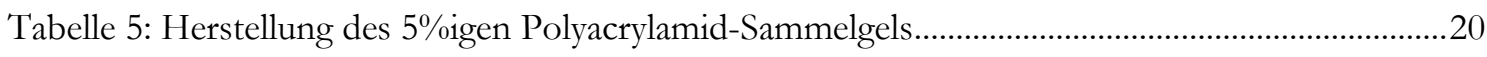

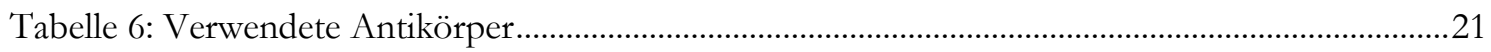

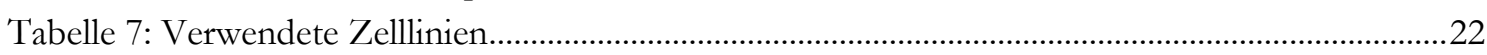

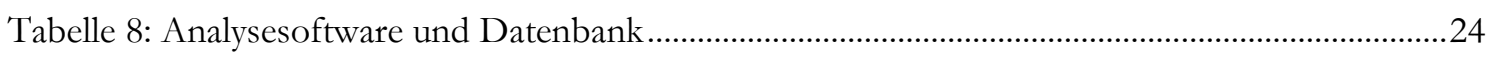

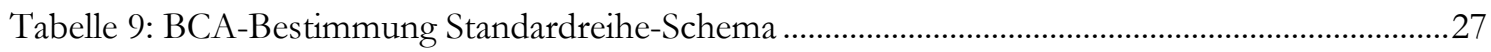




\section{Abkürzungsverzeichnis}

APS

AWMF

$\mathrm{BC}$

bFGF

Bp

BSA

$\mathrm{CD}$

CRC

CRP

CTC

$\mathrm{Ct}$

ctDNA, cfRNA

Cyr61

DAF

DKG

dkfz

DMEM

DMSO

DNA

DTC

DTT

ECM

EGF

EMT

EDTA

ELISA

ER

EU

FACS
Ammoniumperoxodisulfat

Arbeitsgemeinschaft der Wissenschaftlichen

Medizinischen Fachgesellschaften

Bicinchoninsäure

breast cancer (Mammakarzinom)

basic fibroblast growth factor (Fibroblasten-Wachstumsfaktor)

Basenpaar(e)

Bovines Serumalbumin

cluster of differentiation (Differenzierungscluster)

colorectal cancer (kolorektales Karzinom)

C-reaktives Protein

circulating tumor cell ( zirkulierende Tumorzelle)

C-terminale

zellfreie zirkulierende Nukleinsäuren

cysteine-rich angiogenic inducer 61

decay-accelerating factor (Zerfallsbeschleunigungsfaktor)

Deutsche Krebsgesellschaft

Deutsches Krebsforschungszentrum

Dulbecco's Modified Eagle Medium

Dimethylsulfoxid

Desoxyribonukleinsäure

disseminated tumor cell (disseminierte Tumorzelle)

Dithiothreitol

extracellular matrix (Extrazelluläre-Matrix-Komponente)

epidermal growth factor (epidermale Wachstumsfaktor)

Epithelial-mesenchymale Transition

Ethylendiamintetraacetat

ensyme-linked immunosorbent assay (enzymverbundendes

Immunosorbens-Assay)

Östrogenrezeptor

Europäische Union

fluorescence-activated cell sorting (fluoreszensaktivierte 
FCS

FITC

HRP

HSPG

IGFBP

IARC

LPIP

MET

NSCLC

PBS

PC

PCR

PSA

ROC

RPMI

TEMED

TBST

TMB

TSR

VEGF

vWC

ZfKD
Zellsortierung)

fetal calf serum (fetales Kälberserum)

Fluoreszeinisothiocyanat

horseradish peroxidase (Merettichperoxidase)

Heperansulfat Proteoglykane

Insulin-like-growth-factor-Bindungsprotein

International Agency for Research on Cancer

lysophosphatidylinositol monophosphate

mesenchymal-epitheliale Transition

Non-Small Cell Lung Carcinoma (nicht kleinzelliges

Bronchialkarzinom)

phosphate-buffered saline (phosphatgepufferte Salzlösung)

prostate cancer (Prostatakarzinom)

polymerase chain reaction (Polymerase-Kettenreaktion)

prostataspezifisches Antigen

receiver operating characteristic

Roswell Park Memorial Institute

Tetramethylethylendiamin

Tris-buffered saline with Tween

(Tris-gepufferte Kochsalzlösung mit Tween)

3,3',5,5'-Tetramethylbenzidin

Thrombospondin-Typ 1-Wiederholungsdomäne

vascular endothelial growth factor

(vaskulärer Endothelwachstumsfaktor)

Von-Willebrand-Typ-C-Wiederholungen

Zentrum für Krebsregisterdaten 


\section{Einleitung}

Die jährliche Inzidenz von Krebserkrankungen liegt bei 500.000 Menschen pro Jahr in Deutschland und die Tendenz ist steigend. Davon erkranken allein 73.000 Menschen an Mammakarzinom (ZfKD 2017). Oft entsteht der Tumor zunächst lokalisiert, streut aber schon frühzeitig über die Lymph- und Blutbahn in andere Organe (Hannahan und Weinberg 2011). Dort können sich disseminierte Tumorzellen (DTCs) ansiedeln, sich an die neuen Mikroumgebungsbedingungen anpassen und dann zu Metastasen heranwachsen (Kang und Pantel 2013; Mohme et al. 2016). Im Folgenden soll ein Überblick über die Inzidenz, Mortalität und Früherkennung des Mammakarzinoms gegeben werden.

\subsection{Inzidenz, Mortalität und Früherkennung des Mammakarzinoms}

Das Mammakarzinom ist die häufigste neoplastische Neubildung bei Frauen im Alter unter 45 Jahren sowie zwischen 45 und 65 Jahren und somit die krebsbedingte Haupttodesursache von Frauen weltweit (Fitzmaurice et al. 2018). Im Jahr 2016 wurden weltweit 1,7 Millionen neue Mammakarzinomdiagnosen gestellt, wobei 35.000 Frauen und 10.000 Männer daran verstarben (Fitzmaurice et al. 2018). Damit ist es die fünfthäufigste Krebstodesursache kombiniert bei beiden Geschlechtern im Jahr 2016 weltweit. Das Mammakarzinom war 2016 die Hauptursache für einen Krebstod bei Frauen (Fitzmaurice et al. 2018). Es wird davon ausgegangen, dass eine frühe Erkennung des Mammakarzinoms zu einer erheblichen Reduzierung in der Sterblichkeit führen könnte (Puliti et al. 2008). Dennoch verringerte sich die Mortalitätsrate bei steigender Inzidenz über die letzten zwanzig Jahre lediglich um 7,5 \% (ZfKD 2017).

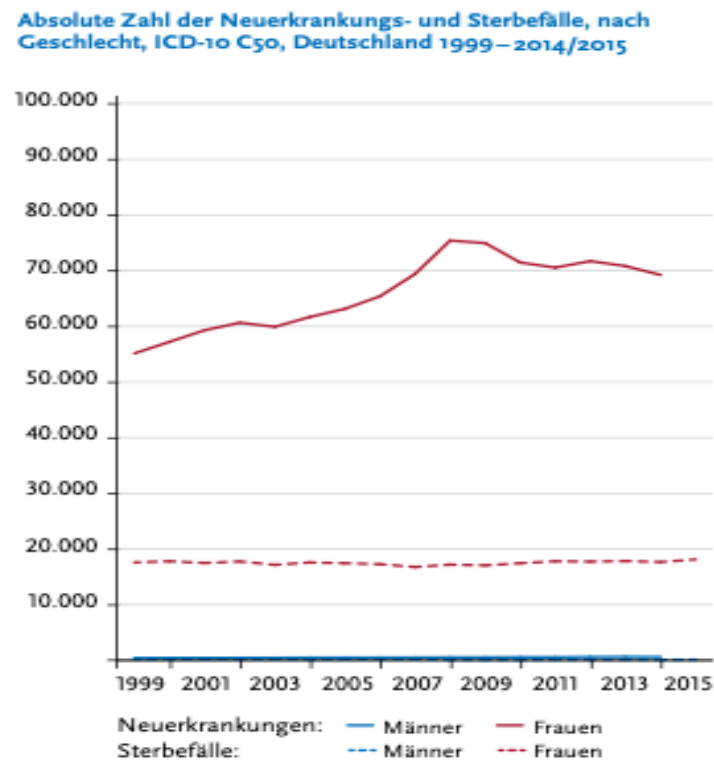

Abbildung 1: Absolute Zahl der Neuerkrankungen am Mammakarzinom und Sterbefälle in Deutschland von 1999 2014/2015. (ZfKD 2017; mit freundlicher Genehmigung vom Robert KochInstitut). 
Mit der Einführung des Mammographie-Screening-Programms 2005 bis 2009 sind die Erkrankungsraten zunächst in diesem Zeitraum bis zu einem Maximum angestiegen und danach gefallen, während die Sterberaten im gesamten Zeitraum relativ konstant blieben. In Deutschland übernehmen die gesetzlichen Krankenkassen die Kosten für eine regelmäßige Früherkennungsuntersuchung. Das Alter der Frau bestimmt das Intervall zwischen den Untersuchungen. So sollen bei Frauen zwischen 30 und 49 Jahren und ab 70 Jahren einmal jährlich die Brustdrüsen und Lymphknoten in den Achselhöhlen und am Schlüsselbein abgetastet werden. Zudem wird die Brustwarze inspiziert und palpiert. Frauen zwischen 50 und 69 Jahren bekommen zusätzlich alle zwei Jahre eine Einladung am Mammographie-Screening teilzunehmen. Bei erblicher Vorbelastung und Vorliegen einer Genveränderung, beispielsweise BRCA1 - oder BRCA2-Genmutationen, sollen Frauen bereits ab dem 25. Lebensjahr alle sechs Monate eine Tast- und Ultraschalluntersuchung bekommen, und zusätzlich wird einmal jährlich eine Kernspintomographie empfohlen. Die zweijährige Mammographie darf in solchen Fällen schon ab dem 40. Lebensjahr stattfinden und wird ab diesem Zeitpunkt von den Krankenkassen übernommen (Puliti et al. 2008; Leitlinie Mammakarzinom 2018; DKG 2018). Dieses Vorsorgeprogramm verursacht, aufgrund von 10,4 Millionen anspruchsberechtigten Frauen, hohe Kosten. Von diesen nehmen circa $70 \%$ an einem Mammographie-Screening in Deutschland teil, was Kosten von fast 250 Millionen Euro jährlich verursacht. Mit eingeschlossen sind in diese Rechnung ebenso der Aufwand für Qualitätssicherungsmaßnahmen, Doppelbefundungen und Abklärungsdiagnostik (Bick 2006).

Trotzdem ist die Mammographie heute unentbehrlich. Die Mammographie ist die einzige von der Europäischen Kommission anerkannte Methode zur Früherkennung von Brustkrebs für Frauen zwischen 50 und 69 Jahren. Es ist eine morphologische Methode zur Untersuchung der Brust in ihrer Gesamtheit und bietet bisher die höchste Empfindlichkeit auch für Tumoren im Frühstadium (Tis, T1, T2) (Altobelli und Lattanzi 2014). Ihre Spezifität ist allerdings durch die Dichte der Brust, die Technik und den Arzt, der auswertet, stark beeinflusst. Der Wert für das Areal unter der Kurve (AUC-Wert) einer Receiver-Operator-Kurve (ROC) liegt für die Detektion eines duktalen Karzinoms in situ (DCIS) bei 0,731 bis 0,837 und für die Detektion eines frühen invasiven Tumors bei 0,830 bis 0,907 (Aminololama-Shakeri et al. 2017).

DCIS sind prämaligne Neoplasien der Brust, die als frühste Läsion des Brustkrebses gelten. Die Größe des Tumors, seine Ausbreitung und der Befall ferner liegender Organe werden in der sogenannten TNM-Klassifikation beschrieben. Dabei steht T für das Tumorstadium bzw. die Ausdehnung des Tumors. $N$ steht für die Beurteilung der regionären Lymphknoten bis zur 
Schlüsselbeinregion und $\mathrm{M}$ steht für die Beurteilung der Fernmetastasen in der Leber, der Lunge, den Knochen oder im Gehirn (Psychrembel Redaktion 2016).

Die Einführung der digitalen Mammographie führte zu einem starken Anstieg der Mammakarzinomdiagnosen, hat aber bisher eine erwartete Verringerung der Sterblichkeitsrate von $20 \%$ bis $30 \%$ nicht erreicht. Altobelli und Lattanzi (2014) sprechen sogar davon, dass die Mammographie die Sterblichkeit nicht signifikant beeinflusst haben soll, da die Sterblichkeit im Zusammenhang mit einer Vielzahl von krankheitsrelevanten Faktoren steht. Untersuchungen von Mortalitätsänderungen des Mammakarzinoms ergaben, dass in Ländern, die nach 2006 ein Screening-Programm eingeführt haben, von 2006 zu heute eine geringe Reduktion der allgemeinen Sterblichkeitsraten stattgefunden hat. Dies wird unter anderem durch den überlebensfördernden Effekt von verbesserten Operationstechniken, Strahlen- oder Chemo/Antikörpertherapien erklärt (Botha et al. 2003; Altobelli und Lattanzi 2014). Trotzdem ist die Mammographie der derzeitige Goldstandard bei der Früherkennung von Mammakarzinomen. Vorteile des Mammographie-Screenings ergeben sich aus der Möglichkeit, einen Tumor heutzutage schon in kleiner Größe zu erkennen (Tis, T1). Nachteile sind neben der Strahlenbelastung und den hohen Kosten falsch-positive oder falsch-negative Ergebnisse die zu einer starken emotionalen Belastung der Patientinnen führen. Zudem können Tumore zwischen den Intervallgrenzen von zwei Jahren entstehen, die dann zu spät entdeckt werden (Kooperationsgemeinschaft Mammographie GbR 2018). Die Einführung eines Krebsvorsorgeprogramms beinhaltet zudem stets einen Anstieg der Diagnoseraten und ebenso der Überdiagnoseraten und daraus resultierender Übertherapie, die 2014 auf fünf bis 30 \% geschätzt wurden (IARC 2014).

Die Zahl der Männer und Frauen, die in der EU Krebsfrüherkennungsprogramme wahrgenommen haben, hat sich 2016 im Vergleich zu 2007 verdoppelt (Basu et al. 2018). In Anbetracht dessen, dass noch zu viele potenziell heilbare Tumore zu lange unentdeckt bleiben, empfehlen Basu et al. (2018) den EU-Staaten, die Inbetrachtziehung neuer Ansätze, wie Blutuntersuchungen, ergänzend neben den bildgebenden Verfahren, zu etablieren. Zudem sei die Teilnahme an fortlaufenden Überwachungen, regelmäßigen Rückmeldungen und regelmäßigen Berichten essenziell, um die gewünschten Auswirkungen der Screening-Programme in der EU festzustellen und gegebenenfalls intervenieren und Innovationen anstreben zu können.

\subsection{Gewebediagnostik und ihre Limitationen beim Mammakarzinom}

Eines der Hauptziele in der Krebsforschung ist es, den Krebs zu detektieren, bevor dieser in andere Körperregionen metastasiert. Für viele Krebsarten gilt, dass dieser 20 bis 30 Jahre braucht, um sich aus einer neoplastischen Läsion zu einem Krankheitsstadium zu entwickeln. 
In den letzten Jahren, bevor diese Läsion zu einem Tumor wird, verwandeln sich neoplastische Zellen erfolgreich in eine Saat, aus der metastatische Läsionen schon in der frühen Tumorentstehung hervorgehen können (Vogelstein et al. 2013; Vogelstein und Kinzler 2015). Denn gerade zu dem Zeitpunkt, wenn die Metastasierung soeben initiiert wurde und radiologisch noch nicht erkennbar ist, besteht schon die Möglichkeit, dass mit einer frühen systemischen Therapie der Krebs in 50 \% der Fälle noch erfolgreich behandelt werden kann. Ausgereifte Tumore dagegen mit ausgereiften Metastasen sind therapieresistenter, wodurch eine systemische Therapie keine Heilung erzielt (Huang et al. 2017). Besteht bei einer Frau der Verdacht auf ein Mammakarzinom, muss dieser durch eine Nadelbiopsie aus dem verdächtigen Bereich histopathologisch verifiziert werden. Der resezierte Tumor wird dann zusätzlich immunzytochemisch und molekular klassifiziert durch beispielsweise einer Bestimmung des Hormonrezeptor- und HER2-Rezeptor-Status. Diese Klassifizierung dient oft auch als Entscheidungshilfe zur Behandlung eines metastatischen Rezidivs. Zu den Hormonrezeptoren gehören der Östrogenrezeptor (ER) und der Progesteronrezeptor (PR). Zudem wird der HER2/neu -Rezeptor-Status bestimmt. Als HER2/neu bezeichnet man einen Wachstumsfaktorrezeptor und sein zugehöriges Gen. Beim Mammakarzinom kann es zu einer Überexpression des HER2/neu-Rezeptors auf der Oberfläche von Mammakarzinomzellen kommen. Dies wird mit einer erhöhten Chemotherapieresistenz und erhöhten Invasivität assoziiert (Jordan et al. 2016; Pschyrembel Online 2016).

Die bloße Analyse des resezierten Primärtumors allein, derzeitige Standardpraxis in der Onkologie, kann jedoch irreführende Informationen in Bezug auf die Merkmale von Metastasen liefern. Denn Metastasen können im Laufe ihrer langjährigen Evolution einzigartige genomische Charakteristiken entwickeln, die bei der Untersuchung des Primärtumors noch nicht zu detektieren waren (Gerlinger et al. 2012; Bardelli und Pantel 2017).

Patientinnen mit ER-positiven Brusttumoren beispielsweise, erhalten eine endokrine Therapie, können jedoch gleichzeitig ER-negative zirkulierende Tumorzellen (CTC) und ER-negative metastatische Läsionen beherbergen (Paoletti et al. 2015). Diese könnten das Potenzial besitzen Resistenzmechanismen hervorzurufen, was derzeit in klinischen Versuchen untersucht wird. Mutationen des ER-Gens finden sich in etwa 20 \% der Biopsien von metastasierten Mammakarzinompatientinnen (Toy et al. 2013). Diese Daten deuten darauf hin, dass Blut verwendet werden kann, um zusätzliche ER-Mutationen zu identifizieren, die durch Sequenzierung einer einzelnen primären oder metastatischen Läsion nicht gefunden werden (Chu et al. 2016).

Ein weiteres Beispiel ist das HER2-Onkogen, welches in etwa $20 \%$ der primären Mammakarzinome amplifiziert und überexprimiert wird und pharmakologisch wirksam blockiert werden 
kann. Ebenso werden hierbei derzeit die primären Tumore verwendet, um die für Patientinnen korrekte HER2-gerichteten Therapien zu stratifizieren, obwohl offene Fernmetastasen und CTCs in bis zu 30 \% der Fälle eine Diskrepanz im HER2-Status im Vergleich zum Primärtumor aufweisen (Jordan et al. 2016). Bei Frauen mit fortgeschrittenem HER2-positiven oder HER2negativen Mammakarzinom, kann eine HER2- positive Subpopulation nach mehrfachen Therapieverläufen verbleiben (Fehm et al. 2009). Insbesondere können HER2- positive und HER2negative CTCs spontan interkonvertieren, wobei Zellen eines Phänotyps Tochterzellen mit gegenteiligem Profil produzieren (Jordan et al. 2016). Dies kann dynamische Funktionszustände in CTCs hervorrufen, die dazu beitragen der HER2-Therapie zu entkommen, sodass dann neue Therapiestrategien erhoben werden müssen. Die ersten beiden begleitenden Diagnosetests mittels Liquid Biopsy, zur Bestimmung von epithelial-growth-factor(EGF)-Rezeptoren-Mutationen in ctDNA, wurden bereits von der Aufsichtsbehörde in Europa und in den USA genehmigt (Bardelli und Pantel 2017).

Zudem liegen Metastasen oft in verschiedenen Organen gleichzeitig vor und weisen eine starke, teilweise organabhängige Heterogenität auf (Gerlinger et al. 2012; Bardelli und Pantel 2017). Auch bei einer Neubewertung der Tumoreigenschaften, basierend auf der Biopsie der best zugänglichen Metastase, ist es somit möglich, dass die Eigenschaften anderer Metastasen in weniger zugänglichen Organen (z. B. Lunge oder Gehirn) übersehen werden. Diese Heterogenität verlangt nach Mehrfachbiopsien verschiedener Metastasen in einem Krebspatienten, die jedoch in der klinischen Routine nur schwer zu implementieren sind.

Dieses diagnostisches Dilemma führte zur Entwicklung der „Liquid Biopsy“ (Flüssigbiopsie), ein Sammelbegriff für ein neues diagnostisches Konzept, das vor circa 10 Jahren von Prof. Pantel und Dr. Alix-Panabieres eingeführt wurde (Pantel und Alix-Panabières 2010; Merker et al. 2018). Unter Liquid Biopsy versteht man die Analyse von zirkulierenden Tumorzellen (CTC), disseminierten Tumorzellen (DTC), zellfreien zirkulierenden Nukleinsäuren (ctDNA, cfRNA) und extrazellulären Vesikeln oder Proteinen, die vom Primärtumor oder Metastasen bereits früh ins periphere Blut abgegeben werden. Neben anderen klinischen Anwendungsbereichen (Abbildung 2) ermöglicht die Liquid Biopsy unter anderem die Entwicklung neuer Methoden zur Krebsfrüherkennung (Bardelli und Pantel 2017; Pantel und Alix-Panabières 2019). 


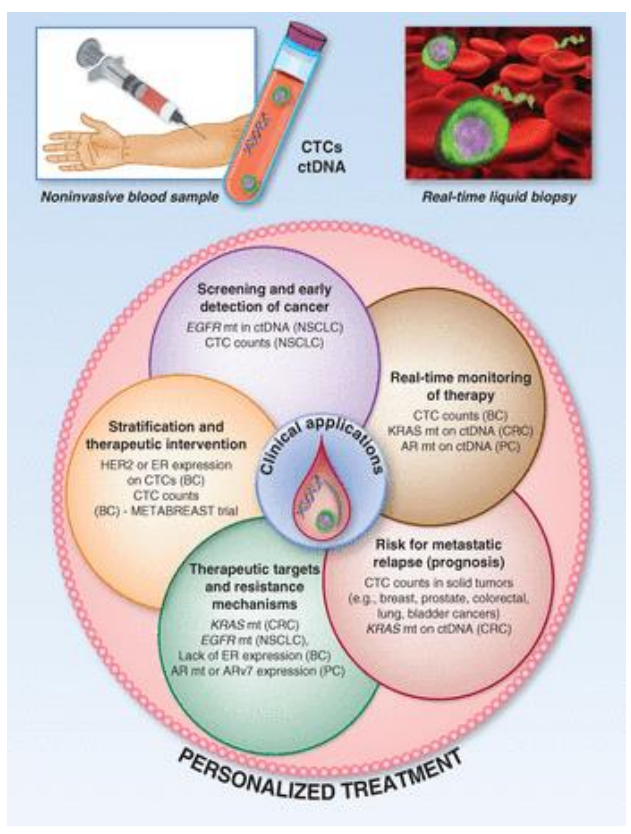

Abbildung 2: Tumorzellen und zirkulie-
rende Tumor-DNA als Flüssigbiospie. Kli-
nische Anwendungen von CTCs und ctDNA
als Flüssigbiopsie für die personalisierte Medi-
zin. Blutproben können wiederholt entnommen
werden, um einen Rückfall bei M0-Patienten o-
der eine metastatische Progression bei M1-Pati-
enten vorherzusagen, die Wirksamkeit von The-
rapien zu überwachen und mögliche Resistenz-
mechanismen zu verstehen. Mt Mutation; BC
Mammakarzinom; PC Prostatakrebs; CRC
Darmkrebs (Alix-Panabières und Pantel 2016;
mit freundlicher Genehmigung von Cancer
Discovery, AACR).

Der einzige bereits für eine Krebsfrüherkennung in der Klinik etablierte Bluttest ist bei der Diagnose von Prostatakarzinomen zu finden und basiert auf der Detektion von Prostata-spezifischem Antigen (PSA) im Blutserum von Männern. Für das Mammakarzinom und andere solide Tumore gibt es bisher noch keinen auf Blutanalysen basierenden, verlässlichen Früherkennungstest. Die üblichen Tumormarker wie CEA oder CA15-3, die zur Verlaufskontrolle in fortgeschrittenen Stadien genutzt werden, eignen sich aufgrund fehlender Sensitivität und Spezifität nicht zur Krebsfrüherkennung (dkfz 2014). Deshalb arbeiten derzeit verschiedene Arbeitsgruppen intensiv an der Entwicklung neuer Marker. Die umfangreichste Studie wurde im Jahr 2018 in Science publiziert (Cohen et al. 2018). Die Autoren von der Johns Hopkins University in Baltimore (USA) beschreiben in ihrer Arbeit einen Bluttest, der auf dem komplexen Nachweis von mehr als 1000 Mutationen in 16 Krebsgenen, kombiniert mit der zusätzlichen Detektion von acht tumorassoziierten Blutplasmaproteinen, basiert. Diese Komplexität huldigt der enormen Heterogenität von soliden Tumoren wie dem Mammakarzinom. Dieser Cancer-SEEKTest wurde an 1.005 Patientinnen mit nicht-metastasierten Krebserkrankungen der Ovarien, der Leber, des Magens, der Bauchspeicheldrüse, der Speiseröhre, des Kolorektums, der Lunge oder der Brustdrüse getestet und mit den entsprechenden Werten von gesunden Kontrollpersonen verglichen. Durch bioinformatische Analysen der hochkomplexen Daten konnte ein Algorithmus entwickelt werden, der eine hohe Bluttest-Spezifität von mehr als $99 \%$ garantierte. Durch den Cancer-SEEK-Test wurden im Durchschnitt 70 \% der Krebspatientinnen als „positiv“ getestet. Die Detektionsraten reichten von sehr guten $98 \%$ bei Ovarialkarzinomen bis zu enttäuschenden $33 \%$ beim Mammakarzinom. Trotzdem kann diese Studie dennoch als wegweisend bezeichnet werden. Andere Krebsbiomarker, wie Metaboliten, mRNA-Transkripte, miRNAs oder methyliert DNA-Sequenzen könnten auf ähnliche Weise in Zukunft kombiniert werden. 
Gewebebiopsien bleiben derzeit der Goldstandard und die Referenz für die Durchführung einer Flüssigbiopsieanalyse. Insgesamt stellen diese Biopsien auch die Grundlage zukünftiger Studien dar, die verwendet werden sollen, um Flüssigbiopsien in die klinische Praxis zu integrieren. Wichtig ist hier, dass neue Bluttests eine sehr hohe Spezifität aufweisen müssen, ansonsten würden zu viele gesunde Menschen ein positives Testergebnis bekommen, obwohl sie keinen Krebs haben, was, neben der starken emotionalen Belastung, zu unnötigen weiterführenden Untersuchungen führt (Thomas et al. 2017).

\subsection{Biologie der Tumorzelldisseminierung und Metastasierung}

Trotz erheblicher Fortschritte bei der Diagnose und Behandlung von soliden Tumoren bleiben Fernmetastasen die Hauptursache für einen krebsbedingten Tod. Die frühe Ausbreitung von Tumorzellen wird normalerweise nicht erkannt, auch nicht bei hochauflösenden Bildgebungstechnologien, was dann frühzeitige, potenziell wirksame Maßnahmen verhindert. Empfindliche immunzytochemische und molekulare Assays ermöglichen den spezifischen Nachweis von okkulten und disseminierenden Tumorzellen in frühen Stadien. Diese Technologien bieten das Potenzial für eine effektivere Überwachung der systemischen Tumorzellverbreitung im Blut und Knochenmark, was einen der ersten entscheidenden Schritte in der metastatischen Kaskade darstellt (Alix-Panabières et al. 2016; Mohme et al. 2016).

Als ein begünstigender Auslöser für die Freisetzung von CTCs in die Blutbahn, als einer der ersten Schritte in der metastatischen Kaskade, gilt der Epitheliale-Mesenchymale-Übergang (epithelial-mesenchymal-transition), kurz EMT (Hanahan und Weinberg 2011; Nieto et al. 2016). Die Induktion der EMT geht mit einer dynamischen Reprogrammierung des Epigenoms einher, die Änderungen der DNA-Methylierung und mehrere posttranslationale Histonmodifikationen umfasst. Diese Veränderungen fördern wiederum die Expression von mesenchymalen Genen oder unterdrücken diejenigen, die mit einem epithelialen Phänotyp assoziiert sind (Bedi et al. 2014). Es konnte gezeigt werden, dass EMT die Dissoziation von Karzinomzellen von Primärkarzinomen triggert, die dann in die Ferne wandern und über die Blutbahn in sekundäre Organe disseminieren. Interessanterweise wird angenommen, dass dann die MesenchymleEpitheliale-Übergang, kurz MET („,mesenchymal-epithelial-transition“) notwendig ist, damit sich aus den disseminierten Tumorzellen solide Metastasen bilden können (Bedi et al. 2014). Mittlerweile wird ebenso angenommen, dass diese Zellen nicht zwischen einem absoluten epithelialen zu einem absoluten mesenchymalen Zustand wechseln. Sie bewegen sich vielmehr durch ein Spektrum von Zwischenphasen. Diese hohe Plastizität ist ein großer Vorteil für die 
Tumorzellen und wird daher als wichtiges Kriterium für metastasenbildende CTCs angesehen (Abbildung 3) (Nieto et al. 2016).

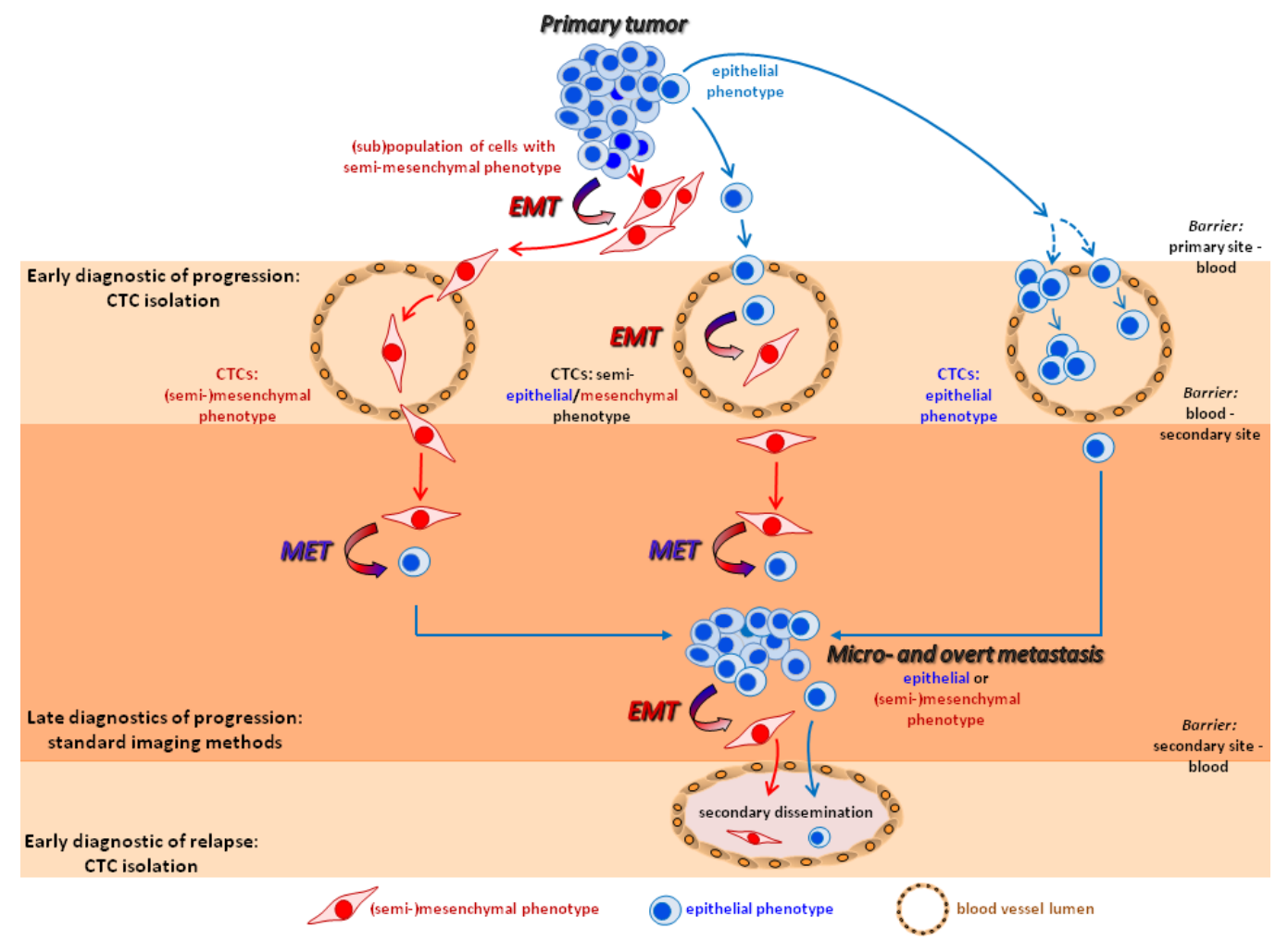

Abbildung 3: Tumorzelldissemination und Tumorzellplastizität. Aktuelle Modelle legen nahe, dass sich bösartige Zellen mit einem aggressiven Phänotyp zu einem bestimmten, jedoch noch nicht definierten Zeitpunkt der Tumorentwicklung über den Blutstrom in entfernte Organe verbreiten. Dieser invasive Phänotyp scheint mit einem epithelial-mesenchymalen Übergang (EMT) verbunden zu sein, der die Ablösung von Tumorzellen von einer primären Stelle und die Migration ermöglicht. Der umgekehrte Prozess des mesenchymal-epithelialen Übergangs (MET) könnte eine entscheidende Rolle in den weiteren Schritten der Metastasierung spielen, wenn sich zirkulierende Tumorzellen (CTCs) in entfernten Organen ansiedeln und (Mikro-)Metastasen bilden (Bednarz-Knoll et al. 2012; mit freundlicher Genehmigung von Cancer Metastasis Review, Springer).

CTCs von Mammakarzinompatientinnen zeigen eine ganze Palette von EMT-Phänotypen, die möglichweise an einer erfolgreichen Metastasierung beteiligt sind. Zudem beeinflussen die Krebstherapien die CTC-Zahl und deren Phänotyp. Therapierefraktäre Patientinnen weisen mehr CTCs mit einem mesenchymalen Phänotyp auf (Alix-Panabières und Pantel 2016). Diese Beobachtung stimmt mit jüngsten Studien überein, die die Bedeutung von EMT bei der Vermittlung von Resistenzen gegenüber Chemotherapien in Brust- und Bauchspeicheldrüsenkrebsmodellen hervorheben (Fischer et al. 2015).

Neben der EMT spielt auch die sogenannte Tumor-Dormancy eine Rolle bei der Tumorzelldetektion und Therapieresistenz. 2007 wurden zwei verschiedene Zustände von Krebsruhe postuliert, 
und zwar die Tumorzellruhe und Tumormassenruhe. Tumorzellruhe tritt auf, wenn einzelne DTCs nicht proliferativ und in einem "Ruhezustand" sind, während Tumormassenruhe ein Stadium beschreibt, in dem Krebszellen aktiver sind und sich vermehren, aber das Wachstum der Tumormasse gehemmt wird, weil eine gleiche Fraktion von Tumorzellen eine Apoptose durchlaufen (Aguirre-Ghiso 2007).

Viele solide Tumoren durchlaufen durch einen längeren Zeitraum einen „Ruhezustand", gekennzeichnet durch überlebende Zellen, die wiederum Metastasen entstehen lassen können. Zum Beispiel können metastasierende Rückfälle bei Patientinnen mit Mammakarzinom in mehr als zehn Jahre nach der Diagnose und Resektion des Primärtumors auftreten (Pantel und Hayes 2017; Pantel und Alix-Panabières 2019). Interessant ist in diesem Zusammenhang, dass CTCs bei Patientinnen mit Mammakarzinom nachgewiesen wurden, die aber nach 22 Jahren immer noch frei waren von Metastasen, sodass spekuliert wird, dass viele vermeintlich geheilte Krebspatientinnen dormante Tumorzellen besitzen könnten (Meng et al. 2004).

Zurzeit ist wenig über die Faktoren bekannt, die eine Rolle für das Aufwachen von ruhenden Tumorzellen und den Übergang in eine dynamische Phase der Metastasenbildung spielen könnten. Es gibt zahlreiche präklinische Beweise dafür, dass die Angiogenese ein wichtiger Schalter für das Erwachen aus der Krebsruhe und die anschließende Bildung von Metastasen ist. Zusätzlich können Mikroumgebungsprozesse den Ruhezustand von DTCs und Mikrometastasen beeinflussen (Lam et al. 2014). Bei Entzündungen und Wundheilungsprozessen beispielsweise werden eine Vielzahl von Zytokinen freigesetzt, wovon einige Faktoren die Migration und das Wachstum von DTCs induzieren (Coussens und Werb 2002; Chang et al. 2004). Ein Faktor, der in diesem Prozess eine Rolle spielt, ist das Protein Cysteine-rich angiogenic 61.

\subsection{Cystein-rich angiogenic protein 61 (CYR61) als potenzieller Biomarker für die Tumordetektion}

In dieser Dissertation soll die Rolle von Cystein-rich angiogenic inducer 61 (CYR61) als blutbasierter Tumormarker in der Früherkennung von Mammakarzinomen untersucht werden. Um den Einfluss von CYR61 in der Tumorbiologie besser zu verstehen, werden zudem funktionelle Analysen zu metastasierungsfördernden Eigenschaften von CYR61 durchgeführt. CYR61 ist ein bevorzugt sekretiertes, angiogeneseinduzierendes Protein, welches zu der CCN-Familie gehört. Diese Gruppe beinhaltet neben CYR61 auch die Faktoren CTGF und NOV (Sampath et al. 2002). Diese Proteine fungieren als Extrazellularmatrix(EZM)-assoziierte Signalmoleküle, die Strukturmodule enthalten, die es ihnen ermöglichen, direkt andere Einheiten in der perizellulä- 
ren Umgebung zu binden (Brigstock 2002). Das CYR61-Gen ergibt ein 2,4 kb großes Transkript, das durch verschiedene Wachstumsfaktoren induzierbar ist und das bereits früh abgelesen und somit zu den immediate early genes gezählt wird (Brigstock 2002). CYR61 wurde erstmals 1985, unter der damaligen Bezeichnung 3CH61, erwähnt (Lau und Nathans 1985). O`Brien et al. prägten 1990 den Namen CYR61, nachdem sie herausfanden, dass das von Lau und Nathans entdeckte Gen 3CH61 für ein cysteinreiches Protein codiert. Das CYR61-Protein enthält 381 Aminosäuren mit einem N-terminalen Sekretionssignalpeptid, gefolgt von vier strukturell unterschiedlichen Domänen: die Insulin-like-Growth-Factor-Bindungsprotein(IGFBP)-Domäne, die Von-Willebrand-Typ-C-Repeats(vWC)-Domäne, die Thrombospondin-Typ-1(TSR1)-Wiederholungsdomäne und die C-terminale(CT)-Domäne, die ein Cystein-Knoten-Motiv enthält (siehe Abbildung 4) (Grzeszkiewicz et al. 2002). CYR61 hat, wie der Name schon zeigt, einen ungewöhnlich hohen Gehalt an Cysteinrückständen von insgesamt 10 \% (O’Brien et al. 1990). CYR61 induziert Angiogenese, Wachstum, Zelladhäsion und fördert Zellmigration und verbessert wachstumsfaktorstimulierte Mitogenese in Fibroblasten und Endothelzellen (Grzeszkiewicz et al. 2002). Eine Großzahl dieser Effekte werden durch Zelloberflächenintegrine vermittelt, darunter Integrin $\alpha \mathrm{v} \beta 3$ in Endothelzellen, $\alpha 6 \beta 1$ und Heparansulfat-Proteoglykane (HSPGs) in Fibroblasten und glatten Muskelzellen. Hinzu kommen $\alpha \operatorname{IIb} \beta 3$ in aktivierten Plättchen, $\alpha \mathrm{M} \beta 2$ in Monozyten und Makrophagen und $\alpha \mathrm{D} \beta 2$ in Makrophagenschaumzellen (Jedsadayanmata et al. 1999; Grzeszkiewicz et al. 2002; Schober et al. 2002; Bai et al. 2010). So vermittelt CYR61 beispielsweise die Zelladhäsion von Gefäßmuskelzellen und Chemotaxis über eine Interaktion mit Integrin $\alpha_{6} \beta_{1}$ und den an Zelloberflächen befindlichen HSPGs. Zudem konnte gezeigt werden, dass das CYR61-Protein in Endothelzellen als Antwort auf einen basischen Fibroblastenwachstumsfaktor (bFGF) oder vaskulären Endothelwachstumsfaktor (VEGF) transkriptionell aktiviert wird.

\begin{tabular}{|c|c|c|c|c|c|}
\hline Domain: & SP & IGFBP & VWC & TSP-1 & CT \\
\hline \multicolumn{6}{|l|}{ CCN1. } \\
\hline $\begin{array}{l}\text { Interacting } \\
\text { partners: }\end{array}$ & & IGF & $\begin{array}{l}\text { Integrins } \\
\text { BMP4 } \\
\text { TGF } \beta\end{array}$ & $\begin{array}{l}\text { Integrins } \\
\text { collagen V } \\
\text { Fibronectin } \\
\text { TGF } \beta \\
\text { LRP1 }\end{array}$ & $\begin{array}{l}\text { Integrins } \\
\text { HPSG } \\
\text { Notch } 1 \\
\text { Fibulin } \mathrm{C}^{1}\end{array}$ \\
\hline
\end{tabular}

\footnotetext{
Abbildung 4: Modelhafte Darstellung des Aufbaus von CCN1-Proteinen: CYR61. Es besteht aus vier Domänen: die Insulin-like-Growth-Factor-Bindungsprotein(IGFBP)-Domäne, die Von-Willebrand-Typ-C-Repeats(vWC)-Domäne, die Thrombospondin-Typ-1(TSP-1)-Wiederholungsdomäne und die C-terminale(CT)-Domäne. Über diese Domänen tritt das Protein in Kontakt mit bestimmten Interaktionspartnern (Basierend auf Babic et al. 1998, S. 61).
} 
Brigstock (2002) zeigte, dass CYR61-Knockout-Mäuse während der Embryogenese und der Entwicklung des Fötus Gefäßfehler aufwiesen. Sowohl CTGF als auch CYR61 seien intrinsisch in In-vivo-Assays bezüglich angiogener Aktivität aktiv. Sie können jedoch auch die Produktion oder Aktivität anderer angiogener Moleküle (z. B. bFGF, VEGF) regulieren, die die Integrität oder Stabilität des EZM beeinflussen (z. B. Kollagen und Matrix-Metalloproteasen (MMPs)). Zudem wurden in Zelllinien, die keine CYR61-mRNA besitzen, wie die Mammakarzinomzelllinie MCF-7 oder die gesunde Brustzelllinie MCF-12A, CYR61 injiziert. Das Resultat in solchen Mäusen waren große, stark vaskularisierte Tumoren, die viele Endothelzellen besaßen (Brigstock 2002). Die Bindung von CYR61 an HSPGs und Zelloberflächenintegrine kann, so Brigstock, ein Mittel zur Verfügung stellen, um beträchtliche Plastizität zu erreichen, denn Wachstumsfaktoren und CCN-Proteine, die von HSPGs zurückgehalten werden, seien in dynamischem Fluss miteinander. Es wird demnach vermutet, dass CYR61 genauso gut, durch andere Integrinkontakte und Wachstumsfaktoren beeinflusst werden kann (Brigstock 2002). Northernanalysen ergaben, dass CYR61 in den invasiven und EMT-assoziierten Mammakarzinomzelllinien wie MDA-MB-231 stark exprimiert wurde und in Zelllinien mit weniger tumorerzeugender Wirkung wie MCF-7 und BT-20 nur in sehr geringen Mengen gefunden wurde. Genauso wurden in den normalen Brustzelllinien wie MCF-12A kaum nachweisbare CYR61-Mengen exprimiert. Eine weitere univariate Analyse der Arbeitsgruppe um Xie und Miller (2001) zeigte einen signifikanten oder grenzwertig signifikanten Zusammenhang zwischen der Expression von CYR61 und dem Stadium der Tumorgröße, der Positivität des Lymphknotens, dem Alter und dem Östrogenrezeptorstatus. Interessanterweise erhöhte sich die Expression von CYR61mRNA in MCF-12A um das acht- bis zwölffache und in MCF-7-Zellen um das drei- bis fünffache nach 24- bzw. 48-stündiger Exposition von Östrogenen. Die erzwungene Expression von CYR61 in MCF-7-Zellen stimulierte deutlich ein verankerungsunabhängiges Zellwachstum in Weichagar und erhöhte in vivo signifikant Tumorigenität und Vaskularisation.

In einer weiteren Studie sollte die Sexualsteroidregulierung von CYR61 und seine Rolle bei der hormonellen Karzinogenese untersucht werden. In dieser Studie wurde sowohl CYR61-mRNA als auch CYR61-Protein durch das Promegestone R5020 (Gestagenmedikament), in Brustadenomkarzinomzellen, dosis- und zeitabhängig induziert. Zusammengenommen sollen diese Daten nahelegen, dass CYR61, zusätzlich zu seiner proangiogenetischen Aktivität, ein neuer Mediator die Progesteronaktivität sein kann, um so bei der Steigerung des durch Wachstumsfaktoren gesteuerten Tumorwachstums bei Mammakarzinomen mitzuwirken (Sampath et al. 2002).

Auch unter hypoxischen Bedingungen konnte gezeigt werden, dass bei einer Hochregulation des Hypoxie-induzierten Faktors HIFalpha1 ebenso eine transkriptionelle Hochregulation von 
CYR61 stattfand. Am Beispiel der Endometriose konnte über eine Ausschüttung von HIFalpha1 auch eine erhöhte CYR61-Expression beobachtet werden, sodass unter Hypoxie induzierte angiogene Faktoren wie VEGF, Leptin und CYR61 zur Erleichterung der Etablierung von funktionsfähigen Blutgefäßsystemen beitragen (Hsiao 2015). Angiogenese, die Bildung neuer Kapillaren aus bereits bestehenden Blutgefäßen, ist für das Wachstum solider Tumore erforderlich, um der hypoxischen Situation entgegenzuwirken. Dieser Prozess ist komplex und umfasst Migration und Proliferation von Endothelzellen sowie die Bildung von Gefäßen. Es wird durch viele Faktoren reguliert, zu denen unter anderem das CYR61-Protein gehört, indem die Migration menschlicher Mikrogefäßendothelzellen gefördert und die Neovaskularisation über das $\alpha \mathrm{v} \beta 3$-Integrin induziert wird (Babic et al. 1998). Es konnte gezeigt werden, dass durch Förderung des durch das $\alpha v \beta 3$-Integrin aktivierte ERK1/ERK2-MAPK-Signal Proliferation und Überleben von Mammakarzinomzellen als auch eine Taxol-Resistenz gefördert wurden. Deshalb nimmt man, dass die Beeinflussung der autokrinen Schleife von CYR61- $\alpha \mathrm{v} \beta 3$-Integrin ein mögliches Angriffsziel einer Therapie darstellen kann (Menendez et al. 2005). Daten von Hellinger et al. (2019) legen ebenso nahe, dass eine Unterdrückung von CYR61 die Bildung eines invasiven Krebszellphänotyps hemmt, indem die ERK1 / 2-Phosphorylierung reduziert wird. Die Unterdrückung von CYR61 durch RNA-Interferenz reduzierte die Expression von S100A4 in Abhängigkeit von der ERK1 / 2-Aktivitätsregulation. Nicht-invasive Brustkrebszellen wurden aufgrund der extrazellulären CYR61-Ergänzung invasiv. Die Autoren schließen heraus, dass CYR61 ein potenzielles therapeutisches Ziel und ein prognostischer Marker für invasiven Brustkrebs und Metastasen darstellt.

Zusammengefasst ist CYR61 ein Protein, das vor allem unter Stimulation mit Wachstumsfaktoren und unter hypoxischen Bedingungen, Angiogenese, Wachstum, Migration und Zelladhäsion bewirkt, die Transkription weiterer Wachstumsfaktoren begünstigt und somit Tumorwachstum und Neovaskularisierung maßgeblich unterstützt.

\subsection{Fragestellung}

Für Patientinnen mit Mammakarzinom stellt die frühe Erkennung der Erkrankung einen wichtigen Wert dar, da der primäre Tumor durch operative Verfahren geheilt werden kann. Die Idee, eine Krebserkrankung anhand von bestimmten Proteinen im Blut feststellen zu können, bevor der Tumor disseminiert ist und Metastasen bilden kann, beschäftigt die angewandte Krebsforschung schon seit Jahrzehnten. Bisher gelingt dies, wenn auch mit sehr eingeschränkter Genauigkeit, nur beim Prostatakarzinom. Bei allen anderen Karzinomarten gibt es derzeit keinen Bluttest, der in der Klinik etabliert ist. 
Deshalb war es das vorrangige Ziel dieser Arbeit, die Biologie des stressinduzierten Proteins CYR61 besser zu verstehen, um es dann effektiver als potenziellen blutbasierten Tumormarker einsetzen zu können. In der Literatur wurde CYR61 bereits mit Krebserkrankungen in Zusammenhang gebracht. Der genaue Einfluss von CYR61 auf die Tumorentwicklung- und Tumorprogression ist aber noch Gegenstand derzeitiger Untersuchungen. Die Rolle von CYR61 als Tumormarker ist ebenso ungeklärt. Obwohl CYR61 schon im Blut von Krebspatientinnen gefunden wurde, ist es bisher nicht bekannt, ob es sich zur frühzeitigen Diagnostik des Mammakarzinoms eignen könnte.

Aus den genannten Gründen bestand das vorrangige Ziel dieses Promotionsvorhaben darin, Plasmaproben von Mammakarzinompatientinnen und einer Kontrollgruppe von gesunden Patientinnen auf das Vorhandensein von CYR61 hin zu untersuchen und mögliche Zusammenhänge zwischen den CYR61-Konzentrationen im Blutplasma und den krankheitsbezogenen Daten zu erstellen. Vorab sollte anhand von funktionellen Experimenten untersucht werden, in welcher Form und Konzentration das CYR61-Protein in verschiedenen Mammakarzinomtypen vorliegt und ob hypoxischen Bedingungen und Wachstumsfaktoren, die charakteristisch für Mammakarzinome sind, eine verstärkte CYR61-Sekretion induzieren. Diese Untersuchungen sollen neue Einblicke in die Biologie von CYR61 beim Mammakarzinom geben, die wiederum wichtig sind, um einen guten diagnostischen Test zu entwickeln. 


\section{Material und Methoden}

\subsection{Liste der Geräte, Materialien und Chemikalien}

Für die experimentelle Durchführung wurden die in der Tabelle 1 -3 beschriebenen Laborgeräte, Materialien und Chemikalien verwendet.

\subsubsection{Laborgeräte}

In Tabelle 1 sind die für die Experimente verwendeten Laborgeräte und ihre Hersteller mit Firmensitz aufgeführt.

Tabelle 1: Laborgeräte

\begin{tabular}{|c|c|}
\hline Geräteliste & Hersteller, Firmensitz \\
\hline Automatic-Sarpette ${ }^{\circledR}$ & Sarstedt, Nümbrecht, Deutschland \\
\hline $\begin{array}{l}\text { Bio-Rad PowerPac } 300 \text { GEL Electrophore- } \\
\text { sis }\end{array}$ & $\begin{array}{l}\text { Bio-Rad Laboratories GmbH, München, } \\
\text { Deutschland }\end{array}$ \\
\hline Bio-Rad PowerPac Power Supply 1645050 & $\begin{array}{l}\text { Bio-Rad Laboratories GmbH, München, } \\
\text { Deutschland }\end{array}$ \\
\hline $\begin{array}{l}\text { ELISA-Leser NanoQuant infinite } \\
\text { M200 pro }\end{array}$ & Tecan, Männedorf, Schweiz \\
\hline Gefrierschrank $-20^{\circ} \mathrm{C}$ & Liebherr, Kirchdorf, Deutschland \\
\hline HERAcell@150i CO${ }_{2}$-Zellkulturinkubator & Thermo Fisher Scientific, Waltham, USA \\
\hline Heraeus $^{\mathrm{TM}}$ Megafuge 8 Centrifuge & Thermo Fisher Scientific, Waltham, USA \\
\hline Heraeus $^{\text {TM }}$ Multifuge 3 S-R & Thermo Fisher Scientific, Waltham, USA \\
\hline Microcentrifuge $5415 \mathrm{R}$ & Eppendorf AG, Hamburg, Deutschland \\
\hline $\begin{array}{l}\text { Mikrobiologische Sicherheitswerkbank } \\
\text { HERA-safe } \AA\end{array}$ & Thermo Fisher Scientific, Waltham, USA \\
\hline Neubauer-Zählkammer & Brand GmbH, Wertheim, Deutschland \\
\hline Novex XCell Sure-Lock-Minisystem & Invitrogen, Groningen, Niederlande \\
\hline Pipetus ${ }^{\circledR}$ & $\begin{array}{l}\text { Hirschmann Laborgeräte, Eberstadt, } \\
\text { Deutschland }\end{array}$ \\
\hline Protean II xi-Zelle & Bio-Rad, Hercules, USA \\
\hline
\end{tabular}




\begin{tabular}{|l|l|}
\hline Geräteliste & Hersteller, Firmensitz \\
\hline $\begin{array}{l}\text { Research Pipetten }(0,1-2,5 \mu \mathrm{l} / 0,5-10 \mu \mathrm{l} / 2 \text { - } \\
20 \mu \mathrm{l} / 20-200 \mu \mathrm{l} / 100-1000 \mu \mathrm{l})\end{array}$ & Eppendorf AG, Hamburg, Deutschland \\
\hline Rollenmischer RS-TR5 & Phoenix Instrument, Garbsen, Deutschland \\
\hline SIGMA 1-15K Mikrozentrifuge & $\begin{array}{l}\text { Sigma Laborzentrifugen } \\
\text { Osterode, Deutschland }\end{array}$ \\
\hline Thermo Mixer C & Eppendorf AG, Hamburg, Deutschland \\
\hline Thermomixer comfort & Eppendorf AG, Hamburg, Deutschland \\
\hline Tischzentrifuge Rotofix 32 & Hettich, Tuttlingen, Deutschland \\
\hline Ultraschallgerät UP50H & Hielscher, Teltow, Deutschland \\
\hline Ultratiefkühlgerät TSX Series -80 ${ }^{\circ} \mathrm{C}$ & Thermo Fisher Scientific, Waltham, USA \\
\hline Vortex Genie 2 & Scientific Industries, New York, USA \\
\hline Wasserbad GFL-1012 & GFL, Großburgwedel, Deutschland \\
\hline
\end{tabular}

\subsubsection{Materialien}

In Tabelle 2 sind die für die Experimente verwendeten Materialien und ihre Hersteller dargestellt.

Tabelle 2: Verwendete Materialien

\begin{tabular}{|l|l|}
\hline \multicolumn{1}{|c|}{ Material } & \multicolumn{1}{c|}{ Hersteller, Firmensitz } \\
\hline Cassettes $1.0 \mathrm{~mm}$ & Novex, Carlsbad, USA \\
\hline Cellstar ${ }^{\circledR}$ Cell Culture Dishes & $\begin{array}{l}\text { Greiner Bio-One, Frickenhausen, } \\
\text { Deutschland }\end{array}$ \\
\hline Cellstar ${ }^{\circledR}$ Tubes & $\begin{array}{l}\text { Greiner bio-one, Kremsmünster, } \\
\text { Österreich }\end{array}$ \\
\hline CellSave Preservative Tubes & $\begin{array}{l}\text { Menarini-Silicon Biosystems, Bologna, } \\
\text { Italien }\end{array}$ \\
\hline Dako Pen & Dako Denmark A/S, Glostrup, Dänemark \\
\hline $\begin{array}{l}\text { Falcon }{ }^{\text {TM }} \text { Zentrifugationsröhrchen }(15 \mathrm{ml}, \\
50 \mathrm{ml})\end{array}$ & $\begin{array}{l}\text { Fisher Scientific GmbH, Schwerte, } \\
\text { Deutschland }\end{array}$ \\
\hline
\end{tabular}




\begin{tabular}{|c|c|}
\hline Material & Hersteller, Firmensitz \\
\hline Fixogum-Kleber & Marabu, Tamm, Deutschland \\
\hline Immobilon-PSQ-Membranen & Millipore GmbH, Schwalbach, Deutschland \\
\hline Nunc ${ }^{\mathrm{TM}}$ CryoTube ${ }^{\mathrm{TM}}$-Vials & Thermo Fisher Scientific, Waltham, USA \\
\hline Pipettenspitzen & Eppendorf AG, Hamburg, Deutschland \\
\hline ProLong ${ }^{\mathrm{TM}}$ Gold Antifade Mountant & Thermo Fisher Scientific, Waltham, USA \\
\hline Röntgenfilm & Agfa HealthCare, Mortsel, Belgien \\
\hline $\begin{array}{l}\text { Sarstedt Serological Pipette }(2 \mathrm{ml}, 5 \mathrm{ml}, 10 \\
\mathrm{ml}, 25 \mathrm{ml})\end{array}$ & $\begin{array}{l}\text { Sarstedt AG \& Co. KG, Nümbrecht, } \\
\text { Deutschland }\end{array}$ \\
\hline TC-Flasche T25 & $\begin{array}{l}\text { Sarstedt AG \& Co. KG, Nümbrecht, } \\
\text { Deutschland }\end{array}$ \\
\hline TC-Flasche /75 & $\begin{array}{l}\text { Sarstedt AG \& Co. KG, Nümbrecht, } \\
\text { Deutschland }\end{array}$ \\
\hline TC-Plattes 96 Well Platte, Standard, F & $\begin{array}{l}\text { Sarstedt AG \& Co. KG, Nümbrecht, } \\
\text { Deutschland }\end{array}$ \\
\hline 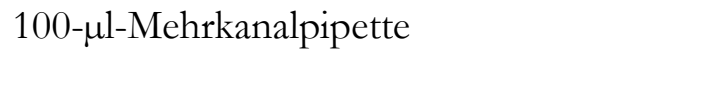 & $\begin{array}{l}\text { Sarstedt AG \& Co. KG, Nümbrecht, } \\
\text { Deutschland }\end{array}$ \\
\hline
\end{tabular}

\subsubsection{Chemikalien und Reagenzien}

Die verwendeten Chemikalien und Reagenzien und ihre Hersteller mit Firmensitz sind in Tabelle 3 aufgeführt.

Tabelle 3: Verwendete Chemikalien, Reagenzien und Puffersubstanzen

\begin{tabular}{|l|l|}
\hline Chemikalien und Reagenzien & Hersteller, Firmensitz \\
\hline APS: Ammoniumpersoxodisulfat & Roth, Karlsruhe, Deutschland \\
\hline AB-Serum & $\begin{array}{l}\text { Bio-Rad Medical Diagnostics GmbH, Drei- } \\
\text { eich, Deutschland }\end{array}$ \\
\hline DAKO Protein Block Serum-Free & DAKO Corporation, CA, USA \\
\hline $\begin{array}{l}\text { Dulbecco's Modified Eagle's Medium } \\
\text { (DMEM) }\end{array}$ & PAN \\
\hline
\end{tabular}




\begin{tabular}{|c|c|}
\hline Chemikalien und Reagenzien & Hersteller, Firmensitz \\
\hline Ethanol $99 \%$ Vollvergällt & Chemsolute, Warschau, Polen \\
\hline Fetal Bovine Serum Mycomplex (FBS) $10 \%$ & $\begin{array}{l}\text { PAA Laboratories GmbH, Pasching, } \\
\text { Österreich }\end{array}$ \\
\hline Flow Cytometry Human Lyse Buffer (10 x) & RD-Systems, Minneapolis, USA \\
\hline $\begin{array}{l}\text { Gibco }{ }^{\circledR} \text { Dulbecco's Phosphate Buffered Sa- } \\
\text { line }\end{array}$ & Life Technologies, Paisley, UK \\
\hline Gibco $®$ L-Glutamine $(200 \mathrm{mM})$ & Life Technologies, Paisley, UK \\
\hline Gibco $®$ Penicillin-Streptomycin Mix $(0,5 \%)$ & Life Technologies, Paisley, UK \\
\hline Gibco ${ }^{\circledR}$ Trypsin-EDTA $(0,25 \%)$ & Life Technologies, Paisley, UK \\
\hline Isopropanol (2-Propanol rein) & Chemsolute, Warschau, Polen \\
\hline $\begin{array}{l}\text { LPIP (lysophosphatidylinositol monophos- } \\
\text { phate) }\end{array}$ & $\begin{array}{l}\text { SIGMA Aldrich Chemical Company, } \\
\text { St.Louis, Missouri, USA }\end{array}$ \\
\hline 2-Mercaptoethanol & Merck, darmstadt, Deutschland \\
\hline Milchpulver, blocking grad, pulv., fettarm & Roth, Karlsruhe, Deutschland \\
\hline Natriumhydroxid $(\mathrm{NaOH})$ & Carl Roth GmbH, Karlsruhe, Deutschland \\
\hline Paraformaldehyd (PFA) & Carl Roth GmbH, Karlsruhe, Deutschland \\
\hline peqGOLD-Proteinmarker V & Peqlab, Erlangen, Deutschland \\
\hline Pierce BCA Protein Assay Kit & Pierce, Rockford, USA \\
\hline $\begin{array}{l}\text { Rotiphorese Gel } 30 \text { (wässrige } 30 \% \text { Ac- } \\
\text { rylamid-, Bisacrylamid-Stammlösung im Ver- } \\
\text { hältnis 37,5:1) }\end{array}$ & Roth, Karlsruhe, Deutschland \\
\hline Signal Fire ECL-Reagenz & Cell Signaling Technology, Danvers, USA \\
\hline
\end{tabular}




\begin{tabular}{|c|c|}
\hline Chemikalien und Reagenzien & Hersteller, Firmensitz \\
\hline Stopp Solution für TMB-Substrate & $\begin{array}{l}\text { Immunochemistry Technologies, Blooming- } \\
\text { ton, USA }\end{array}$ \\
\hline $\begin{array}{l}\text { TEMED } \\
\text { (N,N,N',N'-Tetramethylethylendiamin) }\end{array}$ & $\begin{array}{l}\text { SIGMA Aldrich Chemical Company, } \\
\text { St.Louis, Missouri, USA }\end{array}$ \\
\hline The Blocking Solution & $\begin{array}{l}\text { Candor Bioscience GmbH, Wangen, } \\
\text { Deutschland }\end{array}$ \\
\hline $\begin{array}{l}\text { TMB-Einkomponenten-HRP-Mikrotiterplat- } \\
\text { ten-Substrat }\end{array}$ & Bethyl Laboratories, Mont-gomery, USA \\
\hline Triton X 100 & Merck, Darmstadt, Deutschland \\
\hline Trypan Blue Solution (0,4 \%) & Merck, Darmstadt, Deutschland \\
\hline Tween 20 & Roth, Karlsruhe, Deutschland \\
\hline \multicolumn{2}{|l|}{ Puffer und Lösungen } \\
\hline Bromphenol blau & $\begin{array}{l}\text { SIGMA Aldrich Chemical Company, } \\
\text { St.Louis, Missouri, USA }\end{array}$ \\
\hline 1,4-Dithiothreitol (DTT) & Roth, Karlsruhe, Deutschland \\
\hline Glycerol (plant)in & $\begin{array}{l}\text { SERVA Electrophoresis GmbH, } \\
\text { Heidelberg, Deutschland }\end{array}$ \\
\hline Glycin & Roth, Karlsruhe, Deutschland \\
\hline SDS/ Natriumlaurylsulfat & Roth, Karlsruhe, Deutschland \\
\hline TBST (Tris buffered saline with Tween) & Roth, Karlsruhe, Deutschland \\
\hline KITS & \\
\hline Pierce BCA Protein Assay Kit & Pierce, Rockford, USA \\
\hline $\begin{array}{l}\text { Venor GeM Classic Mycoplasma Detection } \\
\text { Kit }\end{array}$ & Pierce, Rockford, USA \\
\hline
\end{tabular}




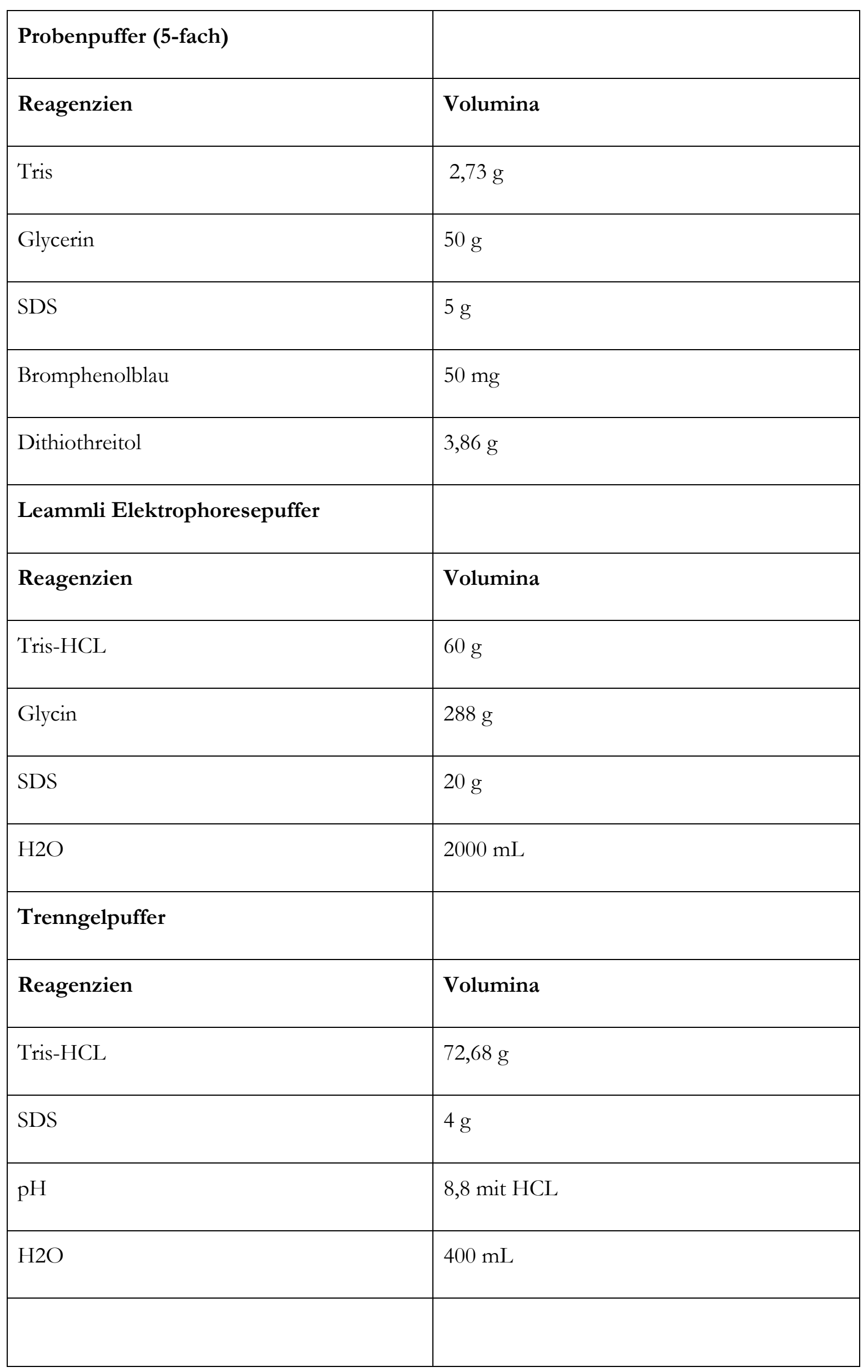




\begin{tabular}{|l|l|}
\hline Sammelgelpuffer & \\
\hline Reagenzien & Volumina \\
\hline Tris-HCL & $12,11 \mathrm{~g}$ \\
\hline SDS & $0,8 \mathrm{~g}$ \\
\hline pH & $6,8 \mathrm{mit} \mathrm{HCL}$ \\
\hline H2O & $200 \mathrm{~mL}$ \\
\hline
\end{tabular}

Tabelle 4: Herstellung des 10\%igen Polyacrylamid-Trenngels

\begin{tabular}{|l|l|}
\hline Reagenzien & Volumina \\
\hline $10 \%$ SDS & $25 \mu \mathrm{L}$ \\
\hline $10 \%$ APS & $50 \mu \mathrm{L}$ \\
\hline H2O & $2,5 \mathrm{~mL}$ \\
\hline TEMED & $7,5 \mu \mathrm{L}$ \\
\hline $30 \%$ Acrylamid & $2,08 \mathrm{~mL}$ \\
\hline Trenngelpuffer & $1,56 \mathrm{~mL}$ \\
\hline
\end{tabular}

Tabelle 5: Herstellung des 5\%igen Polyacrylamid-Sammelgels

\begin{tabular}{|l|l|}
\hline Reagenzien & Volumina \\
\hline $10 \%$ SDS & $75 \mu \mathrm{L}$ \\
\hline $10 \%$ APS & $75 \mu \mathrm{L}$ \\
\hline H2O & $3 \mathrm{~mL}$ \\
\hline TEMED & $5 \mu \mathrm{L}$ \\
\hline $30 \%$ Acrylamid & $0,65 \mathrm{~mL}$ \\
\hline Puffer & $1,25 \mathrm{~mL}$ \\
\hline
\end{tabular}




\subsubsection{Antikörper}

In Tabelle 4 sind die für die Experimente verwendeten Antikörper, eingeteilt nach primärem und sekundärem Einsatz und ihre Verdünnung als auch Hersteller mit Firmensitz beschrieben.

Tabelle 6: Verwendete Antikörper

\begin{tabular}{|c|c|c|c|c|c|}
\hline Antigen & Klon & Spezies & $\begin{array}{l}\text { Verdün- } \\
\text { nung }\end{array}$ & Hersteller & Firmensitz \\
\hline $\begin{array}{l}\text { Anti- } \\
\text { AKT(pan) }\end{array}$ & $11 \mathrm{E} 7$ & $\begin{array}{l}\text { Kaninchen, } \\
\text { polyklonal }\end{array}$ & $1: 5000$ & $\begin{array}{l}\text { Cell Signaling } \\
\text { Technology }\end{array}$ & $\begin{array}{l}\text { Davers, } \\
\text { MA, USA }\end{array}$ \\
\hline $\begin{array}{l}\text { Anti-alpha- } \\
\text { Tubulin }\end{array}$ & $11 \mathrm{H} 10$ & $\begin{array}{l}\text { Kaninchen, } \\
\text { monoklonal }\end{array}$ & $1: 10,000$ & $\begin{array}{l}\text { Cell Signaling } \\
\text { Technology }\end{array}$ & $\begin{array}{l}\text { Frankfurt, } \\
\text { Deutsch- } \\
\text { land }\end{array}$ \\
\hline Anti-CYR61 & $\mathrm{H} 78$ & $\begin{array}{l}\text { Kaninchen, } \\
\text { polyklonal }\end{array}$ & $\begin{array}{l}\text { 1:1000 } \\
\text { (MDA 468, } \\
\text { MCF7) } \\
1: 10,000 \\
\text { (andere) }\end{array}$ & $\begin{array}{l}\text { Santa Cruz Bio- } \\
\text { technology }\end{array}$ & $\begin{array}{l}\text { Santa Cruz, } \\
\text { USA }\end{array}$ \\
\hline $\begin{array}{l}\text { Anti-CYR61 } \\
\text { H2 }\end{array}$ & $\mathrm{H} 2$ & $\begin{array}{l}\text { Maus, } \\
\text { monoklonal }\end{array}$ & $\begin{array}{l}\text { 1:1000 } \\
\text { (MDA 468, } \\
\text { MCF7) } \\
\text { 1:10,000 } \\
\text { (andere) }\end{array}$ & $\begin{array}{l}\text { Santa Cruz Bio- } \\
\text { technology }\end{array}$ & $\begin{array}{l}\text { Santa Cruz, } \\
\text { USA }\end{array}$ \\
\hline Anti-EGF & D38B1 & $\begin{array}{l}\text { Kaninchen, } \\
\text { monoklonal }\end{array}$ & 1:1000 & $\begin{array}{l}\text { Cell Signaling } \\
\text { Technology }\end{array}$ & $\begin{array}{l}\text { Danvers, } \\
\text { MA, USA }\end{array}$ \\
\hline $\begin{array}{l}\text { Anti-pan-cy- } \\
\text { tokeratin }\end{array}$ & $\begin{array}{l}\text { AE1/A } \\
\text { E3 }\end{array}$ & $\begin{array}{l}\text { Maus, } \\
\text { monoklonal }\end{array}$ & $1: 10,000$ & $\begin{array}{l}\text { Affymetrix eBio- } \\
\text { science, }\end{array}$ & $\begin{array}{l}\text { Frankfurt, } \\
\text { Deutsch- } \\
\text { land }\end{array}$ \\
\hline $\begin{array}{l}\text { Anti-Phos- } \\
\text { pho AKT } \\
\text { (Ser473) }\end{array}$ & 193H12 & $\begin{array}{l}\text { Kaninchen , } \\
\text { monoklonal }\end{array}$ & $1: 500$ & $\begin{array}{l}\text { Cell Signaling } \\
\text { Technology }\end{array}$ & $\begin{array}{l}\text { Danvers, } \\
\text { MA, USA }\end{array}$ \\
\hline $\begin{array}{l}\text { Anti- } \\
\text { Vimentin }\end{array}$ & RV202 & $\begin{array}{l}\text { Maus, } \\
\text { monoklonal }\end{array}$ & $1: 5000$ & $\begin{array}{l}\text { BD Pharmingen, } \\
\text { Erembodegem, } \\
\text { Belgium }\end{array}$ & $\begin{array}{l}\text { Franklin- } \\
\text { Lakes NJ, } \\
\text { USA }\end{array}$ \\
\hline
\end{tabular}




\begin{tabular}{|l|l|l|l|l|l|}
\hline Antigen & Klon & Spezies & $\begin{array}{l}\text { Verdün- } \\
\text { nung }\end{array}$ & Hersteller & Firmensitz \\
\hline E-Cadherin & 36 & Maus & $1: 5000$ & $\begin{array}{l}\text { BD Biosciences } \\
\text { Novocas- } \\
\text { tra/Leica }\end{array}$ & $\begin{array}{l}\text { Nussloch, } \\
\text { Deutsch- } \\
\text { land }\end{array}$ \\
\hline $\begin{array}{l}\text { Sekundäre } \\
\text { Antikörper }\end{array}$ & Anti-Kanin- \\
chen- \\
$\begin{array}{l}\text { Immunglo- } \\
\text { buline }\end{array}$ & Ziege, & $\begin{array}{l}1: 1000(\text { Aus } \\
\text { gangsver- } \\
\text { dünnung) }\end{array}$ & DAKO A/S & $\begin{array}{l}\text { Glostrup, } \\
\text { Dänemark }\end{array}$ \\
\hline $\begin{array}{l}\text { Anti-Maus } \\
\text { Immunglo- } \\
\text { buline }\end{array}$ & $\begin{array}{l}\text { Ziege, } \\
\text { polyklonal }\end{array}$ & $\begin{array}{l}1: 1000 \\
+(\text { Aus- } \\
\text { gangsver- } \\
\text { dünnung) }\end{array}$ & DAKO A/S & Glostrup, \\
Dänemark
\end{tabular}

\subsubsection{Verwendete Zelllinien}

In Tabelle 5 sind die für die Experimente verwendeten Zelllinien mit Gewebetyp, Kulturmedium und Bezugsquelle aufgelistet.

Tabelle 7: Verwendete Zelllinien

\begin{tabular}{|l|l|l|l|}
\hline Bezeichnung & Gewebetyp & $\begin{array}{l}\text { Kulturme- } \\
\text { dium }\end{array}$ & Bezugsquelle \\
\hline BC-M1 & $\begin{array}{l}\text { DTC Zelllinie } \\
\text { Adenokarzinom der Brust com- } \\
\text { plete } \\
5 \% \text { CO2 } \\
\text { BT-20 }\end{array}$ & $\begin{array}{l}\text { Karzinom der Brust /Brust- } \\
\text { drüse OME }\end{array}$ & $\begin{array}{l}\text { K. Pantel } \\
\text { (Putz et al. 1999) }\end{array}$ \\
& & $10 \%$ CO2 & ATCC $®$ HTB-19 \\
\hline
\end{tabular}




\begin{tabular}{|c|c|c|c|}
\hline Bezeichnung & Gewebetyp & $\begin{array}{l}\text { Kulturme- } \\
\text { dium }\end{array}$ & Bezugsquelle \\
\hline BT-474 & $\begin{array}{l}\text { Kazinom der Brust / Brust- } \\
\text { drüse }\end{array}$ & $\begin{array}{l}\text { RPMI } \\
5 \% \mathrm{CO} 2 \\
10 \% \mathrm{O} 2\end{array}$ & $\begin{array}{l}\text { ITB, UKE } \\
\text { ATCC® HTB-20 } 2 \text { TM }\end{array}$ \\
\hline GI-101 & $\begin{array}{l}\text { Kazinom der Brust / Brust- } \\
\text { drüse }\end{array}$ & $\begin{array}{l}\text { DMEM } \\
10 \% \mathrm{CO} 2\end{array}$ & $\begin{array}{l}\text { ITB, UKE } \\
\text { CVCL_0278 }\end{array}$ \\
\hline Hs-578t & $\begin{array}{l}\text { Karzinom der Brust / Brust- } \\
\text { drüse }\end{array}$ & $\begin{array}{l}\text { DMEM } \\
10 \% \mathrm{CO} 2\end{array}$ & $\begin{array}{l}\text { ITB, UKE } \\
\text { ATCC } ® \\
\text { HTB-126 }\end{array}$ \\
\hline LC-M1 & $\begin{array}{l}\text { DTC Zelllinie aus dem Kno- } \\
\text { chenmark bei Lungenkarzinom }\end{array}$ & $\begin{array}{l}\text { RPMI com- } \\
\text { plete } \\
5 \% \mathrm{CO} 2 \\
10 \% \mathrm{O} 2\end{array}$ & $\begin{array}{l}\text { ITB, UKE } \\
\text { K. Pantel } \\
\text { (Putz et al. 1999) }\end{array}$ \\
\hline MCF-7 & $\begin{array}{l}\text { Adenokarzinom der Brust, } \\
\text { Pleuraeffusion }\end{array}$ & $\begin{array}{l}\text { DMEM } \\
5 \% \mathrm{CO} 2\end{array}$ & $\begin{array}{l}\text { ITB, } \quad \text { UKE } \\
\text { ATCC® } \text { HTB-22 }^{\text {TM }}\end{array}$ \\
\hline $\begin{array}{l}\text { MDA-MB- } \\
231\end{array}$ & $\begin{array}{l}\text { Adenokarzinom der Brust, } \\
\text { Pleuraeffusion }\end{array}$ & $\begin{array}{l}\text { DMEM } \\
5 \% \mathrm{CO} 2\end{array}$ & $\begin{array}{l}\text { ITB, UKE } \\
\text { ATCC® HTB-26'TM }\end{array}$ \\
\hline $\begin{array}{l}\text { MDA-MB- } \\
231-B O 2\end{array}$ & $\begin{array}{l}\text { Metastasiertes Adenokarzinom; } \\
\text { Entnahme aus Knochenmark }\end{array}$ & $\begin{array}{l}\text { DMEM } \\
5 \% \mathrm{CO} 2 \\
10 \% \mathrm{O} 2\end{array}$ & $\begin{array}{l}\text { (Peyruchaud et al. } \\
\text { 2001) }\end{array}$ \\
\hline $\begin{array}{l}\text { MDA-MB- } \\
231-\mathrm{Br}\end{array}$ & $\begin{array}{l}\text { Hirnmetastase eines Adenokar- } \\
\text { zinoms der Brust }\end{array}$ & $\begin{array}{l}\mathrm{DMEN} \\
5 \% \mathrm{CO} 2\end{array}$ & $\begin{array}{l}\text { Frank Winkler, } \\
\text { Universitätsklini- } \\
\text { kum Heidelberg, } \\
\text { Deutschland } \\
\text { (Wetterwald et al. } \\
\text { 2002) }\end{array}$ \\
\hline MDA-468 & $\begin{array}{l}\text { Karzinom der Brust- } \\
\text { drüse/Brust; abgeleitet von me- } \\
\text { tastasiertem Ort: Pleuraerguss }\end{array}$ & $\begin{array}{l}\text { DMEM } \\
10 \% \mathrm{CO} 2\end{array}$ & $\begin{array}{l}\text { ITB, UKE } \\
\text { ATCC } ® \\
\text { HTB-132'TM }\end{array}$ \\
\hline
\end{tabular}




\begin{tabular}{|l|l|l|l|}
\hline Bezeichnung & Gewebetyp & $\begin{array}{l}\text { Kulturme- } \\
\text { dium }\end{array}$ & Bezugsquelle \\
\hline MDA-435 S & melanozytärer Zelltyp & $\begin{array}{l}\text { DMEM } \\
10 \% \text { CO2 }\end{array}$ & $\begin{array}{l}\text { ATC, UKE } \\
\text { HTB-129 }\end{array}$ \\
\hline
\end{tabular}

\subsubsection{Analysesoftware und Datenbank}

In Tabelle 6 sollen die für die Experimente verwendeten Analysesoftware und Datenbanken mit Bezugsquelle aufgelistete werden.

Tabelle 8: Analysesoftware und Datenbank

\begin{tabular}{|l|l|l|}
\hline Software/Datenbank & Verwendungszweck & Bezugsquelle \\
\hline imageJ & Bildbearbeitung & Imagej.nih.gov/ij/ \\
\hline Pubmed & Datenbank für Literatur & $\begin{array}{l}\text { www.pubmed.de/gate- } \\
\text { way/nlm-pubmed/ }\end{array}$ \\
\hline $\begin{array}{l}\text { R Foundation for Statisti- } \\
\text { cal Computing }\end{array}$ & Statistische Auswertung & www.r-project.org/foundation \\
\hline SPSS Statistics & Statistische Auswertung & IBM, Armonk, NY, USA \\
\hline
\end{tabular}

\subsubsection{Patientinnenproben}

Für alle Patientinnen liegt eine schriftliche Einwilligungserklärung vor. Die Studie wurde durch die Ethikkommission der Hamburger Ärztekammer (PV.5392) genehmigt. Dieses Ethikvotum ist im Anhang zu finden. Von allen Patientinnen wurde vor allen studienbezogenen Verfahren eine schriftliche Einwilligungserklärung eingeholt. Es wurden Proben von Frauen mit Mammakarzinom oder gesunden Kontrollpersonen verwendet, die am Universitätsklinikum Hamburg-Eppendorf, Deutschland, behandelt wurden. Für die Analyse von Blutplasma von Mammakarzinompatientinnen wurden entweder frisches Blut oder gelagerte Aliquots der Abteilung für Gynäkologie untersucht. Blut von gesunden Patientinnen wurde vom Institut für Transfusionsmedizin, in der Leitung von Prof. Sven Peine, des Universitätsklinikums HamburgEppendorf erhalten. 


\subsection{Methoden}

Im Folgenden soll die angewandte Methodik geschildert werden.

Zunächst werden Zellkulturmethoden und anschließend eine Protokollierung der BCA Proteinbestimmung beschrieben, um dann die SDS-Polyacrylamid-Gelelektrophorese und die angewandte Westernblotanalyse darzustellen. Zudem soll der verwendete Sandwich-ELISA (ELICYR) beschrieben werden.

Dies führt letztlich zu der Methode der Berechnung der intrazellulären und sekretorischen Menge an CYR61 und anschließend zur Beschreibung der Methodik des Hypoxieexperiments und der EGF-Stimulation.

Dieses Kapitel endet mit der Beschreibung des Sandwich-ELISAs (ELICYR) für den Umgang mit Plasmaproben von Mammakarzinompatientinnen und mit der Methodik der ergänzenden Datenerfassung und statistischen Auswertung dieser Daten, in Bezug auf das quantitative Vorkommen von CYR61 im Plasma der Patientinnen.

\subsubsection{Zellkultur-Methoden}

\subsubsection{Standardkultivierung von humanen Zelllinien}

Die Kultivierung der Zellen erfolgte in den im Abschnitt 2.1.5 angegebenen Kulturmedien. Bei der Verwendung von DMEM wurden $10 \%$ FCS, 2 mM L-Glutamin und $1 \%$ PenicillinStreptomycin-Mix zugesetzt. Bei der Verwendung von RPMI wurden 10 \% FCS, 2 mM L- Glutamin und $1 \%$ Penicillin-Streptomycin-Mix hinzugefügt.

Alle Zelllinien wurden konstant bei $37^{\circ} \mathrm{C}$ in wassergesättigter Atmosphäre und unter sterilen Bedingungen bei $10 \%$ bzw. $5 \%$ CO2 kultiviert. Abhängig von der Wachstumsgeschwindigkeit, wurden die Zellen in regelmäßigen Abständen kontrolliert und passagiert. Hierzu wurden die Zellen mit PBS gewaschen und mit Trypsin-EDTA von der Haftung am Boden des Zellkulturgefäßes gelöst. Diese Zellsuspension wurde in serumhaltigen Kulturmedium aufgenommen und bei $244 \mathrm{x}$ g für drei Minuten zentrifugiert. Anschließend wurde das Pellet resuspendiert und in neue Zellkulturflaschen je nach Menge aufgesplittet.

\subsubsection{Kryokonservierung und erneute Kultivierung von Zellen der Zelllinien}

Zur Lagerung von humanen Zelllinien wurde in Kryokonservierungsröhrchen jeweils $1 \mathrm{~mL}$ Zellsuspension mit $100 \mu \mathrm{L}$ DMSO als Gefrierschutz versetzt und bei $-80{ }^{\circ} \mathrm{C}$ gelagert. Um diese Zellen erneut zu kultivieren wurden diese bei $37^{\circ} \mathrm{C}$ aufgetaut, in $5 \mathrm{~mL}$ Kulturmedium 
aufgenommen und bei 244 x g für drei Minuten zentrifugiert. Anschließend erfolgte die Suspendierung des Zellpellets und die erneute Kultivierung in einem Kulturgefäß.

\subsubsection{Test auf Mykoplasmen-Kontamination}

In regelmäßigen Abständen wurden Überstände der kultivierten Zellen mithilfe des PCR-basierten Venor-GeM-Classic-Mycoplasma-Detection-Kits auf die Kontamination mit Mykoplasmen getestet. Im Falle eines positiven Tests und dem damit verbundenen Nachweis von Mykoplasmen, wurden Zellen verworfen und durch mykoplasmasmenfreie kryokonservierte Zellen ersetzt.

\subsubsection{Herstellung von Proteinextrakten und BCA-Proteinmengenbestimmung}

\subsubsection{Herstellung von Zelllysaten}

Zwölf Mammakarzinomzelllinien wurden unter normalen Zellkulturbedingungen kultiviert und stets in biologischen Triplikaten analysiert. Das Lysat der Zelllinien wurde nach 72 Stunden wie folgt geerntet: Die Zellen in den $75 \mathrm{~cm}^{2}$ Zellkulturflaschen wurden dreimal mit $37{ }^{\circ} \mathrm{C}$ vorgewärmter phosphatgepufferter Salzlösung (PBS) gewaschen und anschließend in $300 \mu \mathrm{l}$ Lysispuffer pro Zellkulturflasche gelöst und geerntet. Zehn Milliliter des Lysispuffers bestehen aus 5,88 g Harnstoff, $150 \mu \mathrm{L}$ von $2 \mathrm{M}$ Tris und $300 \mu \mathrm{L}$ von 0,5 M EDTA. Diese Zelllysate wurden auf Eis durch Ultraschallbehandlung mit dem Ultraschallgerät UP50H in drei identischen Schritten bei einer Amplitude von $100 \%$ für 10 s homogenisiert und inkubierten bei Raumtemperatur für eine Stunde im Lysepuffergemisch. Nun folgte eine Zentrifugation von $15.000 \mathrm{~g}$ in Raumtemperatur für fünf Minuten. Das Pellet wurde verworfen und der Überstand mit dem Proteinextrakt in ein neues Reaktionsgefäß überführt. Nun wurden die Proben bei - 80 ${ }^{\circ} \mathrm{C}$ für eine spätere BCA-Testung gelagert oder es erfolgte die direkte Bestimmung der Proteinkonzentration mittels BCA-Test.

\subsubsection{BCA-Test zur Bestimmung der Proteinkonzentration von Zelllysaten}

Die Proteinkonzentration wurde unter Verwendung des Pierce-BCA-Protein-Assay-Kit gemäß den Anweisungen des Herstellers und unter Verwendung von Bovines Serumalbumin (BSA) als Standard bestimmt. Dazu wurden die Proteinextrakte für drei Stunden auf den Thermomixer bei $20{ }^{\circ} \mathrm{C}$ und $1000 \mathrm{rpm}$ solubilisiert und alle 30 Minuten per Ultraschallsonde homogenisiert. Anschließend wurden sie in die Zentrifuge für eine Minute bei $10.000 \mathrm{rpm}$ zentrifugiert. Hiernach sollte nur noch ein hauchdünnes Pellet zu sehen sein. Der proteinreiche Überstand wurde nun in ein neues Reaktionsgefäß überführt. Für den BCA-Test gab man 2,5 $\mu$ g eines jeden Lysats in $22,5 \mu \mathrm{L} \mathrm{H} 2 \mathrm{O}$ und es konnte eine Standardreihe nach folgendem Schema pipettiert werden: 
Tabelle 9: BCA-Bestimmung Standardreihe-Schema

\begin{tabular}{|l|l|l|l|l|}
\hline $\begin{array}{l}\text { BSA Konzent- } \\
\text { ration }[\mu \mathrm{g} / \mathrm{mL}]\end{array}$ & H20 $[\mu \mathrm{L}]$ & $\begin{array}{l}\text { Volumen Harn- } \\
\text { stoff }[\mu \mathrm{L}] \\
\text { (Lsyemix) }\end{array}$ & $\begin{array}{l}\text { Konzentration } \\
\text { BSA-Stammlö- } \\
\text { sung }[\mathrm{mg} / \mathrm{mL}]\end{array}$ & $\begin{array}{l}\text { Volumen BSA } \\
{[\mu \mathrm{L}]}\end{array}$ \\
\hline 0 & 22,5 & 2,5 & & 5 \\
\hline 200 & 17,5 & 2,5 & 1 & 10 \\
\hline 400 & 12,5 & 2,5 & 1 & 15 \\
\hline 600 & 7,5 & 2,5 & 1 & 2,5 \\
\hline 1000 & 20 & 2,5 & 10 & 10 \\
\hline
\end{tabular}

Sobald $500 \mu \mathrm{L}$ des BCA-Reagenz hinzugegeben wurden, wurde die Reaktion für zwei bis drei Minuten in einem $52{ }^{\circ} \mathrm{C}$ warmen Wasserbad angestoßen. Abgestoppt wurde die Reaktion für zwei Minuten bei $4{ }^{\circ} \mathrm{C}$. Anschließend wurde per Fotometer die Extinktion bestimmt. Aus den gemessenen Extinktionen der Standardreihe wurde die Geradengleichung für die Bestimmung der Proteinkonzentration der Proben abgeleitet.

Die anhand der bekannten Proteinkonzentrationen der Proben der Standardreihe bestimmte Gerade hat die Form: $y=m x+b$. Die Bezeichnung $b$ hat durch Subtraktion des Hintergrundes am Photometer den Wert null, $y$ stellt die Proteinkonzentration [in $\mu \mathrm{g} / \mathrm{mL}$ ] dar und $x$ gibt die Extinktion bei $562 \mathrm{~nm}$ an. Als $m$ wird die empirisch ermittelte Proportionalitätskonstante bezeichnet.

Das Einsetzen der ermittelten Extinktion in die Kalibrationsgerade liefert die Proteinkonzentration der Probe. Die Proteinkonzentration wird in einem Volumen von $25 \mu \mathrm{L}$ bestimmt. Da üblicherweise nur 2,5 $\mu \mathrm{L}$ Probenvolumen eingesetzt wurden, musste die erhaltene Proteinkonzentration noch mit zehn multipliziert werden.

Anschließend wurde das Probenvolumen für $20 \mu \mathrm{g}$ Protein pro Probe berechnet. Diese Volumina wurden anschließend für eine SDS-PAGE bei einer Westernblotanalyse eingesetzt (siehe 2.2.3 Westernblotanalyse). 


\subsubsection{Westernblotanalyse}

Es wurden von jeder Zelllinie (MCF-7, MDA-MB-231, MDA-MB-231-BO2, MDA-MB-231Br, MDA-468, Hs-578t, MDA-435S, BC-M1, LC-M1, BT-20, GI-101 und BT-474) vier T75 $\mathrm{cm}^{2}$ Zellkulturflaschen hochgezogen. Die vierte T75- $\mathrm{cm}^{2}$-Zellkulturflasche sollte als Reserve zur Weiterkultivierung dienen.

Von jeder der oben genannten Zelllinien wurden drei Proteinextrakte gewonnen, deren Proteine mittels SDS-Polyacrylamid-Gelelektrophorese nach ihrer Größe aufgetrennt wurden. In der anschließenden Westernblotanalyse wurden sie auf das Vorhandensein von zytoplasmatischem CYR61, Pan-Zytokeratinen mittels Antikörper AE1/AE3 und mesenchymalen Strukturen mittels Vimentin-Antikörper untersucht. Zur Positivkontrolle verwendete ich einen alpha-TubulinAntikörper. Dies sollte neben der möglichen Erkenntnis, dass CYR61 in den jeweiligen Zelllinien existiert, ebenso eine Zuordnung zum Epithelialen-Mesenchymalen-Phänotyp ermöglichen, der mit aggressiven und metastasierenden Eigenschaften vergesellschaftet ist.

\subsubsection{SDS-Polyacrylamid-Gelelektrophorese}

Die SDS-Polyacrylamid-Gelelektrophorese, kurz SDS-PAGE, ist eine denaturierende Polyacrylamid-Gelelektrophorese von Proteinen nach der Vorschrift von Laemmli (1970). Dazu erstellt man ein vertikales Gel mit einer Zweiteilung in Sammelgel und Trenngel. Die Proteintrennung erfolgte mit dem Novex XCell Sure-Lock-Minisystem oder der Protean II xi-Zelle unter Verwendung von 10 \%igen Polyacrylamid-Trenngelen und einem 5 \%igen Polyacrylamid-Sammelgel in einem Laemmli-Laufpuffer, der Gylcin enthält. Für die Elektrophorese werden die Gele durch radikalische Polymerisation aus den Stoffen Acrylamid und N,N'-Methylenbisacrylamid hergestellt. Letzteres dient zur Quervernetzung der ansonsten linearen PolyacrylamidKetten, sodass ein starres Gel entsteht. Begonnen wurde mit der Trenngelmischung, die mit Radikalstarter Ammoniumperoxodisulfat (APS) sowie dem Polymerisierungskatalysator Tetramethylethylendiamin (TEMED) versetzt und zügig zwischen zwei abgedichtete Plastikplatten (Novex Cassettes) gegossen wurde. Das Trenngel wurde schließlich mit Ethanol überschichtet, um zum einen eine Glättung der Gelgrenze zu erreichen und zum anderen den Kontakt mit Sauerstoff auszuschließen, damit die radikalische Polymerisation nicht gestört wird. Nach etwa 45 Minuten war das Trenngel auspolymerisiert, der Alkohol konnte abgegossen werden und das Sammelgel wurde mit APS und TEMED versetzt und etwa einen Zentimeter hoch über das Trenngel pipettiert. Hier steckt man nun einen speziellen Kamm ein, um Taschen zum Einfüllen der Proben zu erhalten. Nach etwa 20 Minuten war auch dieses Gel auspolymerisiert und der Kamm kann entfernt werden. Das fertige Polyacrylamid-Gel wurde in eine ElektrophoreseApparatur (Novex XCell Sure-Lock-Minisystem oder der Protean II xi-Zelle) eingespannt. Die 
Proben wurden mit SDS-Probenpuffer (5-fach) komplexiert, fünf Minuten bei $95{ }^{\circ} \mathrm{C}$ denaturiert und auf die Gele geladen. Als Molekulargrößenstandard wurde der peqGOLD-Proteinmarker V verwendet. Für die Westernblotanalyse wurden $20 \mu \mathrm{g}$ Protein oder $40 \mu \mathrm{g}$ Protein pro Probe aufgetragen.

Die negativ geladenen monomeren und gestreckten Polypeptidketten wandern in einem elektrischen Feld zunächst durch das Sammelgel und anschließend durch das Trenngel zur Anode und werden entsprechend ihrer Größe aufgetrennt. Trenn- und Sammelgel enthalten Chlorid-(Cl)Ionen als Gegen-Ionen der Puffersubstanz Tris. Der Elektrophoresepuffer enthält Glycin. Bei Einschalten des Stroms wandern SDS-Proteinkomplexe, Chlorid- und Glycinat-Ionen in Richtugn Anode, wobei die Chloridionen am schnellsten und die Glycinmoleküle des Puffers am langsamsten wandern, da das chemische Gleichgewicht zwischen ionischer und nichtionischer Form im niedrigen $\mathrm{pH}$-Wert des Sammelgels weit auf die Seite der ungeladenen Form des Glycins verschoben ist und deshalb nur ein Bruchteil der Moleküle in geladener Form vorliegt. Die SDS-Proteinkomplexe bewegen sich zwischen Chlorid-Ionen-Front und Glycin-GlycinatMolekülen. Die SDS-Proteinkomplexe als einzige Ladungsträger werden beschleunigt, erreichen die Chlorid-Ionen-Front, wo sie aufgrund der Spannungsverminderung durch die Chloridionen wieder gebremst werden. Hier konzentrieren sich die SDS-Proteinkomplexe als eine scharfe Bande, die bei erreichen des Trennsgels wieder verloren geht, denn Glycin geht aufgrund des erhöhten pH-Wertes im Trenngel nun in eine vollständig ionisierte Form über und überholt daher die SDS-Proteinkomplexe. Anhand der soeben erklärten Vorgänge konnten die Proteine in diesem Experiment nun entsprechend ihrer Größe aufgetrennt werden (Laemmli 1970).

Das Novex XCell Sure-Lock-Minisystem oder die Protean II xi-Zelle wurde zunächst auf 80 Volt eingestellt. Nach Erreichen des Trenngels wurde die Spannung auf 120 Volt erhöht, sodass die Proteintrennung nach 90 bis 120 Minuten auf dem Trenngel abgeschlossen war. Nun folgte der Transfer der Gele auf eine Immobilon-PSQ-Membran.

\subsubsection{Westernblotanalyse und Proteindetektion}

Nach der SDS-PAGE wurden die Proteine auf Immobilon-PSQ-Membranen übertragen. Diese Übertragung fand mittels Tank-Blot und unter Verwendung des Mini-VE-Elektrophoresesystems mit Tank-Blot-Transfereinheiten statt. Der dafür benötigte Transferpuffer bestand aus 11,64 g TrisHCL, 5,86 g Glycin und $200 \mathrm{ml}$ Ethanol (99 \%) in $2000 \mathrm{~mL} \mathrm{H} 2 \mathrm{O}$.

Die Membran wurde anschließend in 5-\%ig fettarmen-Milchpulver in Tris-gepufferte Salzlösung mit Tween20 (TBST-Puffer) gelöst und für eine Stunde, unter leichtem Schwenken, blockiert. Der TBST-Puffer besteht aus $20 \mathrm{mM}$ Tris-HCL, $15 \mathrm{mM} \mathrm{NaCl}$ und 0,05 \% Tween20, 
eingestellt auf einen pH-Wert von 7,6. Die Primärantikörper wurden, gemäß den Anweisungen des Herstellers, in einem 5\% igen Blockierungspuffer verdünnt und bei $4{ }^{\circ} \mathrm{C}$ unter leichter Rotation über Nacht auf die Membranen aufgebracht. Die geeigneten sekundären Antikörper, die mit Meerrettichperoxidase konjugiert waren, wurden in Verdünnungen von 1: 500 bis 1: 10.000 verwendet, abhängig von der Signalintensität für das einzelne Experiment. Alle sekundären Antikörper wurden mit Blockierungspuffer verdünnt. Die Banden wurden mit dem Signal Fire ECL-Reagenz und Röntgenfilmen gemäß den Anweisungen des Herstellers visualisiert. Jede Reaktion wurde in biologischen Triplikaten durchgeführt.

Anschließend wurden die Antikörper von den Membranen entfernt, sodass die Hybridisierung mit einem weiteren Antikörper, z.B. für den Nachweis von alpha-Tubulin, das als Ladekontrolle dient, möglich war. Hierfür wurde ein Stripping-Puffer eingesetzt, der aus 7,56 g Tris, $20 \mathrm{~g}$ SDS und 7,8 $\mathrm{g}$ 2-Mercaptoethanol und $1000 \mathrm{~mL}$ H2O bestand und auf einen $\mathrm{pH}$-Wert von 9,5 unter der Verwendung von HCL eingestellt wurde.

Vor der Verwendung wurden 0,1 g DTT zu $25 \mathrm{~mL}$ des Strippingpuffers frisch zugegeben. Die Membranen inkubierten bei Raumtemperatur unter sanftem Rühren für 45 Minuten. Nach dem Waschen mit TBST inkubierten die Membranen eine Stunde lang mit Blockierungspuffer und ein nächster primärer Antikörper konnte aufgebracht werden.

\subsubsection{Vorbereitung der Proben für eine quantitative Proteinbestimmung mittels Sandwich-ELISA (ELICYR)}

Zu den vier T75- $\mathrm{cm}^{2}$-Zellkulturflaschen, wovon drei für eine Westernblotanalyse in Triplikaten verwendet wurden (Siehe Kapitel 2.2.3), wurden parallel pro Zelllinie drei T25- $\mathrm{cm}^{2}$-Zellkulturflaschen kultiviert. Auch diese wurden für 72 Stunden in ihrem Medium belassen. Nach 72 Stunden wurden diese drei T25- $\mathrm{cm}^{2}$-Zellkulturflaschen wie folgt geerntet:

Zunächst wurde von jeder der T25- $\mathrm{cm}^{2}$-Zellkulturflaschen der Überstand durch eine Pipette entnommen, in ein Gefäß überführt und bei $2500 \mathrm{~g}$ für 15 Minuten zentrifugiert. Anschließend sollte der Überstand wiederum vom Zellpellet am Boden des Röhrchens getrennt und in ein neues Probenröhrchen überführt werden. Diese Überstände wurden gewogen, um so auf das Volumen der Überstande schließen zu können.

Das nun noch übrig gebliebene Zellpellet wurde mit 10 mM EDTA gelöst und bei $1200 \mathrm{~g}$ für drei Minuten zentrifugiert. Nun nahm man das Zellpellet in $5 \mathrm{~mL}$ PBS auf und verwendete 10 $\mu \mathrm{L}$ eines jeden Lysates für eine Neubauer-Zählkammer und bestimmte die Zellzahl. AnschlieBend wurden die $5 \mathrm{~mL}$ Zellsuspension in 1,5 mL und 3,5 mL gesplittet. Das Eppi mit den 1,5 
$\mathrm{mL}$ wurde erneut bei $3000 \mathrm{~g}$ für drei Minuten bei $25^{\circ} \mathrm{C}$ zentrifugiert, der Überschuss abpipettiert und verworfen und das übrig geblieben Zellpellet mit $100 \mu \mathrm{L}$ Lysemix aufgelöst und bei $20{ }^{\circ} \mathrm{C}$ gelagert. Von den Proteinextrakten wurde eine Proteinbestimmung mittels BCA-Tests durchgeführt.

Das Eppi mit den 3,5 mL wurde ebenso nochmals für drei Minuten bei $1400 \mathrm{~g}$ und $25{ }^{\circ} \mathrm{C}$ zentrifugiert und der Überstand abpipettiert und verworfen. Das restliche Zellpellet wurde in $233 \mu \mathrm{L}$ LPIP aufgenommen und lysiert, mit einem Ultraschallgerät homogenisiert und entweder gelagert oder direkt für den Sandwich-ELISA (ELICYR) weiterverwendet.

\subsubsection{Protokoll des Sandwich-ELISAS (ELICYR)}

Die Pipettierschritte wurden mit einer 100- $\mu$ L-Mehrkanalpipette unter Verwendung von einer TC-96-Well-Platte durchgeführt. Für die Beschichtung der Vertiefungen wurde ein AntiCYR61-Antikörper H2 von Santa Cruz Biotechnology verwendet (coating). Der Antikörper wurde in DME-Medium mit 10 \% FCS 1:250 verdünnt und $35 \mu \mathrm{L}$ des verdünnten Antikörpers wurden in jede Vertiefung aufgetragen. Die Platte wurde über Nacht bei $4{ }^{\circ} \mathrm{C}$ unter leichter Rotation inkubiert. Um noch restliche, ungebundene Antikörper zu entfernen, wurde die Platte drei Mal gewaschen. Beim ersten Mal wurden die Vertiefungen mit $100 \mu \mathrm{L}$ PBS gewaschen, gefolgt von zwei weiteren Malen unter Verwendung von PBS mit 0,02\% Tween 20 à $100 \mu \mathrm{L}$. Als nächstes wurde die unspezifische Bindung mit $100 \mu \mathrm{L}$ Blockierungspuffer $(5 \%$ fettfreie Trockenmilch, in PBS mit 0,02\% Tween) pro Vertiefung blockiert. Der Assay wurde unter leichter Rotation über Nacht bei $4{ }^{\circ} \mathrm{C}$ inkubiert. Als nächstes wurden die drei Waschschritte unter Verwendung von jeweils $100 \mu \mathrm{L}$ Volumen, wie oben bereits beschrieben, wiederholt durchgeführt. Für die Inkubation der Zelllinienproben wurde die Menge für einen Einsatz von $10 \mu \mathrm{g}$ je Probe berechnet und mit $25 \mu \mathrm{L}$ PBS Tween auf die Platte aufgetragen. Von den gesammelten Überständen der Zellkulturlinien wurde $1 \mu \mathrm{L}$ Probe in $99 \mu \mathrm{L}$ DME-Medium je Well aufgetragen. Für die Inkubation mit den Plasmaproben wurden 2,5 $\mu \mathrm{L}$ Plasma, verdünnt in 97,5 $\mu \mathrm{L}$ DMEM mit 10 \% FCS, in die Wells gegeben und zwei Stunden bei Raumtemperatur unter leichter Rotation inkubiert. Zudem wurde auf jeder Platte eine Standardreihe mit MDA-MB231 Zellkulturüberstand und eine weitere mit rekombinantem und aufgereinigtem CYR61 pipettiert. Es folgten drei Waschschritte, wobei jeweils $100 \mu \mathrm{L}$ Volumen, wieder wie oben beschrieben, verwendet wurden. Als nächstes wurden $35 \mu \mathrm{L}$ des Anti-CYR61-Antikörpers H78 in die Vertiefungen gegeben. Dieser Anti-CYR61-Antikörper wurde 1:500 in DMEM mit 10 \% FCS verdünnt. Nun folgt eine Inkubationszeit bei Raumtemperatur unter leichter Rotation für zwei Stunden. Es folgten wieder die drei Waschschritte, wobei jeweils $100 \mu \mathrm{L}$ Volumen, wie 
oben beschrieben, verwendet wurden. Zum Nachweis von CYR61 wurde ein polyklonaler Ziegen-Anti-Kaninchen-Immunglobulin-Antikörper, der mit Meerrettich-Peroxidase (HRP) gekoppelt war, 1:250 mit Blockierungspuffer verdünnt und $35 \mu \mathrm{L}$ der Verdünnung wurden auf jede Vertiefung aufgetragen. Dies inkubierte bei Raumtemperatur eine Stunde lang unter leichter Rotation. Es folgten wieder die drei Waschschritte, wobei jeweils $100 \mu \mathrm{L}$ Volumen verwendet wurden. Als nächstes wurden $100 \mu \mathrm{L}$ 3,3',5,5'-Tetramethylbenzidin(TMB)-EinkomponentenHRP-Mikrotiterplatten-Substrat in jede Vertiefung hinzugegeben und für 15 Minuten bei Raumtemperatur und lichtgeschützt inkubiert. Die Reaktion wurde durch Zugabe von $100 \mu \mathrm{L}$ Stopp Solution $\left(1 \mathrm{~N} \mathrm{H}_{2} \mathrm{SO}_{4}\right.$ ) für TMB-Substrate und Inkubation im Dunkeln unter leichter Rotation für 15 Minuten gestoppt. Die Extinktion bei 450/620 nm wurde unter Verwendung des ELISALesers NanoQuant infinite M200 pro nachgewiesen. Die OD-Werte wurden unter Verwendung von rekombinantem und gereinigtem CYR61-Protein als Standardreihe in CYR61-Konzentrationen umgewandelt.

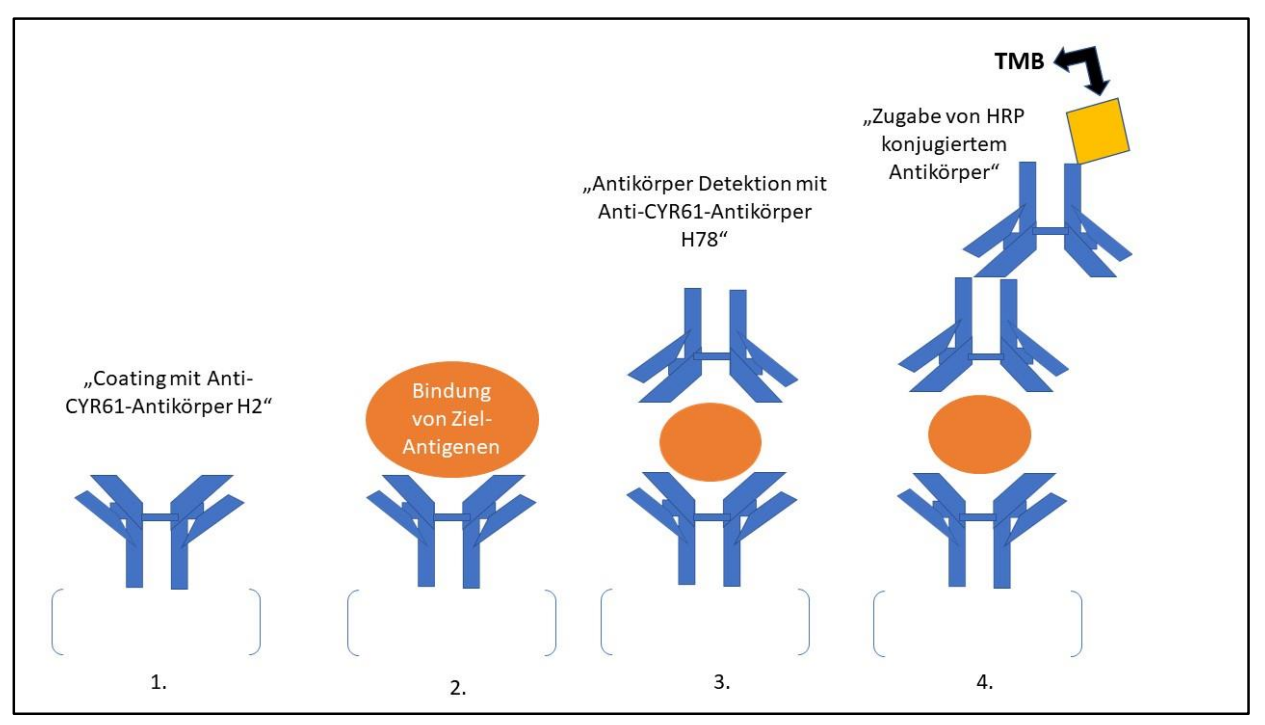

Abbildung 5: Model des Sandwich-ELISAs (ELICYR). Der erste Schritt ist das Coating der Vertiefungen mit dem Anti-CYR61-Antikörper H2. Anschließend erfolgte die Hinzugabe von Plasmaproben oder Zelllinienproben, deren passende Antigene an den gecoateten Antikörper binden. Im nächsten Schritt findet eine Antikörper-Detektion dieser Antigene mit dem Anti-CYR61-Antikörper H78 statt. Nun folgt die Hinzugabe von HRP gekoppeltem, polyklonalem Ziegen-Anti-Kaninchen-Immunglobulin-Antikörper zum Nachweis von CYR61. Das 3,3',5,5'-Tetramethylbenzidin(TMB)-EinkomponentenHRP-Mikrotiterplatten-Substrat wird hinzugegen und konvertiert das HRP in eine photometrisch messbare Form. Bei 450/620 nm wird die Extinktion unter Verwendung des ELISA-Lesers NanoQuantinfinite-M200-pro nachgewiesen.

Durch die angelegte Standardreihe mit rekombinantem CYR61 [in ng] konnte eine Kalibrierungsgerade erstellt werden, die die Umrechnung der OD-Werte [in ng] ermöglichte. Die OD-Werte wurden gegen die entsprechenden rekombinanten CYR61 Werte aufgetragen, 
sodass davon eine Kalibrationsgerade abgleitet werden konnte. Das Einsetzen der ermittelten Extinktion in die Kalibrationsgerade lieferte die Proteinkonzentration der Probe.

Bei einem Einsatz von 2,5 $\mu$ l Plasmaproben gilt folgende Berechnung:

OD Wert $*$ y $=$ CYR61 [in ng] $* 400=$ CYR61 [in ng/mL]

Bei einem Einsatz von $10 \mu \mathrm{g}$ Lysat-Plasmaproben gilt folgende Berechnung:

OD Wert* ${ }^{*}=$ CYR61 [in ng] $* 100=$ CYR61 $[$ in ng/mg]

Bei einem Einsatz von $100 \mu$ l Überstand gilt folgende Berechnung:

OD Wert* $\mathrm{y}=$ CYR61 $[$ in $\mathrm{ng}] * 10=$ CYR61 $[$ in $\mathrm{ng} / \mathrm{mL}]$

Nun erhielt man die Menge an CYR61 [in ng/mL] oder [in ng/mg]. Bei Kenntnis der Zellzahl konnte die Menge an intrazellulären sowie extrazellulären Proteinen pro Zelle berechnet werden.

\subsubsection{Berechnung der intrazellulären und sekretierten CYR61-Menge}

In diesem Kapitel soll gezeigt werden, wie man mittels der zuletzt genannten Methode (Sandwich-ELISA (ELICYR)) die Gesamtproteinmenge (interzelluläre und sekretierte Proteinmenge) von CYR61 bestimmt werden konnte.

Es folgt ein Beispiel zur Berechnung der CYR61-Proteinkonzentration anhand des Überstands der Zelllinie $M D A-M B-231$ (Probe 1):

Die Probe 1 aus einem Triplikat des Überstands von MDA-MB-231 besitzt nach der Auswertung des Sandwich-ELISAs eine CYR61-Konzentration von 1501,7 ng/mL.

Nun wird das in 2.2.4 bestimmte Volumen, hier 5,58 mL, mit der CYR61-Konzentration multipliziert und man erhält die Gesamtmenge an der Cy61 [in ng] in diesem Überstand:

$5,58 \mathrm{~mL} \times 1501,7 \mathrm{ng} / \mathrm{mL}=8380 \mathrm{ng}$

Anschließend wird diese Proteinmenge durch die in 2.2.4.1 berechnete Gesamtzellzahl (1.460.000 Zellen) dividiert und man erhält die pro Zelle sekretierte CYR61-Proteinmenge im Überstand [in ng]:

8379,64 ng / $1460000=0,005739479$ ng CYR61 wird pro Zelle in den Überstand sekretiert.

Es folgt ein Beispiel zur Berechnung der CYR61-Proteinkonzentration anband des Zelllysats der Zelllinie $M D A-M B-231$ (Probe 1): 
Die Probe 1 aus einem Triplikat des Lysats MDA-MB-231 besitzt nach der Auswertung des Sandwich-ELISAs eine CYR61-Konzentration von 11368 ng/mg Gesamtzellysat.

Die Gesamtproteinmenge des Proteinextrakts betrug 0,35415 mg, so dass die Gesamtproteinmenge CYR61

$11367,53 \mathrm{ng} / \mathrm{mg} * 0,35415 \mathrm{mg}=4025,81 \mathrm{ng}$

beträgt.

Anschließend wird durch die Gesamtzellzahl (1460000) dividiert und man erhält die intrazelluläre CYR61-Proteimenge pro Zelle im Zellpellet [in ng]:

4025,81 ng/1460000 = 0,002757 ng CYR61 pro Zelle im Zelllysat

Es folgt ein Beispiel zur weiterführenden Berechnung der sekretierten CYR61-Molekülmase pro Zelle. In diesem Beispiel bleiben wir bei der Probe 1 aus dem Überstand aus der Zellinie MDA-MB-231:

Die Masse von CYR61 pro Zelle wurde oben berechnet als 0,005739479 ng im Überstand.

Die Gesamtmenge von CYR61 [in ng] soll auf Gramm umgerechnet werden, indem man durch $10^{9}$ dividiert:

$0,005739479 \mathrm{ng} / 10^{9}=5.74 \times 10^{-12} \mathrm{~g}$ CYR61

So erhält man CYR61-Proteinmenge in g. Dividiert man nun durch die Molmasse von CYR61, (39438,4 g/mol) erhält man die Stoffmenge (n) [in mol]:

$5.74 \times 10^{-12} \mathrm{~g}$ CYR61/ 39438,4 g $/ \mathrm{mol}=1.45 \times 10^{-16} \mathrm{~mol} \mathrm{CYR61}$

Ein Mol sind 6,02 × $10^{23}$ Moleküle. Also multipliziert man die Stoffmenge [in mol] mit der Avogadrozahl und man erhält somit die Anzahl der CYR61 Moleküle in der Probe:

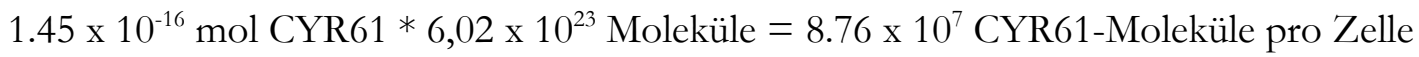

Da der Zellkulturüberstand 72 h auf den Zellen war, läßt sich die Rate der CYR61-Sekretion pro Zelle und Stunde berechnen:

$8.76 \times 10^{7}$ CYR61- Moleküle pro Zelle / $72 \mathrm{~h}=1.22 \times 10^{6}$ Moleküle pro Stunde. 
Eine Zelle MDA-231 sekretiert also etwa 1,2 Millionen CYR61-Moleküle pro Stunde ins Medium.

\subsubsection{Messung der CYR61-Sekretion unter hypoxischen Bedingungen}

Zur Messung der CYR61-Sekretion in den zwei Zelllinien MDA-MB-231 und MDA-468 unter hypoxischen Bedingungen, wurden die Zelllinien bei $1 \%$-Sauerstoff und $5 \%$-CO2 bei $37{ }^{\circ} \mathrm{C}$ kultiviert. Hier solle zunächst bei 0 h, 0,25 h, 6 h, 8 h, 16 h und 24 h der Zellkulturüberstand mittels Sandwich-ELISA untersucht werden. Zusätzlich wurde das Volumen des Zellkulturüberstands bestimmt. Mit dem Sandwich-ELISA wurde die CYR61-Konzentration des Überstands bestimmt und bei Kenntnis des Überstandvolumens wurde hieraus die Gesamtmasse von CYR61 in dem Überstand berechnet. Je Messzeitpunkt wurde mit biologischen Triplikaten und einer Normalkontrolle gearbeitet, um einen Effekt auf die Hypoxie zurückzuführen zu können. Die Überstände wurden zu den entsprechenden Zeitpunkten entnommen und die CYR61Konzentration wurde mittels Sandwich-ELISA wie in 2.2.4.1 beschrieben analysiert.

\subsubsection{Messung der intra- und extrazellulären CYR61-Konzentration unter EGF- Stimulation}

Für dieses Experiment wurden die Zelllinien MDA-MB-231-B02 und MDA-MB-231 verwendet. Beide Zelllinien wurden unter Standard-Zellkulturbedingungen $\left(37^{\circ} \mathrm{C}, 5 \%\right.$-CO2 und 21 \%-O2) in definierter Menge ausgesät. 24 Stunden später wurde das Medium DMEM einmal in den T75- $\mathrm{cm}^{2}$-Zellkulturflaschen ausgetauscht. Dies verblieb 48 Stunden auf den Zellen, um eine Sättigung der kontinuierlich laufenden CYR61-Sekretion zu erreichen. Nach 48 Stunden wurde $1.3 \mu \mathrm{g}$ EGF pro $13 \mathrm{~mL}$ Zellmedium in die Zellkulturflasche gegeben und für $0 \mathrm{~h}, 15 \mathrm{~min}, 1 \mathrm{~h}$, $6 \mathrm{~h}, 14 \mathrm{~h}$ und $24 \mathrm{~h}$ inkubiert. Zudem wurde von jedem Messpunkt eine weitere T75- $\mathrm{cm}^{2}-$ Zellkulturflasche der kein EGF zugegeben wurde, untersucht. Von diesen Proben wurde jeweils das Zellysat gewonnen und $1 \mathrm{~mL}$ Überstand abgenommen und per Sandwich-ELISA (siehe Absatz 2.2.4.1) auf CYR61-Sekretion untersucht. Das Zelllysat wurde wie in Absatz 2.2.2.1 gewonnen, um einen BCA-Test für eine spätere Westernblotanalyse durchführen zu können. Die Durchführung der Westernblotanalyse ist in Abschnitt 2.2.3 beschrieben.

\subsubsection{Sandwich-ELISA (ELICYR) mit Plasmaproben von Patientinnen mit Mammakarzinom}

Insgesamt wurden 850 Plasmaproben von Frauen mit Mammakarzinom und 324 Plasmaproben gesunder Frauen mit einem Alter von über 50 Jahren mittels Sandwich-ELISA analysiert (siehe 
Absatz 3.2.4). Von den Plasmaproben wurden 2,5 $\mu \mathrm{L}$, verdünnt in 97,5 $\mu \mathrm{L}$ DMEM mit $10 \%$ FCS, eingesetzt.

In einer retrospektiven Studie wurden die Plasmaproben und zugehörigen Daten von 850 Patientinnen untersucht, bei denen im Zeitraum von 2011 bis 2016 ein Mammakarzinom primär oder sekundär diagnostiziert wurde. Die Plasmaproben und zugehörigen Daten wurden in Kooperation mit der klinischen und wissenschaftlichen gynäkologischen Abteilung (Prof. Müller und Dr. Oliveira) des Universitätsklinikums Hamburg-Eppendorf freigegeben. Es wurden die Patientinnen und deren Daten aus der Untersuchung ausgeschlossen, die in den jeweiligen Untersuchungsparametern Unvollständigkeiten aufwiesen oder deren Primärtumor kein Mammakarzinom war.

So ergab sich ein Kollektiv aus 786 Patientinnen. Dabei handelte es sich um Frauen, mit einem Altersmittelwert von 67 Jahren und einer Bandbreite von 30-96 Jahren. Untersucht wurden die folgenden Parameter:

OP-Datum, Blutentnahmedatum, Geburtsdatum, Ursprungsorgan des Tumors, Ort der Materialentnahme (Gewebe), Primär/Rezidiv-Status, cT-Stadium, Grading, histologischer Typ $(1=$ duktal; $2=$ lobulär; $3=$ sonstige, $4=$ papillär, $5=$ NST, $6=$ serös, $7=$ endometroid, $8=$ muzinös, $9=$ serös-papillär, $10=$ klarzellig, $11=$ tubulär, 12=inflammatorisch), Nodalstatus $(0=0 ; 1=1)$, Lymphinvasion, vaskuläre Invasion, ER-Status, PR-Status, Her2-Status und die Therapie (adjuvant, neoadjuvant, sonstige). Des Weiteren wurden Follow-up-Daten gesammelt, sofern diese in den Akten vorlagen.

Die 324 Plasmaproben gesunder Frauen wurden in Zusammenarbeit mit der Transfusionsmedizin zusammengestellt. Hier handelte es sich um gesunde Frauen, die mindestens 50 Jahre alt und frei von einer Mammakarzinomerkrankung waren.

\subsubsection{Datenerfassung und statistische Auswertung der Sandwich-ELISA-Messungen von Blutproben in Bezug auf die CYR61-Menge im Plasma der Patientinnen}

Statistische Analysen wurden mit der R-Version 3.3.3 (R Foundation for Statistical Computing) durchgeführt. Die CYR61-Konzentrationen wurden für alle Analysen logarithmisch transformiert, um eine nahezu normale Verteilung zu erhalten.

Die univariate Varianzanalyse wurde angewendet, um die Assoziation zwischen CYR61-Konzentrationen und dem Krankheitsstatus (gesund, DCIS, maligner Krebs) zu berechnen, gefolgt von dem Signifikanztest „Tukey Test“ im paarweisen Vergleich. Die Genauigkeit der CYR61Konzentrationen bei der Unterscheidung gesunder Probanden von Tumorpatientinnen wurde 
unter Verwendung von ROC-Analysen und der AUC durch Kreuzvalidierung unter Verwendung einer binomialen Klassifikationsmodellierung berechnet.

Eine multivariate Analyse wurde durchgeführt, um den Zusammenhang zwischen den klinischen Variablen der Tumorpatientinnen und ihrer entsprechenden CYR61-Konzentration zu bewerten. 


\section{Ergebnisse}

Das Promotionsvorhaben dieses Projektes besteht darin, das Potenzial des Proteins CYR61 zur frühen Detektion von Mammakarzinom zu bestimmen. In dieser Dissertation soll herausgefunden werden, welches Potenzial das Protein CYR61 bei der Früherkennung von Mammakarzinom aufweist, indem zunächst in Zellkulturlinien das Vorhandensein und Verhalten des Proteins untersucht wird, um diese Erkenntnisse dann in klinischen Blutproben zu verifizieren und mit klinischen Daten zu spezifizieren. Das vorliegende experimentelle Promotionsprojekt besteht aus einem funktionellen und einem translationalen Teil. Es sollen zunächst die Ergebnisse aus dem ersten experimentellen Teil mit Zellkulturlinien dargestellt werden. Ziel des funktionellen Teils war es zu erforschen, in welchen Mammakarzinomsubtypen CYR61 exprimiert und in ausreichenden Mengen sezerniert wird und in welcher Weise diese Eigenschaften mit einem aggressiveren EMT-Phänotyp assoziiert sind. Um die Regulation der CYR61-Expression unter Bedingungen, die im Tumormilieu häufig vorliegen, besser zu verstehen, wurden Experimente zur möglichen Stressbedingten Induktion einer CYR61-Sekretion durch Hypoxie und EGFStimulation durchgeführt.

Die Ergebnisse des funktionellen Teils meiner Dissertation sollen Folgendes darstellen:

- die zelltypabhängigen Differenzen in der Expression von CYR61

- der Zusammenhang von zytoplasmatischen und sekretierten CYR61 Protein in Tumorzellen

- die Freisetzung des CYR61-Proteins in Tumorzellen unter hypoxischen Bedingungen

- die Freisetzung des CYR61-Proteins in Tumorzellen unter Stimulation mit EGF

Im zweiten translationalen Teil wurden anonymisiert Daten von Patientinnen mit Mammakarzinom generiert und mithilfe von Krankenakten komplementiert. Anschließend wurden die Blutplasmaproben mittels Sandwich-ELISA(ELICYR) analysiert, die Menge an CYR61 je Probe festgestellt und die Ergebnisse zu den klinischen Daten korreliert. Wichtig war hier neben den personenbezogenen Daten wie Alter und Geschlecht, die vorhandene TNM-Klassifikation, das Grading, der Hormonrezeptorstatus von Östrogen- und Progesteron-Rezeptoren sowie der HER2-Status. Zudem wurden Plasmaproben von 124 gesunden Frauen in einem Alter ab 50 Jahren und älter akquiriert.

Die Ergebnisse des klinischen Teils sollen Folgendes darstellen:

- die Konzentrationen von CYR61 [in ng] im Blutplasma von Frauen mit diagnostiziertem Mammakarzinom 
- die Konzentration von CYR61 [in ng] im Blutplasma von gesunden Frauen ( $\geq 50$ Jahren)

- die statistische Auswertung der Ergebnisse der Blutanalysen in Bezug auf die krankheitsbezogenen Daten der untersuchten Mammakarzinompatientinnen und in Bezug auf gesunde Frauen

\subsection{Zelltypabhängige Differenzen in der Expression von CYR61}

Mittels Westernblotanalyse wurden elf verschiedene Mammakarzinomzelllinien und eine Lungenkarzinomzelllinie untersucht, wobei MDA435S von einem melanozytären Zelltyp abstammt und LC-M1 disseminierte Tumorzellen aus dem Knochenmark einer Patientin mit nicht-kleinzelligem Bronchialkarzinom (engl.: NSCLC) darstellt. Diese Zusammenstellung wurde bewusst vorgenommen, um das Verhalten weiterer Krebszellinien mitbeobachten zu können. Von jeder Zelllinie wurden drei Proteinextrakte gewonnen, die per Westernblotanalyse auf Vorhandensein von zytoplasmatischem CYR61-Protein, pan-Zytokeratinen mittels Antikörper AE1/AE3, mesenchymalen Strukturen mittels Vimentin-Antikörper und Alpha-Tubulin-Antikörper als Ladekontrolle, untersucht wurden (Abbildung 6). Dies ermöglichte eine Zuordnung der CYR61Expression zum Grad der Epithelialen-Mesenchymalen-Transition der Tumorzellen - eine Eigenschaft, die mit einer erhöhten Metastasierungsneigung und Resistenz gegenüber Chemotherapien und anderen Stresssituationen einhergeht.

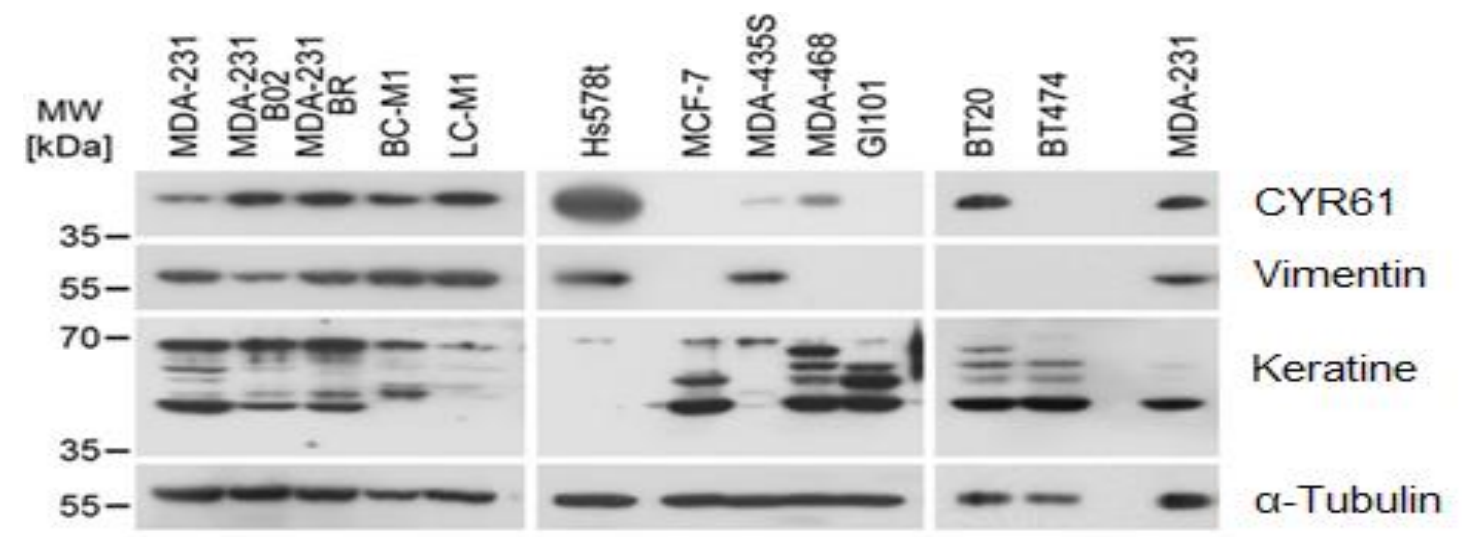

\footnotetext{
Abbildung 6: Westernblotanalyse von CYR61 in elf Mammakarzinomzellinien MDA-MB-231, MDA-468, MDA-MB-231-BR, MDA-MB-231-BO2, BC-M1, Hs-578t, MCF-7, GI-101, BT-20 und BT-474. MDA-435S wurde ursprünglich auch in der Literatur als Mammakarzinomzellinie geführt, hat sich aber in der Zwischenzeit als Melanomzelllinie offenbart. LC-M1 wurde aus DTCs im Knochenmark an einem Lungenkarzinompatienten etabliert. Detektiert wurden CYR61 sowie die EMT-Markerproteine Vimentin und Zytokeratine (pan-Zytokeratin-Antikörper-Klon AE1/AE3). Alpha-Tubulin diente als Ladekontrolle.
} 
Die Zelllinien MDA-MB-231, MDA-MB-231-Br, MDA-MB-231-BO2, BC-M1, LC-M1, HS578t, MDA-468, MDA-435S und BT-20 waren positiv für CYR61. Lediglich die Zelllinien MCF-7 und GI-101 und BT-474 waren negativ für CYR61. Dem mesenchymalen Typ (Keratin/Vimentin+) zuzuordnen war HS-578t, wohingegen MDA-468, MCF-7, GI-101 und BT-20 dem epithelialen Typ (Keratin+/Vimentin-) zuzuordnen waren. Die restlichen Zelllinien (MDA-MB-231, MDA-MB-468, MDA-MB-231-Br, MDA-435S, BC-M1 und LC-M1) waren positiv sowohl für den epithelialen als auch den mesenchymalen Zytoskelettproteintyp (Keratin+/Vimentin+) und somit dem intermediären EMT-Typ zugehörig. Es konnte zudem gezeigt werden, dass vor allem die CYR61-positive Zelllinien einen EMT-assoziierten Phänotyp aufwiesen. Die Zelllinien, MDA-MB-231, MDA-MB-231-BO2, MDA-231-Br, LC-M1, BC-M1 und MDA-468, wiesen eine Expression für Vimentin als mesenchymaler Marker und gleichzeitig für den pan-Zytokeratin-Antikörper als Vertreter der epithelialen Marker auf. Vor allem der mesenchymale Zelltyp als auch die Kombination aus mesenchymalen und epithelialen Zelltyp wird dem EMT-Phänotyp zugeschrieben und kann somit eine aggressivere Form des Mammakarzinoms darstellen (Fischer et al. 2015).

So sollten BT-20 als phänotypisch-epithelialer Vertreter, HS-578t als phänotypisch mesenchymaler Vertreter und MDA-MB-231, MDA-MB-231-BO2, MDA-MB-231-Br, MDA-435S, BC-M1 und LC-M1 als Vertreter des intermediären EMT-Phänotypes in den folgenden Experimenten verwendet werden. MCF-7 wurde von diesem Punkt der Experimente an als Negativkontrolle für CYR61 eingesetzt.

\subsection{Gesamtmenge des zytoplasmatischen und sekretierten CYR61- Proteins in Karzinomzelllinien}

In diesem Experiment sollten die Gesamtmengen in Nanogramm an CYR61 im Lysat pro Zelllinie quantifiziert und dargestellt werden. Nachdem die Lysate gewonnen wurden, konnte mit- 
tels Sandwich-ELISA die CYR61-Proteinkonzentration gemessen werden. Es wurde mit Triplikaten gearbeitet und die Zahlen der Abszisse stellen Mittelwerte mit ihrer zugehörigen Standardabweichung dar.

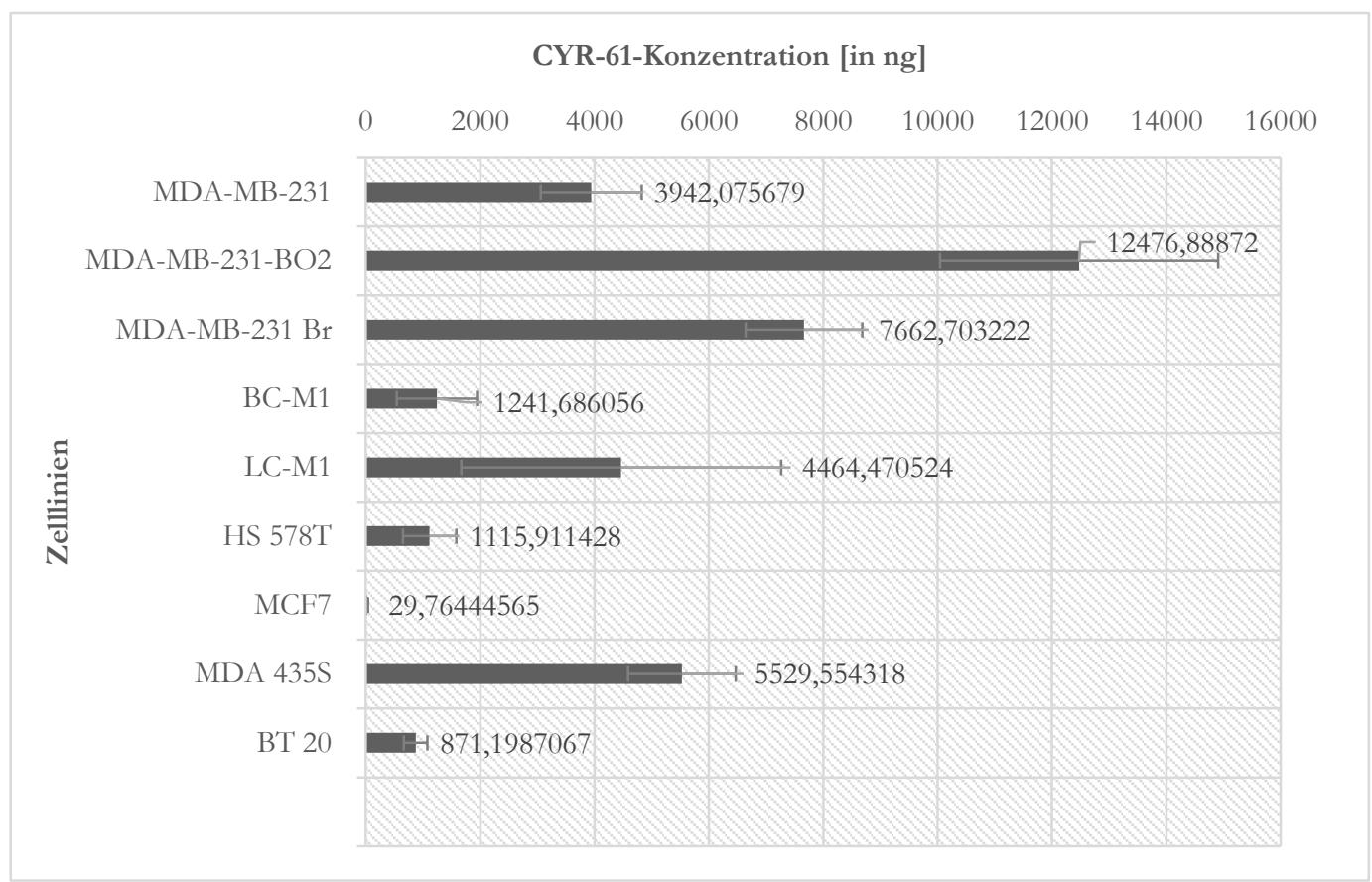

Abbildung 7: Gesamtmenge an rekombinantem CYR61 [in ng] im Zelllysat. MDA-MB-231, MDA-MB-231-BO2, MDA-MB-231-Br, BC-M1, BT-20, HS-578t und MCF-7 sind Mammakarzinomzelllinien. MDA-435S wurde ursprünglich auch in der Literatur als Mammakarzinomzelllinie geführt, hat sich aber in der Zwischenzeit als Melanomzelllinie offenbart. LC-M1 wurde aus DTCs im Knochenmark an einem Lungenkarzinompatienten etabliert. MCF-7 dient als Negativkontrolle. Die Messwerte sind der Mittelwert aus Messungen in biologischen Triplikaten und die Fehlerbalken entsprechen der Standardabweichung.

In diesem Diagramm sind die Gesamtmengen in Nanogramm an CYR61 im Zelllysat pro Zelllinie dargestellt. Die verminderte Expression von unter $31 \mathrm{ng}$ CYR61 in den Lysaten von MCF-7 bestätigte deren Wert als Negativkontrolle. MDA-MB-231-BO2 als Vertreter des intermediären EMT-Phänotyps wies mit 12.477 ng CYR61 im Lysat die höchste Konzentration auf. Dagegen lagen BT-20 als phänotypisch-epithelialer Vertreter und HS-578t als phänotypisch-mesenchymaler Vertreter und BC-M1 als Vertreter des intermediären Phänotyps mit weniger als $2.000 \mathrm{ng}$ CYR61 im Lysat im Mittelmaß. Als Vertreter eines hohen CYR61Expressionslevel und des intermediären EMT-Phänotyps, wies MDA-MB-231 nur 3.942 ng CYR61 im Zytoplasma auf, was einen der drei niedrigsten intrazellulären Werte aller Zellkulturlinien darstellte. Um diese zytoplasmatischen Konzentrationen in ein Verhältnis mit der Sekretion von CYR61 setzen zu können, wurde die Gesamtmenge an CYR61 ebenso im Überstand ermittelt. 


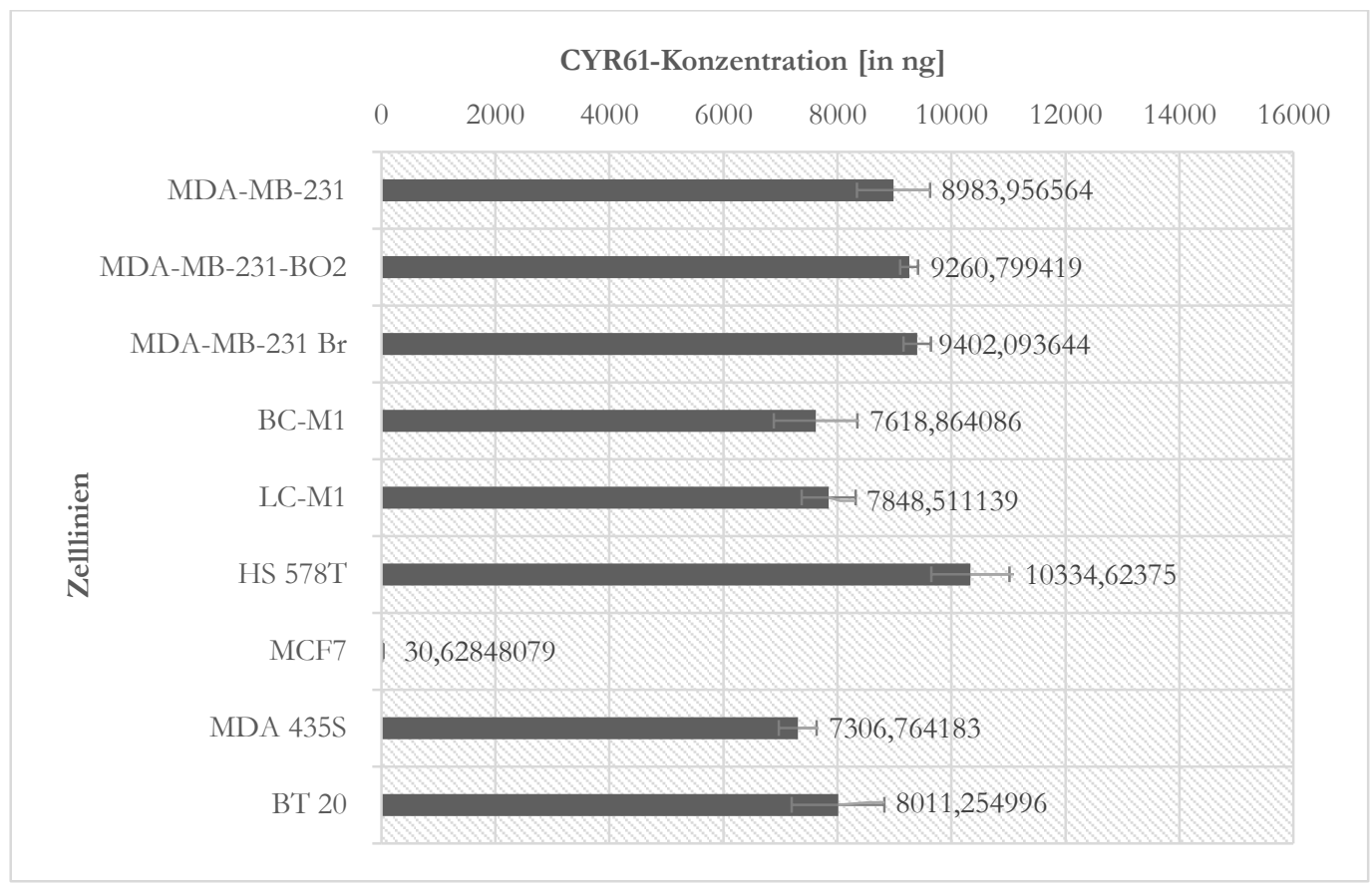

Abbildung 8: Gesamtmenge an rekombinantem CYR61 [in ng] im Überstand. MDA-MB-231,
MDA-MB-231-BO2, MDA-MB-231-Br, BC-M1, BT-20, HS578t und MCF-7 sind Mammakarzinom-
zelllinien. MDA-435S wurde ursprünglich auch in der Literatur als Mammakarzinomzelllinie geführt, hat
sich aber in der Zwischenzeit als Melanomzelllinie offenbart. LC-M1 wurde aus DTCs im Knochenmark
an einem Lungenkarzinompatienten etabliert. MCF-7 dient als Negativkontrolle. Die Messwerte sind der
Mittelwert aus Messungen in biologischen Triplikaten und die Fehlerbalken entsprechen der Standardab-
weichung.

In diesem Diagramm sind die Gesamtmengen in Nanogramm an CYR61 im Überstand pro Zelllinie dargestellt. Es wurde in biologischen Triplikaten gemessen und die obigen Zahlen stellen Mittelwerte mit ihrer Standardabweichung dar. Wie zu erwarten blieb MCF-7 auch hier CYR61-negativ im Überstand. Alle anderen Zellkulturlinien wiesen durchschnittliche CYR61Konzentrationen von $7.000 \mathrm{ng}$ bis über $10.000 \mathrm{ng}$ im Überstand auf. HS-578t als phänotypisch mesenchymaler Vertreter, gefolgt von MDA-MB-231-Br als Vertreter des intermediären EMTPhänotyps, sekretierten die größten Mengen an CYR61 mit bis zu 10.000 ng. Dagegen standen BC-M1 als auch MDA-435S als gemischt phänotypische Zelllinien mit weniger als $8.000 \mathrm{ng}$ CYR61 im Überstand zum Vergleich. MDA-MB-231 wies im Überstand 8.710 ng CYR61 auf und ist somit ein deutliches Beispiele dafür, dass das Protein CYR61 überwiegend sekretiert wurde (3.942 ng vs. $8.710 \mathrm{ng})$.

Vergleicht man die Abbildung 7 und die Menge an CYR61 im Lysat mit der Abbildung 8 und der Menge an CYR61 im Überstand, ist zu erkennen, dass das CYR61-Protein bevorzugt sekretiert wurde, da im Überstand höhere CYR61-Konzentrationen vorlagen als im Zytoplasma. 
Fast alle Zelllinien, bis auf die negativen MCF-7 und MDA-MB-231-BO2, wiesen im Überstand höhere Konzentrationen als im Zytoplasma auf.

Durch die in Kapitel 2.2.5 beschriebene Vorgehensweise war es anschließend rechnerisch möglich, aus der Gesamtproteinmenge je Zelllinie, die Menge an CYR61-Protein zu bestimmen, die sich intra- und extrazellulär befand. Über die Zellzahlbestimmung konnte dann die Menge an CYR61-Protein pro Zelle und die Molekülanzahl von CYR61 pro Zelle für jede Zelllinie bestimmt werden. Der Vorteil in der Berechnung der Moleküle pro Zelle besteht darin, dass dieser Wert um die Zellzahl bereinigt wurde, sodass die CYR61-Expression der verschiedenen Zelllinien direkt miteinander verglichen werden konnte. Die folgende Abbildung ergänzt die bereits in Abbildung 7 und 8 dargestellten CYR61-Mengen durch die Angabe der CYR61-Moleküle pro Zelle, sowohl im Überstand als auch im Lysat. Die Berechnungen dazu und das Durchführen der Messungen mittels Sandwich-Elisa (ELICYR) sind in Kapitel 2.2.4.1 bis 2.2.5 genau aufgeführt.

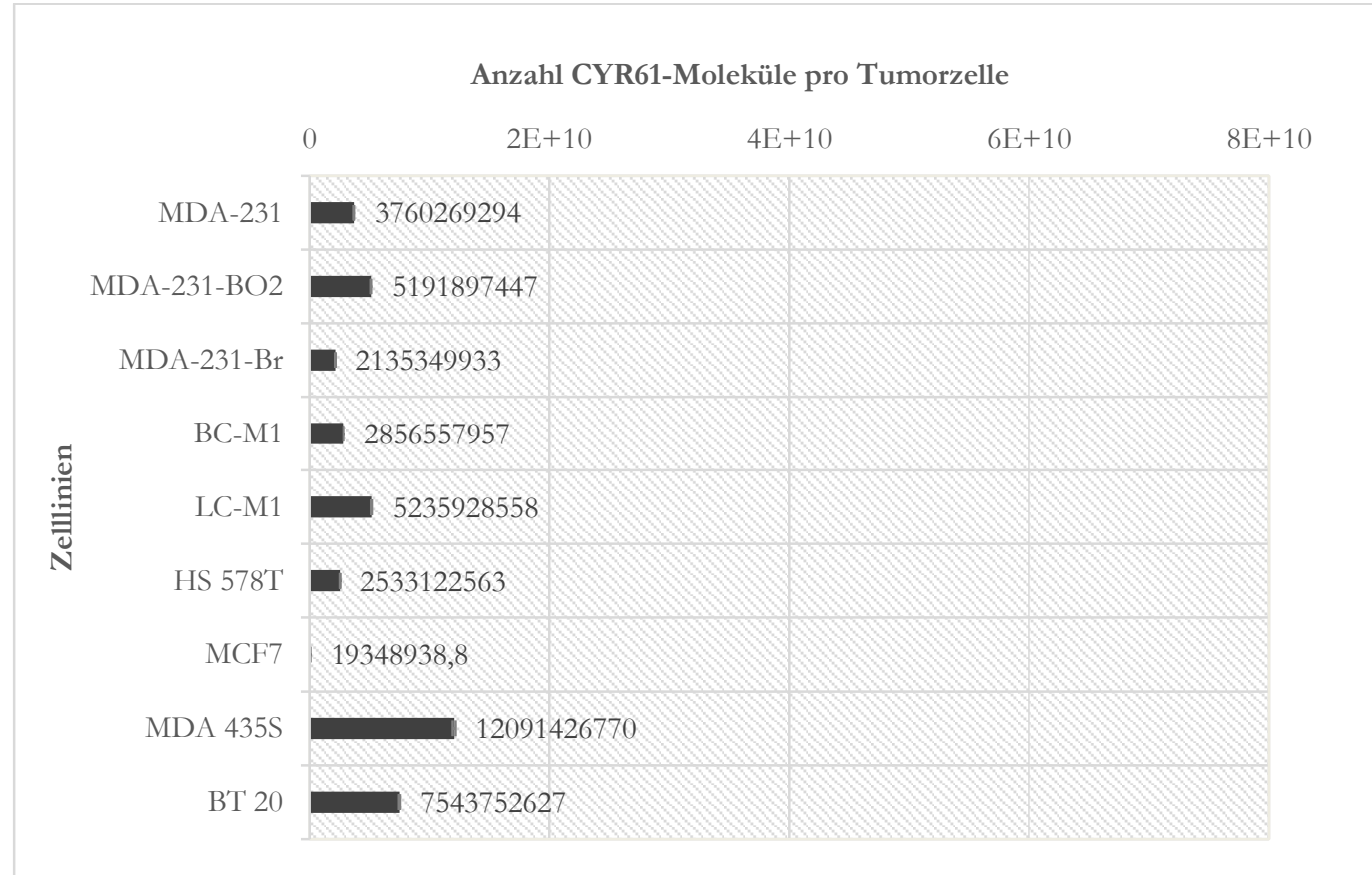

Abbildung 9: Bestimmung der CYR61-Molekülanzahl pro Tumorzelle im Lysat in neun Zelllinien. MDA-MB-231, MDA-MB-231-BO2, MDA-MB-231-Br, BC-M1, BT-20, HS578t und MCF-7 sind Mammakarzinomzelllinien. MDA-435S wurde ursprünglich auch in der Literatur als Mammakarzinomzelllinie geführt, hat sich aber in der Zwischenzeit als Melanomzellinie offenbart. LC-M1 wurde aus DTCs im Knochenmark an einem Lungenkarzinompatienten etabliert. Es wurden die Konzentrationen und Molekülanzahlen sowohl im Zytoplasma als auch im Überstand bestimmt. Die Messwerte sind der Mittelwert von Messungen in biologischen Triplikaten und die Fehlerbalken entsprechen der Standardabweichung. 
Die Abbildung 9 beginnt mit der Darstellung der Anzahl der CYR61-Moleküle im Lysat in den Zelllinien MDA-MB-231, MDA-MB-231-BO2, MDA-MB-231-Br, BC-M1, LC-M1, Hs-578t, MCF-7, MDA-435S und BT-20. Die Bandbreite der Molekülanzahl pro Zelle begann bei 19 Millionen Molekülen pro Zelle in der Zelllinie MCF-7 und stellte damit den niegdrigsten Wert an Molekülen pro Zelle im Zytoplasma dar. Sie stieg an bis zu 5,1 Milliarden Molekülen pro Zelle in der CYR61-positiven Zelllinie MDA-MB-231-BO2 als Vertreter des intermediären EMT-Phänotyps und erhöhte sich auf bis zu mehr als 7 Milliarden Molekülen pro Zelle in der Zelllinie BT-20 als phänotypisch-epithelialer Vertreter. Das Maximum der intrazellulären Molekülanzahlen endete bei ca. 12 Milliarden CYR61-Molekülen in der Zelllinie MDA-435S, was die durchschnittlich größte Anzahl an CYR61-Molekülen pro Zellzytoplasma darstellte. Anschließend bestimmte man die Anzahl der CYR61-Moleküle im Überstand, um dies zu der Anzahl der Moleküle im Lysat in Beziehung zu setzen.

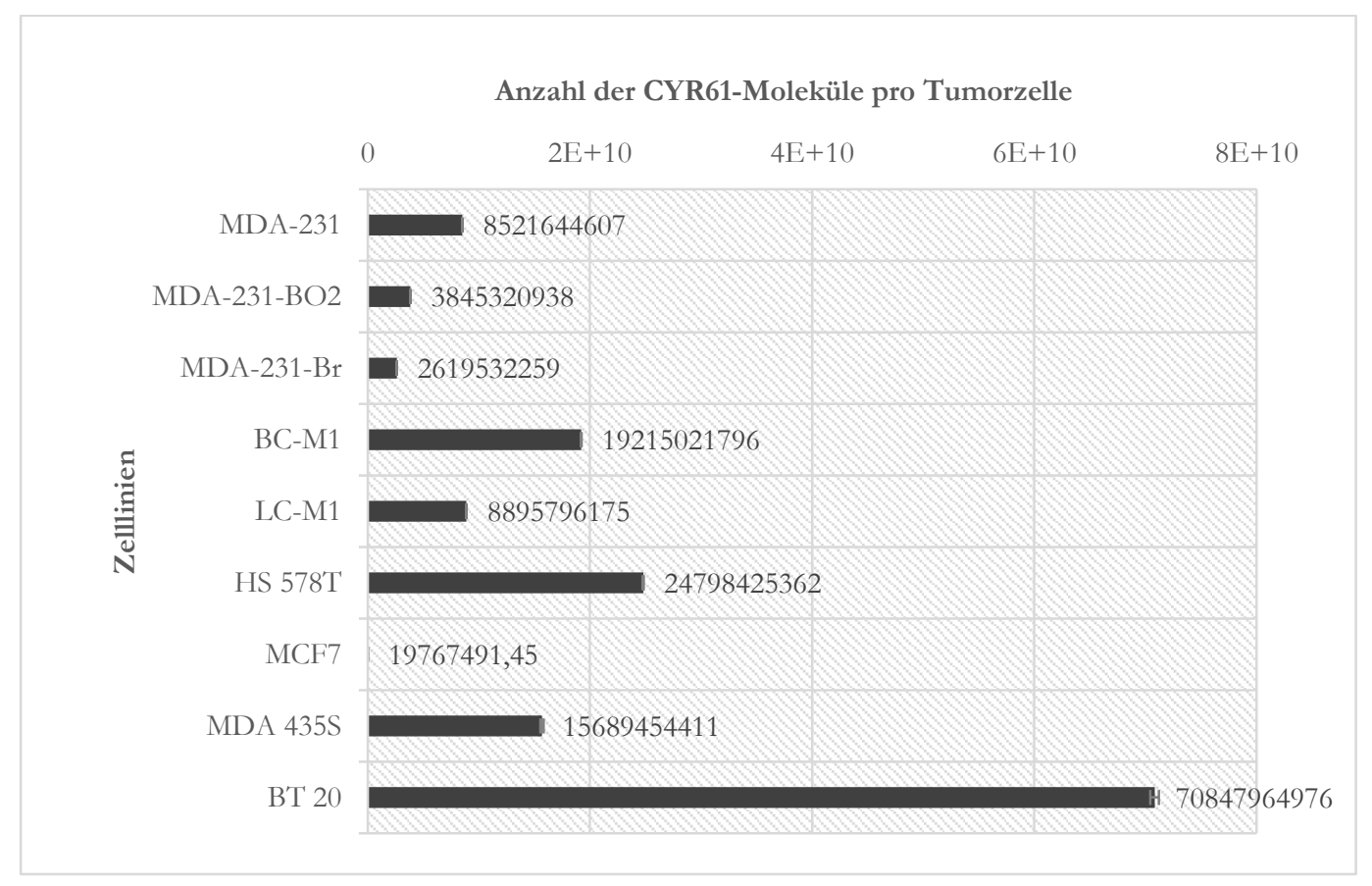

Abbildung 10: Bestimmung der CYR61-Molekülanzahl pro Tumorzelle im Überstand von neun Zelllinien. MDA-MB-231, MDA-MB-231-BO2, MDA-MB-231-Br, BC-M1, BT-20, HS578t und MCF7 sind Mammakarzinomzelllinien. MDA-435S wurde ursprünglich auch in der Literatur als Mammakarzinomzelllinie geführt, hat sich aber in der Zwischenzeit als Melanomzellinie offenbart. LC-M1 wurde aus DTCs im Knochenmark an einem Lungenkarzinompatienten etabliert. Es wurden die Konzentrationen und Molekülanzahlen sowohl im Zytoplasma als auch im Überstand bestimmt. Die Messwerte sind der Mittelwert von Messungen in biologischen Triplikaten und die Fehlerbalken entsprechen der Standardabweichung. 
In diesem Diagramm der Abbildung 10 ist die Anzahl von CYR61-Molekülen pro Zelle im Überstand der bereits genannten Zelllinien abgebildet. Hier wies die Zelllinie BT-20 als Vertreter des epithelialen EMT-Phänotyps die durchschnittlich meisten Moleküle mit über 70 Milliarden Moleküle pro Zelle auf. Im Vergleich dazu lag die durchschnittlich intrazelluläre Anzahl an Molekülen in dieser Zelllinie bei weniger als 7,6 Milliarden CYR61-Molekülen (Abbildung 9). Zudem zeigt diese Abbildung im Vergleich, dass sieben der neun Zelllinien (MDA-MB-231, MDA-MB-231-Br, BC-M1, LC-M1, Hs-578t, MDA-435S und BT-20) extrazellulär höhere Molekülzahlen pro Zellkulturlinie aufwiesen im Vergleich zu den intrazellulären Molekülanzahlen. Außenvor blieben hier MCF-7 als Negativkontrolle, dessen Molekülanzahl bei ca. 19 Millionen Molekülen CYR61 gleichbleibend war und MDA-MB-231-BO2 (5,1 Milliarden intrazellulärevs. 3,8 Milliarden extrazelluläre Cyr61-Moleküle), die als einzige Zelllinie eine höhere CYR61Konzentration und CYR61-Molekülanzahl im Zytoplasma aufwies.

\subsection{Expression von CYR61 in Karzinomzellen unter hypoxischen Bedingungen}

Oft kann die Bildung von Blutgefäßen in einem Tumor nicht mit dem Tumorwachstum mithalten. Eine Vielzahl von Stressantwortproteinen, wie CYR61, wird unter Hypoxie indu-ziert, umso im weiteren Verlauf Angiogenese und Wachstum sicherzustellen (Hsiao 2015). So ist eine Hypothese, dass bei Hypoxieinduktion vermehrt CYR61 sekretiert wird und mit fortschreitender Zeit auch erhöhte CYR61-Mengen vorzufinden sind.

Für das weitere Vorgehen wurde die Zelllinien MDA-MB-231 als Vertreter des intermediären EMT-Phänotyps und MDA-468, als phänotypisch epithelialer Vertreter, ausgewählt. Aus Vorversuchen der Arbeitsgruppe um Dr. K. Bartkowiak wurde eine Runterregulation von zytoplasmatischem CYR61 in der Zelllinie MDA-MB-231 unter Hypoxie beobachtet. Nun galt es herauszufinden, ob dies in direktem Zusammenhang mit sekretiertem CYR61 stand, denn die Hypotese bestand darin, dass sich die intrazelluläre Runterregulation in erhöhten Sekretionsmengen im Überstand sichtbar machen könnte. In diesem Experiment ging es also darum die Sekretionstendenzen in den jeweiligen Gruppen - Kontrolle versus Hypoxie - zu erkennen und zu vergleichen. Die CYR61-Konzentration wurden im Überstand dieser Zelllinien, die unter Hypoxie $\left(37^{\circ} \mathrm{C}, \mathrm{CO}_{2} 5 \%, \mathrm{O}_{2} 1 \%\right)$ und unter atmosphärischer Luft $\left(37{ }^{\circ} \mathrm{C}, \mathrm{CO}_{2} 5 \%, \mathrm{O}_{2} 21 \%\right)$ kultiviert worden waren, mittels Sandwich-ELISA gemessen. Die Durchführung des ELISAs ist in Kapitel 2.2.4 nachzulesen. Zunächst wurden in Triplikaten Kontrollgruppen erstellt, die unter normalen Zellkulturbedingungen $\left(37^{\circ} \mathrm{C}, \mathrm{CO}_{2} 5 \%, \mathrm{O}_{2} 21 \%\right.$ ) nach 0 h, 2 h, 4 h, 8 h, $16 \mathrm{~h}$ 
und $24 \mathrm{~h}$ geerntet und mittels ELISA auf das Sekretionsverhalten von CYR61 über diesen Zeitraum hin analysiert wurden. Parallel dazu kultivierte man die jeweiligen Zellkulturlinien unter hypoxischen Bedingungen $\left(37^{\circ} \mathrm{C}, \mathrm{CO}_{2} 5 \%, \mathrm{O}_{2} 1 \%\right.$ ), analysierte die CYR61- Sekretion ebenfalls mittels ELISA und konnte so das Sekretionsverhalten über den Zeitraum $0 \mathrm{~h}$ bis $24 \mathrm{~h}$ vergleichen.

Zunächst wurde der Überstand der Zelllinie MDA-MB-231 untersucht. Vergleicht man die Ordinaten in der unter normalen Bedingungen $\left(37^{\circ} \mathrm{C}, \mathrm{CO}_{2} 5 \%, \mathrm{O}_{2} 21 \%\right)$ und unter hypoxischen Bedingungen $\left(37^{\circ} \mathrm{C}, \mathrm{CO}_{2} 5 \%, \mathrm{O}_{2} 1 \%\right.$ ) kultivierten Zelllinien, dann erkennt man zu Beginn, also ab der nullten Stunde und nach vier Stunden, zunächst keinen Effekt (Abbildung 11). Es war bis dahin kein CYR61 im Überstand messbar. Ab acht Stunden stieg die CYR61-Konzentration in der Zelllinie MDA-MB-231 unter normalen Zellkultubedingungen auf über 120 $\mathrm{ng} / \mathrm{mL}$ an und erreichte hiermit seine größte Menge im Vergleich zu den beiden weiteren Messzeitpunkten. Ab 16 Stunden flachte die Konzentration hier auf weniger als 120 ng/mL ab, während in der Zelllinie unter hypoxischen Bedingungen $\mathrm{zu}$ diesem Zeitpunkt erst die ersten CYR61-Konzentrationen messbar wurden. Das bedeutet, dass CYR61 in der Zeit zwischen acht und 16 Stunden unter hypoxischen Bedingungen sekretiert wurde. Diese Sekretion stieg zwischen der 16. und 24. Stunde sichtbar an, während die Konzentrationen unter normalen Bedingungen in diesem Zeitraum nahezu auf einem Level blieben.
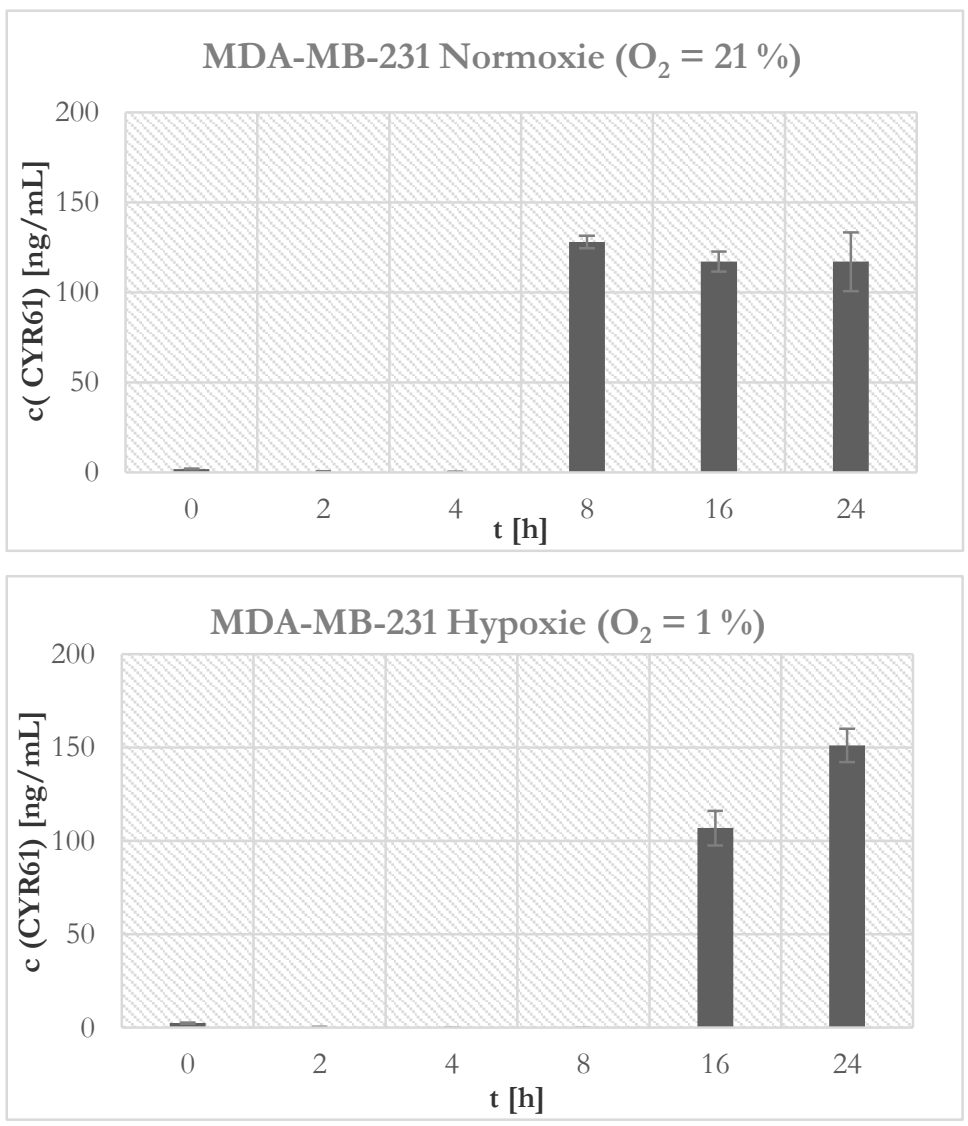

Abbildung 11: Messung der CYR61-Sekretion von hypoxisch und atmosphärisch kultivierten MDA-MB-231-Zellen. Dargestellt ist die CYR61Sekretion von MDA-MB-231Zellen, die unter hypoxischen Bedingungen kultiviert wurden $\left(1 \% \mathrm{O}_{2}\right)$ im Vergleich zu MDAMB-231-Zellen, die unter atmosphärischer Luft kultiviert wurden. Es wurden die CYR61Konzentrationen in biologischen Triplikaten zu den Zeitpunkten 0 h, 2 h, 4 h, 8 h, 16 h und $24 \mathrm{~h}$ gemessen. Die Messwerte zeigen den Mittelwert aus biologischen Triplikaten. Die Fehlerbalken entsprechen der Standardabweichung. 
Im direkten Vergleich sieht man demnach in der unter Hypoxie stehende Zellkulturlinie MDAMB-231 einen verzögerten Sekretionsbeginn ab 16 Stunden, welche bis zur 24. Stunde ansteigend war, während unter normalen Kulturbedingungen die Sekretion ab der achten Stunde begann und sich hier über den Zeitraum von bis zu 24 Stunden bei etwas weniger als $120 \mathrm{ng} / \mathrm{mL}$ einstellte.

Der Hypoxieversuch wurde ebenso mit der Zelllinie MDA-468 durchgeführt. Vergleicht man die Ordinaten in der unter normalen Bedingungen $\left(37^{\circ} \mathrm{C}, \mathrm{CO}_{2} 5 \%, \mathrm{O}_{2} 21 \%\right.$ ) und unter hypoxischen Bedingungen $\left(37{ }^{\circ} \mathrm{C}, \mathrm{CO}_{2} 5 \%, \mathrm{O}_{2} 1 \%\right.$ ) kultivierten Zelllinien, dann erkennt man zu Beginn bei null Stunden bis vier Stunden nur einen kleinen Effekt unter normalen Sauerstoffbedingungen. Unter hypoxischen Bedingungen war bis dahin kein CYR61 im Überstand messbar. Ab acht Stunden stieg die CYR61-Konzentration in der Zelllinie MDA-468 unter normalen Zellkulturbedingungen auf über $120 \mathrm{ng} / \mathrm{mL}$ an. Ab 16 Stunden sank die Konzentration, um nach 24 Stunden ihren Höchstwert mit über 140 ng/mL CYR61 im Überstand zu erreichen. In der Zellinie unter hypoxischen Bedingungen wurden die ersten CYR61-Konzentrationen, ebenso wie bei der Zellinie MDA-MB-231, erst ab der 16. Stunde messbar. Das bedeutet, dass die Zellen unter hypoxischen Bedingungen in der Zeit von acht bis 16 Stunden, damit begonnen haben vermehrt CYR61 zu sekretieren. Diese Sekretion stieg, ebenso wie es bei der Zellinie MDA-MB-231 zu beobachten war, zwischen der 16. und 24. Stunde sichtbar an.
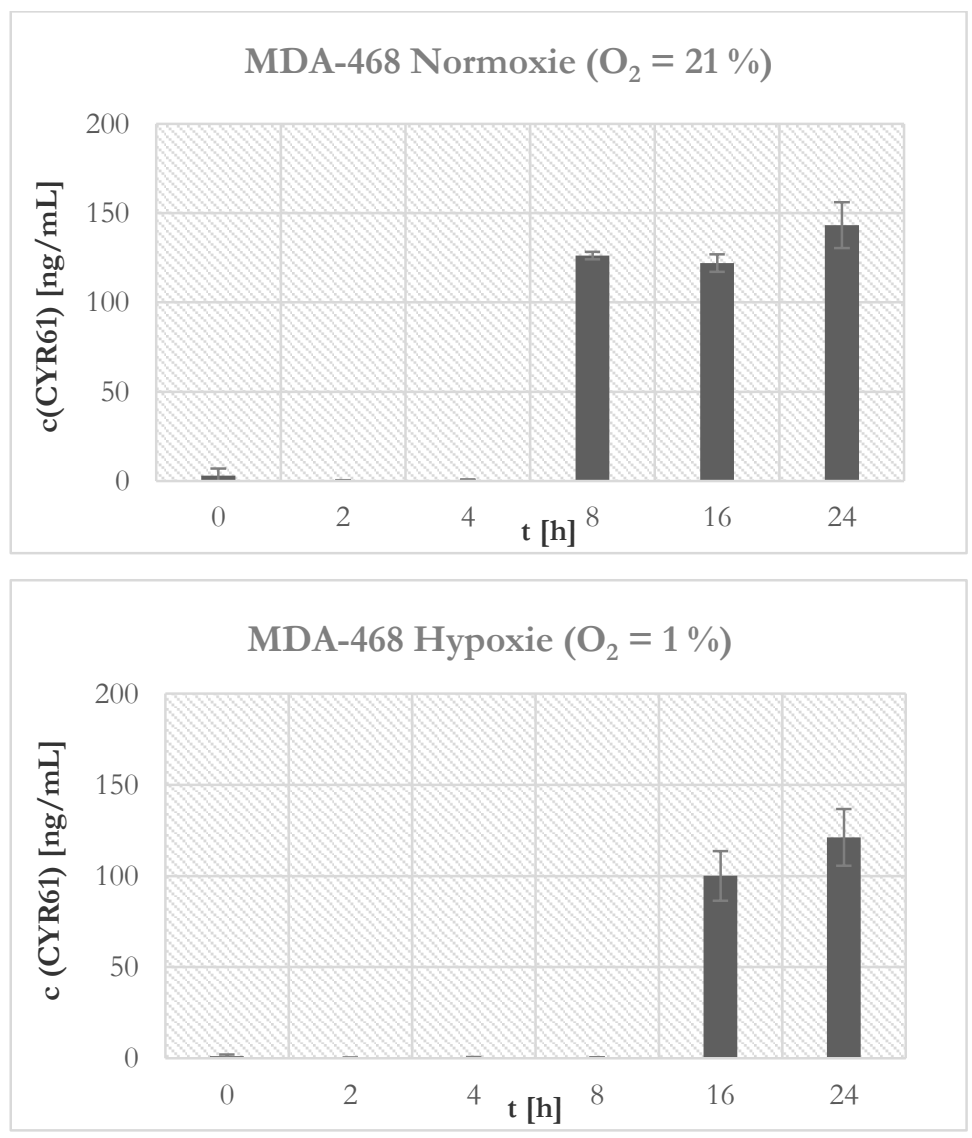

Abbildung 12: Messung der CYR61-Sekretion von hypoxisch und atmosphärisch kultivierten MDA-468-Zellen. Dargestellt ist die CYR61Sekretion von MDA- 468-Zellen, die unter hypoxischen Bedingungen $\left(1 \% \mathrm{O}_{2}\right)$ im Vergleich zu MDA- 468-Zellen, die unter atmosphärischer Luft kultiviert wurden. Es wurden die CYR61-Konzentrationen in biologischen Triplikaten zu den Zeitpunkten 0 h, 2 h, 4 h, 8 h, 16 h und $24 \mathrm{~h}$ gemessen. Die Messwerte zeigen den Mittelwert aus biologischen Triplikaten. Die Fehlerbalken entsprechen der Standardabweichung. 
Im direkten Vergleich sieht man demnach in der unter Hypoxie stehenden MDA-468-Zelllinie einen verzögerten Sekretionsbeginn ab 16 Stunden, welche bis zur 24. Stunde ansteigend war und dort mit einem Verlaufsmaximum endete. Unter normalen Kulturbedingungen wurde eine erste CYR61-Konzentration zwischen dem Beginn und sechs Stunden messbar, die nach acht Stunden deutlich zugewann, nach 16 Stunden leicht abnahm, um dann nach 24 Stunden ihr Verlaufsmaximum zu erreichen.

Es lässt sich folgendes Resultat zusammenfassen: In den beiden Zelllinien, die unter atmosphärischer Luft kultiviert wurden $\left(37^{\circ} \mathrm{C}, \mathrm{CO}_{2} 5 \%, \mathrm{O}_{2} 21 \%\right.$ ) zeigte sich eine deutliche Sekretion von CYR61 ab acht Stunden, die heterogen, unabhängig von der fortschreitenden Zeit an oder abstieg. In den hypoxieinduzierten Zelllinien $\left(37^{\circ} \mathrm{C}, \mathrm{CO}_{2} 5 \%, \mathrm{O}_{2} 1 \%\right)$ stellte sich bei beiden Zelllinien eine verspätete Sekretion von CYR61 heraus, die ab einer Hypoxiedauer von 16 Stunden begann und die mit fortschreitender Zeit und kontinuierlich ansteigender Tendenz ihr Maximum nach 24 Stunden erreichte.

\subsection{Expression von CYR61 in Karzinomzellen unter EGF-Stimulation}

EGF ist ein wichtiger Faktor, der das Wachstum und die Aggressivität von Karzinomzellen, zum Beispiel durch EMT-Induktion, erhöht. Da die Expression von zytoplasmatischem CYR61 durch EGF-Stimulation induziert werden kann (Brigstock 2002), war es wichtig, die Rolle von EGF auf die CYR61-Expression in Mammakarzinomzelllinien zu untersuchen. Allerdings ist für die Induktion der Angiogenese das sekretierte CYR61 relevant. Ich wollte herausfinden, ob solch ein Effekt auch bei Burstkrebszelllinien besteht und in welcher zeitlichen Dynamik eine mögliche Sekretion von CYR61 unter EGF-Stimulation bei Mammakarzinom stattfindet. Um dies zu überprüfen wurden die Zelllinien MDA-MB-231 und MDA-MB-231-BO2 unter Verwendung von AKT (entspricht der Proteinkinase B (PKB)) als Positivkontrolle für das Funktionieren der Stimulation mit EGF stimuliert. Die Arbeitsgruppe um Stefan Werner aus dem Insitut für Tumorbiologie am UKE, die die folgende Westernblotanalyse (Abbildung 13) mitentwickelt hat (Hohensee et al. 2016), zeigte, dass MDA-MB-231 und MDA-MB-231-BO2 für diese Untersuchungen gut geeignet seien, da sie eine starke EGFR-Expression aufweisen. Zudem steht mit der Knochenmetastasen-Sublinie MDA-231-B02 ein Modell zur Verfügung mit dem mögliche Veränderungen der CYR61-Sekretion bei der Metastasierung untersucht werden kann (Hohensee et al. 2016). Die Methodik einer Westerblotanalyse ist im Kapitel 2.2.3 nachzuvollziehen. 


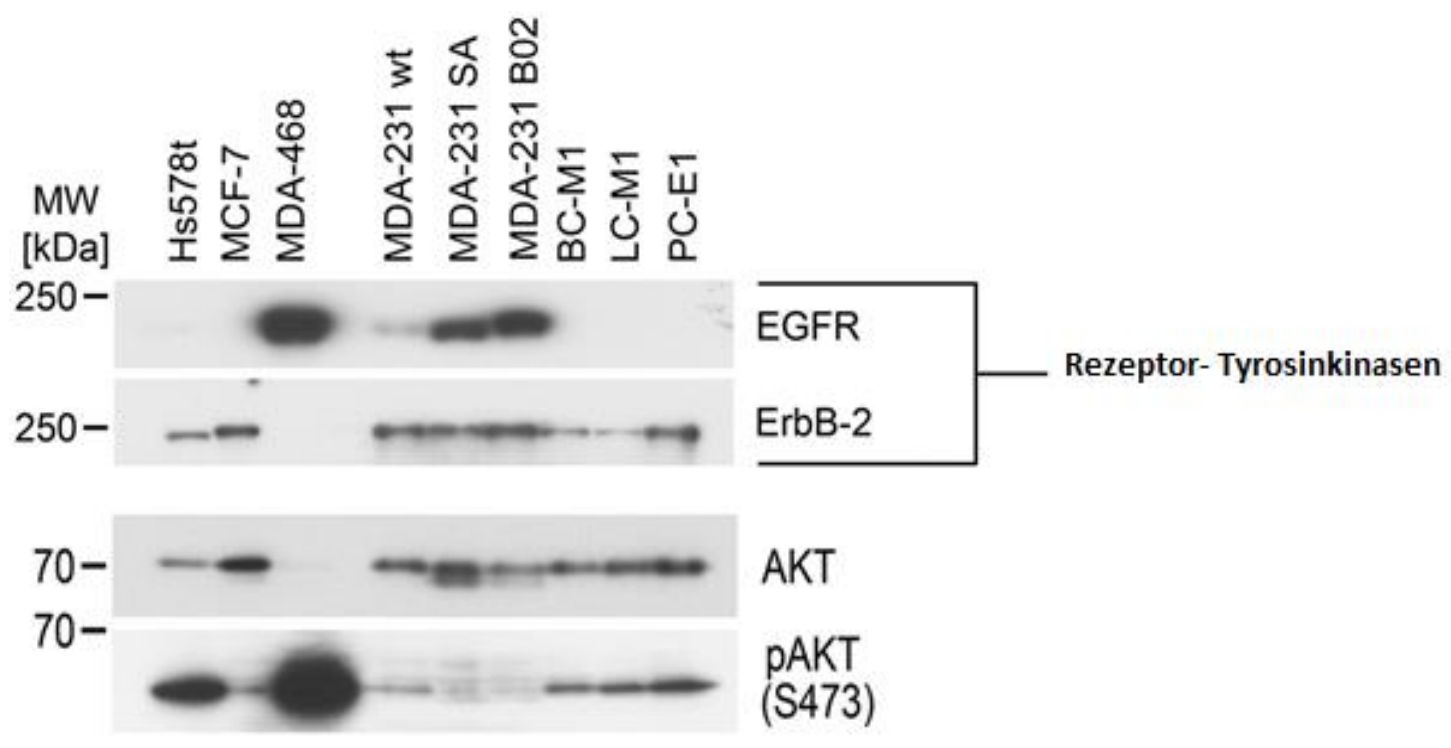

Abbildung 13: Westernblotanalyse über die Expression von EGFR, ErvB-2, AKT und pho-AKT (S743). Auf eine Expression hin untersucht wurden Hs-578t, MCF-7, MDA-468, MDA-MB-231, MDAMB-231-BO2, BC-M1, LC-M1 und PC-E1. MDA-MB-231, MDA-MB-231-BO2, MDA 468, BC-M1, HS578t und MCF-7 sind Mammakarzinomzelllinien. LC-M1 wurde aus DTCs im Knochenmark an einem Lungenkarzinompatienten etabliert. PC-E1 ist eine Prostatakarzinomzelllinie (Hohensee et al. 2016; mit freundlicher Genehmigung vom Impact-Journals-Verlag).

Zur Validierung von Zellkulturlinien, die für eine EGF-Stimulation geeignet sind und EGFRExpression aufweisen, wurde die vorliegende Westernblotanalyse analysiert (Hohensee et al. 2016). MDA-468, MDA-MB-231 und MDA-MB-231-BO2 waren deutlich positiv für EGFRezeptorenexpression, während die restlichen Zelllinien wie HS-578t, MCF-7, BC-M1, LC-M1 und PC-E1 keinen EGF-Rezeptor exprimieren. Zudem waren MDA-MB-231 und MDA-MB231-BO2 ebenso positiv für eine AKT-Expression. Nach EGF-Stimulation wird AKT an Serin 473 phosphoryliert (Hohensee et al. 2016). Der Nachweis einer verstärkten phosphorylierten Form von AKT diente als Kontrolle einer zellulären Reaktion auf die EGF-Stimulation. Um zu überprüfen, ob es sich um eine Induktion der Phosphorylierung oder um eine Induktion der Proteinexpression handelt, wurde außerdem die Expression des AKT-Gesamtproteins ermittelt. Es wurde zunächst die intrazelluläre Freisetzung von CYR61, zu den Zeitpunkten $0 \mathrm{~h}$, 0,25 h, 1 h, 6 h, 14 h und 24 h in nicht stimulierten Kontrollen und mit EGF stimulierten Proben mittels Westernblotanalyse in der Zelllinie MDA-MB-231-BO2 erfasst (Abbildung 14). 


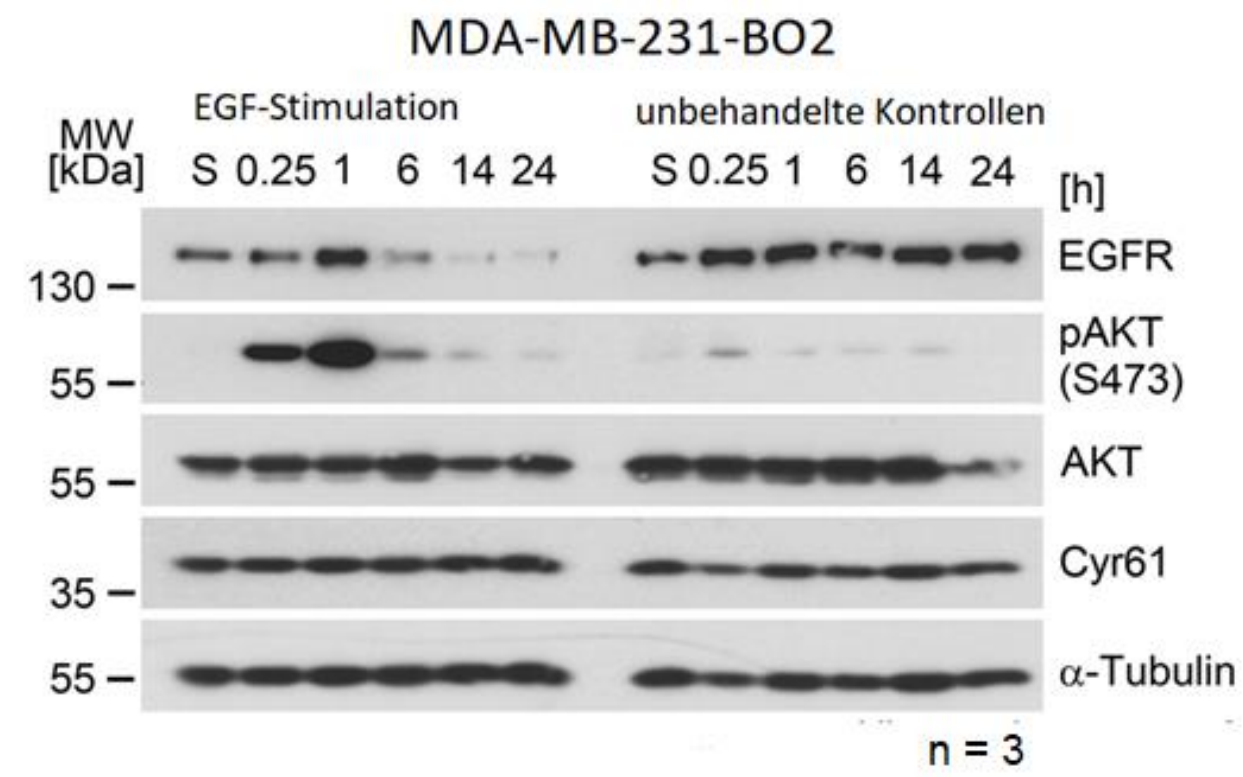

Abbildung 14: Westernblotanalyse der Expression von EGFR unter EGF-Stimulation im Vergleich zu nicht stimulierten Kontrollen der Mammakarzinomzelllinie MDA-MB-231-BO2. Analysiert wurde nach 0 h, 0,25 h, 1 h, 6 h, 14 h und 24 h EGF-Stimulation mit $1.3 \mu \mathrm{g}$ EGF pro $13 \mathrm{~mL}$ Zellmedium. Alle Experimente wurden in Triplikaten durchgeführt und auf die Expression von EGFR, pAKT, AKT und CYR61 untersucht. Alpha-Tubulin diente als Ladekontrolle.

In Abbildung 14 sind zunächst oben auf der linken Seite die genannten Zeitpunkte während der EGF -Stimulation von MDA-MB-231-BO2 Zelllinien und auf der rechten Seite die genannten Zeitpunkte ohne Stimulation aufgeführt. Diese Messwerte können direkt miteinander verglichen werden. An den rechten Seiten stehen die auf Expression getesteten Proteine. Tubulin wurde hier zur Kontrolle identischer Mengenauftragung auf das Gel der Westernblotanalyse genutzt und weist vergleichbare Mengen zu allen Messzeitpunkten auf.

In den EGF-stimulierten Zellen stieg die EGFR-Proteinexpression bis zur ersten Stunde hin an und sank in den folgenden 23 Stunden wiederum kontinuierlich ab. Im Vergleich dazu lag EGFR in der unbehandelten Kontrolle von Beginn des Experiments an bis nach 24 Stunden mit überwiegend ähnlichem Expressionslevel vor. Die starke Aktivierung von AKT, die als Phosphorylierung an S473 gemessen wurde, deutete auf eine erfolgreiche Stimulation der Zellen hin.

Die EGF-Stimulation hatte zudem kaum Einfluss auf die Konzentration von CYR61 im Zytoplasma, da es sowohl in den stimulierten Zelllinien als auch in den Kontrollzelllinien über 24 Stunden mit gleichbleibendem Signal vorlag. 
Anschließend wurde die intrazelluläre Freisetzung von CYR61 zu den Zeitpunkten $0 \mathrm{~h}$, 0,25 h, 1 h, 6 h, 14 h und $24 \mathrm{~h}$ in nicht stimulierten Kontrollen und mit EGF stimulierten Proben mittels Westernblotanalyse in der Zelllinie MDA-MB-231 erfasst (Abbildung 15).

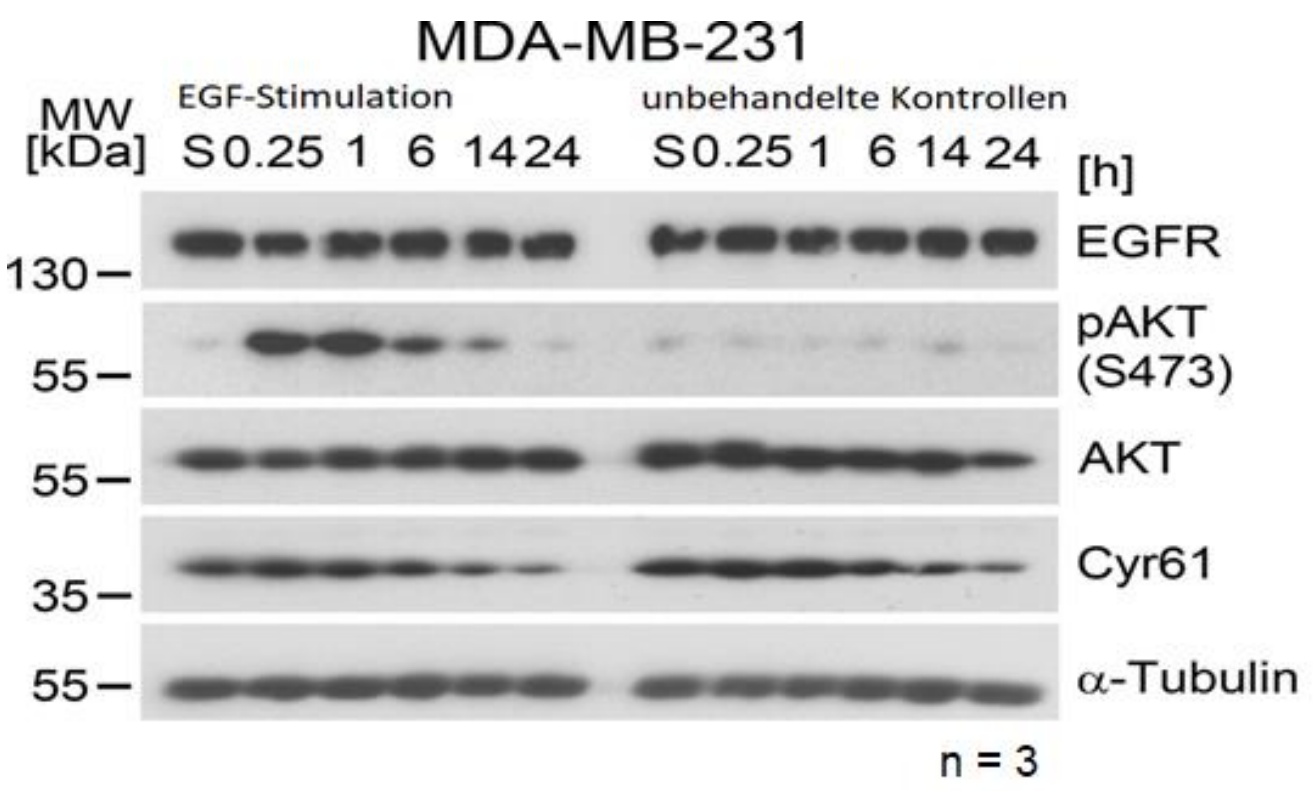

Abbildung 15: Westernblotanalyse der Expression von EGFR unter EGF-Stimulation im Vergleich zu nicht stimulierten Kontrollen der Mammakarzinomzelllinie MDA-MB-231. Analysiert wurde nach $0 \mathrm{~h}, 0,25 \mathrm{~h}, 1 \mathrm{~h}, 6 \mathrm{~h}, 14 \mathrm{~h}$ und $24 \mathrm{~h}$ EGF-Stimulation mit $1.3 \mu \mathrm{g}$ EGF pro $13 \mathrm{~mL}$ Zellmedium. Alle Experimente wurden in Triplikaten durchgeführt und auf die Expression von EGFR, pAKT, AKT und CYR61 untersucht. Alpha Tubulin diente als Ladekontrolle.

In Abbildung 15 sind auf der linken Seite die genannten Zeitpunkte während der EGF -Stimulation von der Zelllinie MDA-MB-231 und daneben auf der rechten Seite die genannten Zeitpunkte ohne Stimulation aufgeführt. Diese Messwerte können direkt miteinander verglichen werden. An den rechten Seiten stehen die auf Expression getesteten Proteine. Tubulin wurde hier zur Kontrolle identischer Mengenauftragung auf das Gel der Westernblotanalyse genutzt und weist vergleichbare Mengen zu allen Messzeitpunkten auf. Die starke Aktivierung von AKT, die als Phosphorylierung an S473 gemessen wurde, deutete ebenso in dieser Zelllinie auf eine erfolgreiche Stimulation der Zellen hin.

In den EGF stimulierten Zellen blieb das Signal die EGFR-Proteinexpression ab dem Startzeitpunkt der Stimulierung bis zu 24 Stunden der Stimulation auf überwiegend einem ähnlichen Niveau. Im Vergleich dazu lag das EGFR-Expressionslevel auch in der unbehandelten Kontrolle von Beginn des Experiments an bis nach 24 Stunden mit gleichbleibendem Signal vor. Hier bestand somit ein Unterschied zu der Tochterzelllinie MDA-MB-231-BO2, da das EGFR- 
Signal sich bei der EGF-stimulierten Zelllinie MDA-MB-231 nicht ab der sechsten Stunde verminderte, sondern zeitlich konstant blieb.

Wie in der Tochterzelllinie hatte die EGF-Stimulation kaum Einfluss auf die Konzentration von CYR61 im Zytoplasma, da es in den stimulierten Zelllinien als auch in den Kontrollzelllinien über 24 Stunden mit gleichbleibendem Expressionslevel vorlag.

Der von diesen Proben geerntete Zellkulturüberstand beider Zellkulturlinien wurde anschlieBend auf die CYR61-Konzentration mittels Sandwich-ELISA untersucht und ist im Folgenden vergleichend dargestellt.

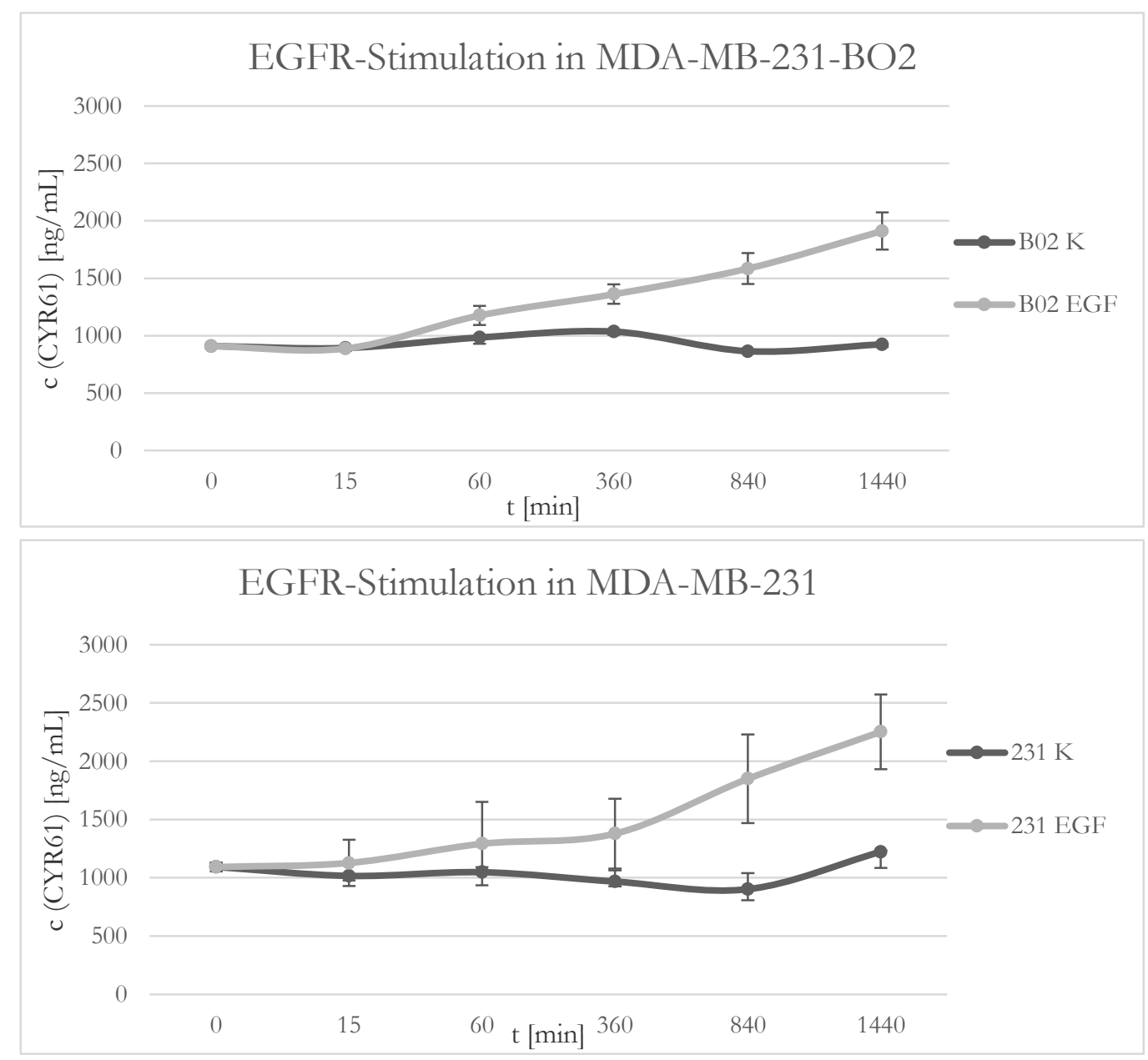

Abbildung 16: Veränderung der Konzentrationen von sekretiertem CYR61-Protein in Mammakarzinomzelllinien nach EGFR-Stimulation. Quantitative Erfassung von extrazellulärem CYR61 [in $\mathrm{ng} / \mathrm{mL}$ ] mittels Sandwich-ELISA nach EGFR-Stimulation in den Mammakarzinomzelllinien MDA-MB-231 und MDA-MB-231-BO2. 231K entspricht der nicht stimulierten Kontrolle der Mammakarzinomzelllinie MDA-MB-231. BO2K entspricht der nicht stimulierten Kontrolle der Mammakarzinomzelllinie MDA-MB-231-BO2. 231 EGF entspricht den stimulierten Zellen der Mammakarzinomzellinie MDA-MB-231. BO2 EGF entspricht den stimulierten Zellen der Mammakarzinomzelllinie MDA-MB-231-BO2. Die Messwerte sind der Mittelwert von Messungen aus biologischen Triplikaten und die Fehlerbalken entsprechen der Standardabweichung. Die Abszisse ist logarithmisch skaliert. 
Abbildung 16 zeigt die Sekretion von CYR61 in den Zelllinien MDA-MB-231 und MDA-MB231-BO2 im Zeitraum von null bis 24 Stunden unter EGF-Stimulation (231EGF/BO2EGF) und ohne Stimulation in den Kontrollen (231K/BO2K). Auf der Abszisse ist die Zeit in Minuten mit einer Spanne von null Stunden bis 24 Stunden und auf der Ordinate ist die CYR61Konzentration in $\mathrm{ng} / \mathrm{mL}$ angegeben. In der Zelllinie MDA-MB-231 stieg die Konzentration an sekretiertem CYR61 direkt zu Beginn an und endet nach 24 Stunden bei mehr als $2000 \mathrm{ng} / \mathrm{mL}$. Im Kontrollansatz war die CYR61-Konzentration über den untersuchten Zeitraum weitgehend konstant und lag bei etwa $1000 \mathrm{ng} / \mathrm{mL}$. Ein ähnliches Bild bot die Zelllinie MDA-MB-231BO2. Hier blieben die stimulierte und nicht stimulierte Gruppe bis zu 15 Minuten auf demselben CYR61-Konzentrationslevel. Dann hob sich die Sekretion unter Stimulation deutlich ab und stieg in 24 Stunden kontinuierlich und andeutungsweise linear an, um dort bei fast 2000 $\mathrm{ng} / \mathrm{mL}$ zu enden. Die Kontrollgruppe blieb über den gesamten Zeitraum von null bis 24 Stunden auf einem Konzentrationsniveau von etwa $1000 \mathrm{ng} / \mathrm{mL}$.

Um noch besser erkennen zu können, ab welchem Zeitpunkt die Sekretion startete, wurde nun noch der Zeitpunkt null Stunden bis eine Stunde hervorgehoben.

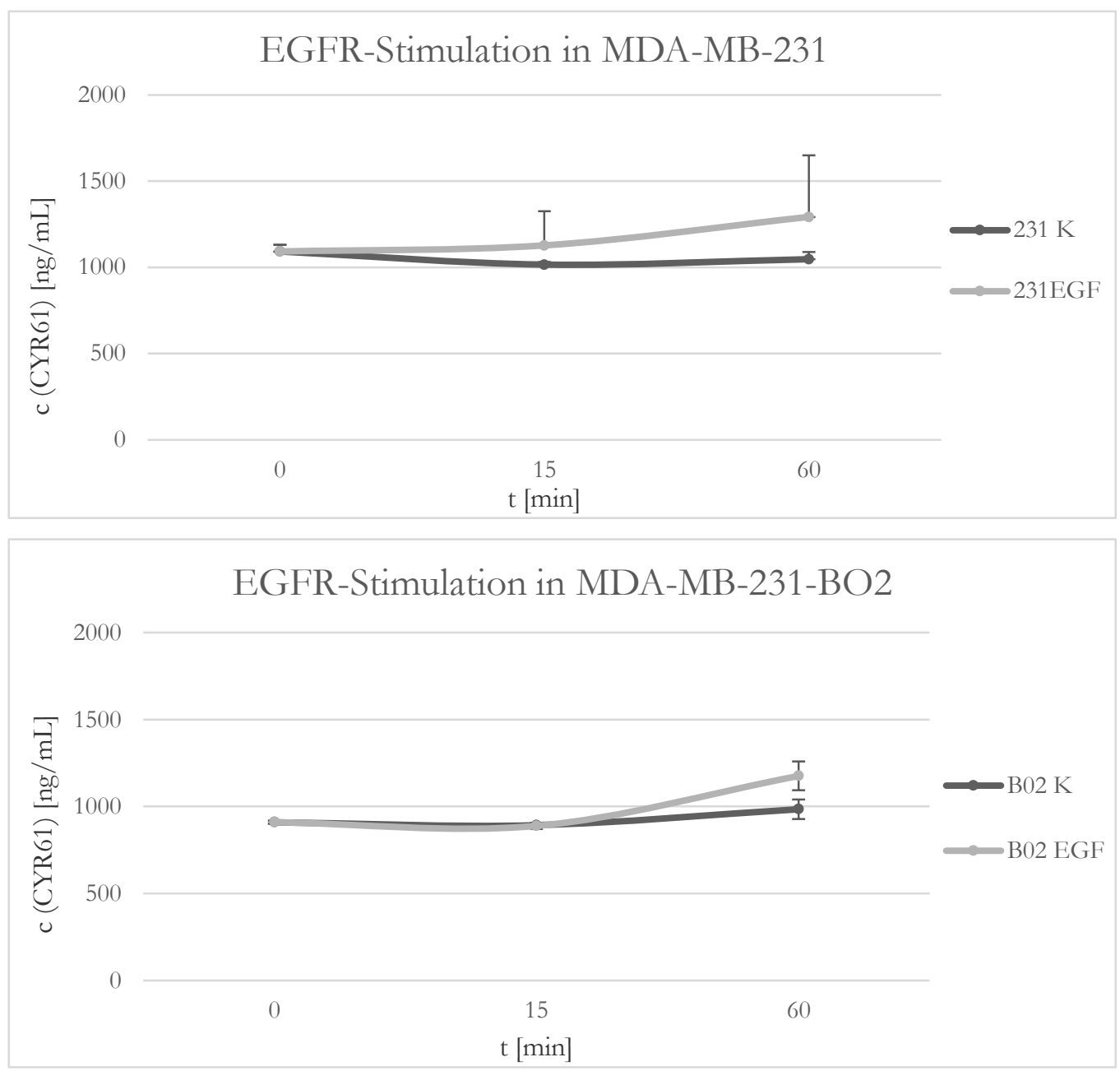


Abbildung 17: Veränderung der Konzentrationen von sekretiertem CYR61-Protein in Mammakarzinomzelllinien nach EGFR-Stimulation. Quantitative Erfassung von extrazellulärem CYR61 [in ng/mL] mittels Sandwich-ELISA nach EGFR-Stimulation. Darstellung der Zeitpunkte null bis eine Stunde in den Mammakarzinomzelllinien MDA-MB-231 und MDA-MB-231-BO2. 231K entspricht der nicht stimulierten Kontrolle der Mammakarzinomzelllinie MDA-MB-231. BO2 K entspricht der nicht stimulierten Kontrolle der Mammakarzinomzelllinie MDA-MB-231-BO2. 231 EGF entspricht den stimulierten Zellen der Mammakarzinomzelllinie MDA-MB-231. BO2 EGF entspricht den stimulierten Zellen der Mammakarzinomzelllinie MDA-MB-231-BO2. Die Messwerte sind der Mittelwert von Messungen aus biologischen Triplikaten und die Fehlerbalken entsprechen der Standardabweichung. Die Abszisse ist logarithmisch skaliert.

In der Abbildung 17 bleiben die Achsenbeschriftungen wie in der Abbildung 16 bestehen, nur stellt sich die Zeitachse von null bis eine Stunde nun deutlicher dar. Bei MDA-MB-231 wurde eine Induktion der CYR61-Sekretion bereits nach 15 Minuten beobachtet, die mit der Zeit der Stimulation kontinuierlich anstieg. Bei MDA-231-B02 wurde hingegen der Sekretionsbeginn mit kontinuierlichem Anstieg nach einer Stunde beobachtet.

Zusammengefasst veränderten sich die extrazellulären CYR61-Konzentrationen in den nicht stimulierten Kontrollgruppen bei beiden Zelllinien kaum. Dagegen stieg die CYR61-Konzentration in den EGF-stimulierten Zelllinien sowohl bei MDA-MB-231 als auch bei MDA-MB231- BO2 kontinuierlich an, was auf eine verstärkte Sekretionsleistung hinwies. Die Induktion der CYR61-Sekretion begann frühestens ab 15 Minuten (MDA-MB-231) und spätestens ab einer Stunde (MDA-MB-231 BO2).

\subsection{Definition von Patientinnen- und Kontrollgruppen und Erhebung klinischer Daten der Mammakarzinompatientinnen}

In Kooperation mit dem Forschungsinstitut der gynäkologischen Klinik des UKE Hamburg, wurden 786 Plasmaproben von Frauen mit Mammakarzinom zur Verfügung gestellt. Die Daten zu diesen Patientinnen mussten zunächst von mir komplimentiert werden. Im besonderen Fokus standen hier neben allgemeinen Daten (Alter, Geschlecht) die TNM-Klassifikation, das Grading, der Hormonrezeptorstatus von Östrogenrezeptor, Progesteronrezeptor und der HER2Status. Ebenso erhoben wurden das Blutabnahme- und OP-Datum, ob der Tumor primär oder als Rezidiv auftritt, der histologische Subtyp und begleitender Mikrokalk oder begleitendes DCIS. Darüber hinaus konnten Followup-Daten erhoben werden, wie die erfolgten Therapien, Remissionen, Rezidive oder der Exitus letalis.

Die Brustkrebpatientinnen haben einen Mittelwert des Alters von 67 Jahren mit einer Spannweite von 30 bis 96 Jahren. 
Um eine Aussage zu Sensitivität und Spezifität und Cut-off-Wert treffen zu können, wurden ebenso Plasmaproben von 324 gesunden Frauen in einem Alter von mindestens 50 Jahren und älter zusammengestellt und analysiert. Diese Blutspenderinnen sind genaustens über viele Jahre hinweg auf bestehende Krankheiten dokumentiert und stellen damit eine hervorragende Kontrollgruppe dar.

\subsection{ELISA-basierte Messung von CYR61-Proteinkonzentrationen im Blutplasma von Mammakarzinompatientinnen und gesunden Frauen}

Anhand des Sandwich-ELISAs (Kapitel 2.2.4 und 2.2.8) wurden die CYR61-Konzentrationen in den jeweiligen Plasmaproben (786 Mammakarzinom Patientinnen, 124 gesunde Frauen) bestimmt. Alle Daten wurden von zwei Personen unabhängig voneinander erhoben, um so die Reproduzierbarkeit darstellen zu können. Diese Werte wurden den anonymisierten Patientinnen zugeordnet und anschließend statistisch ausgewertet.

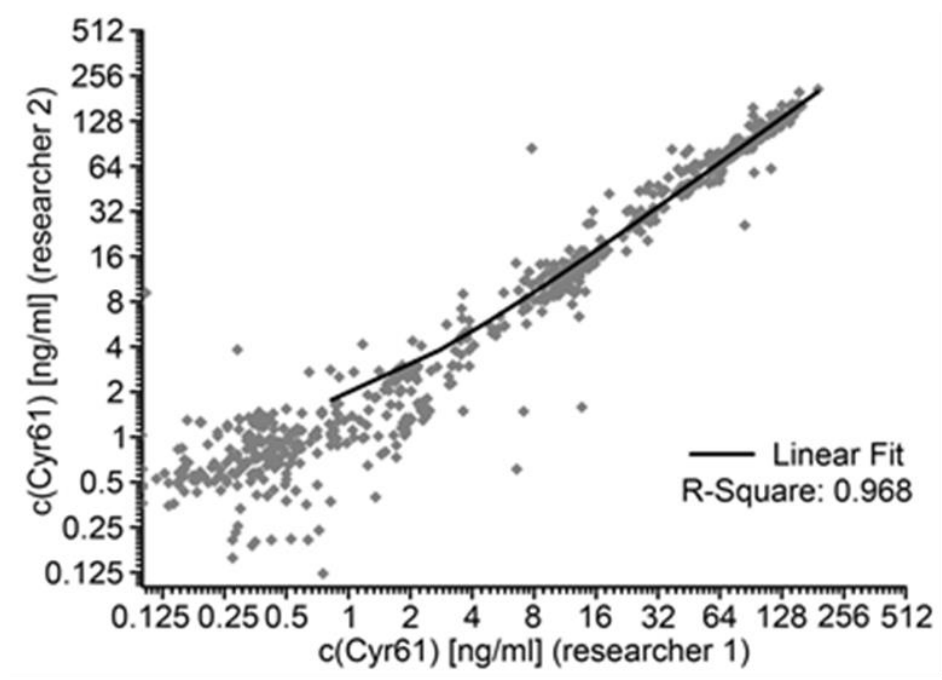

Abbildung 18: Reproduzierbarkeit des CYR61-Sandwich-ELISAs in Plasmaproben von Mammakarzinompatientinnen. Auf der Abszisse sind die von Forscher-1 bestimmten CYR61-Konzentrationen und auf der Ordinate die von Forscher-2 bestimmten CYR61-Konzentrationen angegeben. Jeder Datenpunkt repräsentiert einen Messwert. Der R-Square-Wert beträgt 0,968.

Abbildung 18 gibt die gemessenen CYR61- Konzentrationen [in $\mathrm{ng} / \mathrm{mL}$ ] wieder, die von zwei Forschern, unabhängig voneinander, für die Proben gemessen wurden. Man kann daran erkennen, inwiefern die gemessenen Werte beider Forscher für dieselben Proben übereinstimmen. Die Kurve stellt die lineare Anpassung beider Datensätze dar. Der R-Square für diese Gleichung betrug 0.968, was eine solide Reproduzierbarkeit demonstriert. 


\subsection{Statistische Auswertung: Korrelation der krankheitsbezogenen Daten zu den CYR61-Konzentrationen im Blutplasma}

In diesem Kapitel soll die statistische Auswertung von Korrelationen der krankheitsbezogenen Daten zu den CYR61-Konzentrationen im Blutplasma dargestellt werden. Dazu wurden über 900 Blutproben (124 gesunder Frauen, 786 an Mammakarzinom erkrankte Frauen) mittels des Sandwich-ELISAs (ELICYR) auf das Vorhandensein von CYR61 analysiert und die Konzentrationen wurden in $\mathrm{ng} / \mathrm{mL}$ quantifiziert. Anschließend konnten bestimmte Kohorten nach Tumorstadien, Krankheitszustand und DCIS gebildet werden, um die durchschnittliche CYR61-Konzentration innerhalb dieser Gruppen zu ermitteln. Zudem wurde eine ROC-Kurve zur Ermittlung von Spezifität und Sensitivität angefertigt und in den folgenden Abbildungen dargestellt.

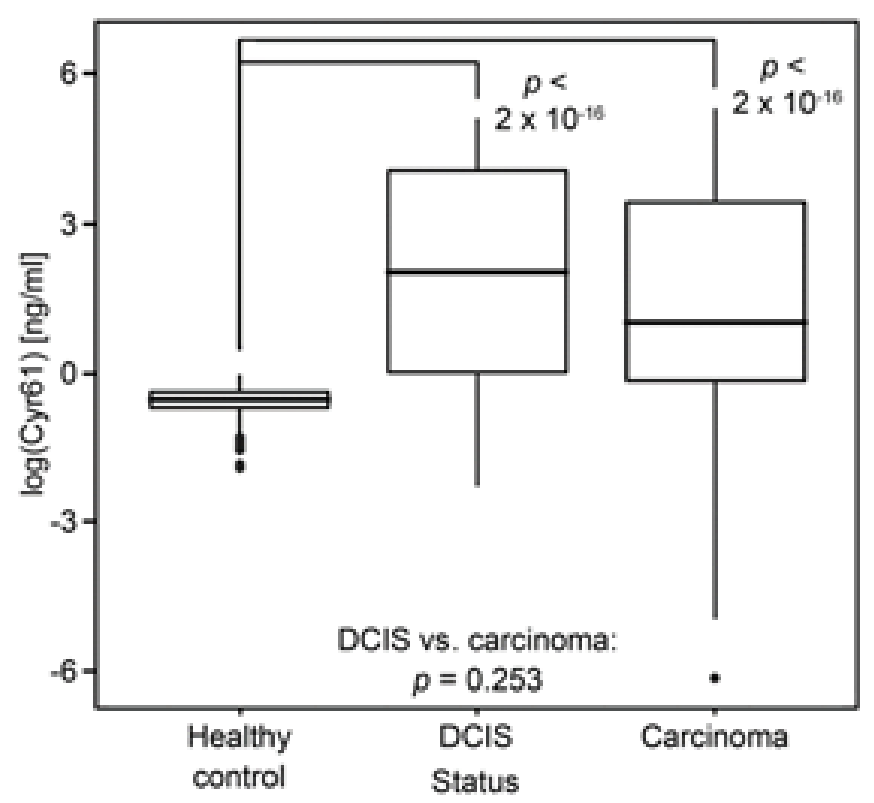

\footnotetext{
Abbildung 19: CYR61-Konzentration im Blutplasma von Mammakarzinompatientinnen und gesunden Frauen. Statistische Analyse der Blutplasma-CYR61-Konzentration in der DCIS-Untergruppe und in den Karzinomen im Vergleich zu weiblichen gesunden Kontrollpersonen (Alter $50+$ ). Abgebildet ist ein Boxplot-Diagramm und deren Fehlerbalken, um so die Verteilung der CYR61-Konzentrationen in den jeweiligen Kohorten (gesunde Kontrollpersonen vs. DCIS vs. invasives Karzinom) darzustellen. Die Markierungen in der Mitte der Boxplotsdiagramme stehen für den Median in den jeweiligen Gruppen [in $\mathrm{ng} / \mathrm{mL}$ ]. Die Ordinate liegt logarrithmisch skaliert vor.
} 
In Abbildung 19 ist ein Boxplot-Diagramm dargestellt, welches die Verteilung der CYR61-Konzentrationen [in $\mathrm{ng} / \mathrm{mL}]$ in den drei folgenden verschiedenen Kohorten darstellt: Kontrolle von gesunden Patientinnen, DCIS und die Karzinome, welche die Tumorstadien T1 bis T4 beinhalten. Gesunde Frauen wiesen eine mittlere/durchschnittliche CYR61-Konzentration von 0,59 \pm $0,19 \mathrm{ng} / \mathrm{mL}$ auf, während Mammakarzinompatientinnen $(\mathrm{n}=708)$ eine erhöhte mittlere/durchschnittliche CYR61-Konzentration von 25,1 \pm 40,9 ng/mL aufwiesen $(\mathrm{p}<2 \times 10-16$, ANOVA). Die durchschnittliche Konzentration von CYR61 der Karzinomgruppe von 25,1 $\mathrm{ng} / \mathrm{mL}$ wies also eine Standardabweichung der Werte von $\pm 40,9 \mathrm{ng} / \mathrm{ml}$ auf. Im Vergleich dazu war die Gruppe gesunder Frauen durch eine signifikant kleinere Durchschnittskonzentration von 0,59 und einer noch geringeren Standardabweichung von $0,19 \mathrm{ng} / \mathrm{mL}$ gekennzeichnet.

In ähnlicher Weise war die CYR61-Konzentration von Patientinnen mit DCIS ( $\mathrm{n}=74) \mathrm{im}$ Vergleich zu den gesunden Kontrollen signifikant mit 31,8 \pm 45,8 ng/mL ( $\mathrm{p}<2 \times 10-16$, ANOVA) erhöht. Allerdings wies die DCIS-Gruppe eine größere Standardabweichung von $\pm 45,8 \mathrm{ng} / \mathrm{mL}$ im Vergleich zu \pm 40,9 ng/mL in der Karzinomgruppe auf. Der Unterschied in der CYR61Konzentration zwischen den Karzinompatientinnen und der DCIS-Gruppe war dennoch statistisch nicht signifikant mit $\mathrm{p}=0,253$.

In der folgenden Abbildung 20 ist eine ROC-Kurve abgebildet, die Aussagen über Spezifität (Abszisse) und Sensitivität (Ordinate) macht, bezogen auf die Messwerte für die Detektion von Mammakarzinomen, die mit unserem Sandwich-ELISA (ELICYR) von dem gesamten Patientinnenkollektiv gemessen wurden.

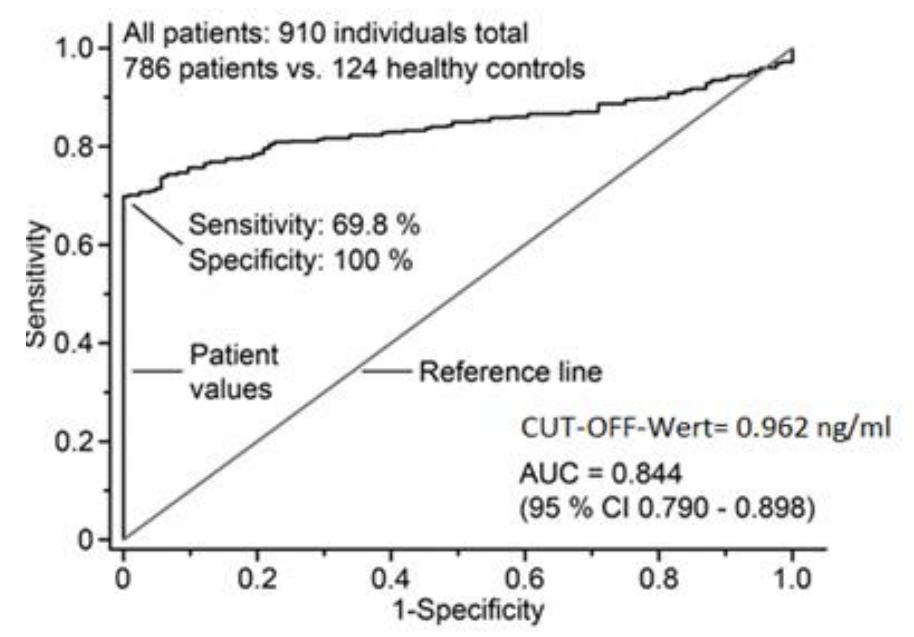

Abbildung 20: ROC-Kurve zur diagnostischen Wertigkeit der CYR61-Konzentration im Blut für alle analysierten Mammakarzinomfälle $(n=786)$ im Vergleich zu gesunden Frauen als Kontrollgruppe (n=124). Der Cut-off-Wert betrug 0,962 ng/mL. Auf der Abszisse ist die Spezifität und auf der Ordinate die Sensitivität angegeben. AUC: Fläche unter der Kurve; CI: Konfidenzintervall. 
Für die Gesamtgruppe von 786 Mammakarzinompatientinnen haben wir eine Sensitivität von 69,8 \% bei einer Spezifität von 100 \% ermittelt. Es ergab sich daraus ein Cut-off Wert von 0,962 $\mathrm{ng} / \mathrm{mL}$ und eine Fläche unter der Kurve von 0,884 mit einem 95-\%-Konfidenzintervall von 0,790 bis 0,898 .

Anschließend wurde die Sensitivität und Spezifität von CYR61 zum Nachweis von Mammakarzinomen in den Subgruppen DCIS und T1 bis T4 bestimmt, wobei ebenso die ROC-Kurvenanalyse für diese Subgruppen der Patientinnen verwendet wurde (Abbildung 21 und 22).
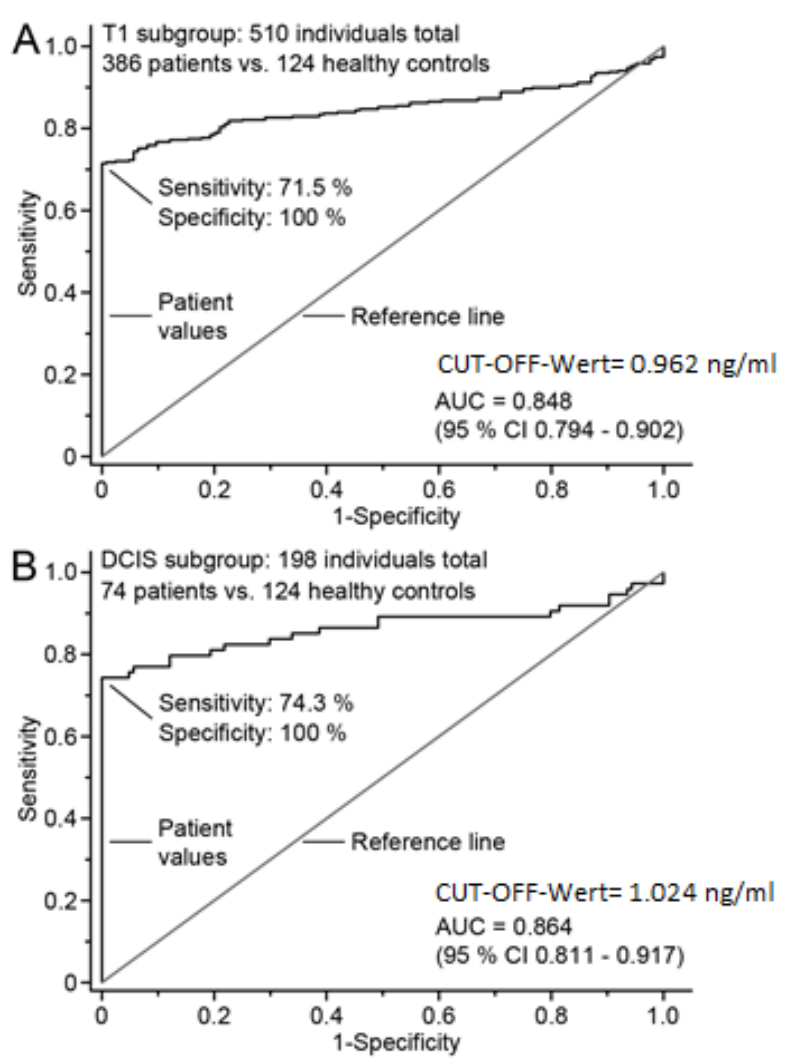

Abbildung 21: ROC-Kurve zur diagnostischen Wertigkeit der CYR61Konzentration im Blut von Mammakarzinompatientinnen (DCIS und Tumorstadium T1). Analysiert wurde das Blut von Patientinnen mit DCIS und Tumorstadium 1. Blutplasma von Mammakarzinompatientinnen wurde mit Blutplasma von gesunden weiblichen Kontrollpersonen verglichen. ROCKurve für das Tumorstadium 1 (A) mit dem Cut-off-Wert von $0,962 \mathrm{ng} / \mathrm{mL}$. ROC-Kurve für DCIS (B) mit dem Cutoff-Wert von $1,024 \mathrm{ng} / \mathrm{mL}$. Auf der Abszisse ist die Spezifität und auf der Ordinate die Sensitivität angegeben. AUC: Fläche unter der Kurve; CI: Konfidenzintervall.

In Abbildung $21 \mathrm{~A}$ und B ist eine ROC-Kurve zur Bestimmung von Sensitivität (Ordinate) und Spezifität (Abszisse) des Bluttests ELICYR (Sandwich-ELISA), in Bezug auf die Detektion von Mammakarzinom in den Stadien DCIS und Tumorstadium T1, dargestellt. Bei den 386 Patientinnen mit invasivem Mammakarzinom im Frühstadium T1 (Abb.21 A) betrug die Sensitivität $71,5 \%$ und die Spezifität ebenfalls $100 \%$. Das Areal unter der Kurve wies einen Wert von 0,848 mit einen 95-\%-Konfidenzintervall von 0,794 bis 0,902 auf. Für den Nachweis von DCIS-Läsionen der Brust (Abb. 21 B) bei 74 Patientinnen wurden Werte mit ähnlicher Genauigkeit erhalten, nämlich mit einer Sensitivität von 74,3\% und eine Spezifität von $100 \%$. Die Fläche unter der Kurve betrug hier 0,864 mit einem 95-\%-Konfidenzintervall von 0,811 bis 0,917. 
Die hohen Spezifitäten waren darauf zurückzuführen, dass das Blutplasma aller 124 gesunden Kontrollen sehr niedrige CYR61-Konzentration aufwiesen und nur ein geringes Maß an Streuung zeigten (0,59 \pm 0,19 ng / mL). Die Sensitivität von 74,3 \% war, im Vergleich zur T1-Gruppe mit einer Sensitivität von 71,5 \% und im Vergleich zur Sensitivität des Gesamtkollektivs von 69,8 \%, in der DCIS-Gruppe am höchsten. Dies bedeutete, dass der Test bei dem gesamten Patientinnenkollektiv mit allen Tumorstadien schon eine Sensitivität von fast $70 \%$ aufwies, die in den frühen Tumorstadien auf über $74 \%$ anstieg, sodass der Test bei bereits frühen Tumorstadien ansprach.

Anschließend wurden ROC-Kurven für die Blutproben von Patientinnen in den weiteren Tumorstadien T2 bis T4 berechnet. Hier ist die Anzahl der Patientinnen mit entsprechenden Tumorstadien sehr heterogen und nahm mit fortschreitendem Tumorstadium ab (Abbildung 22).
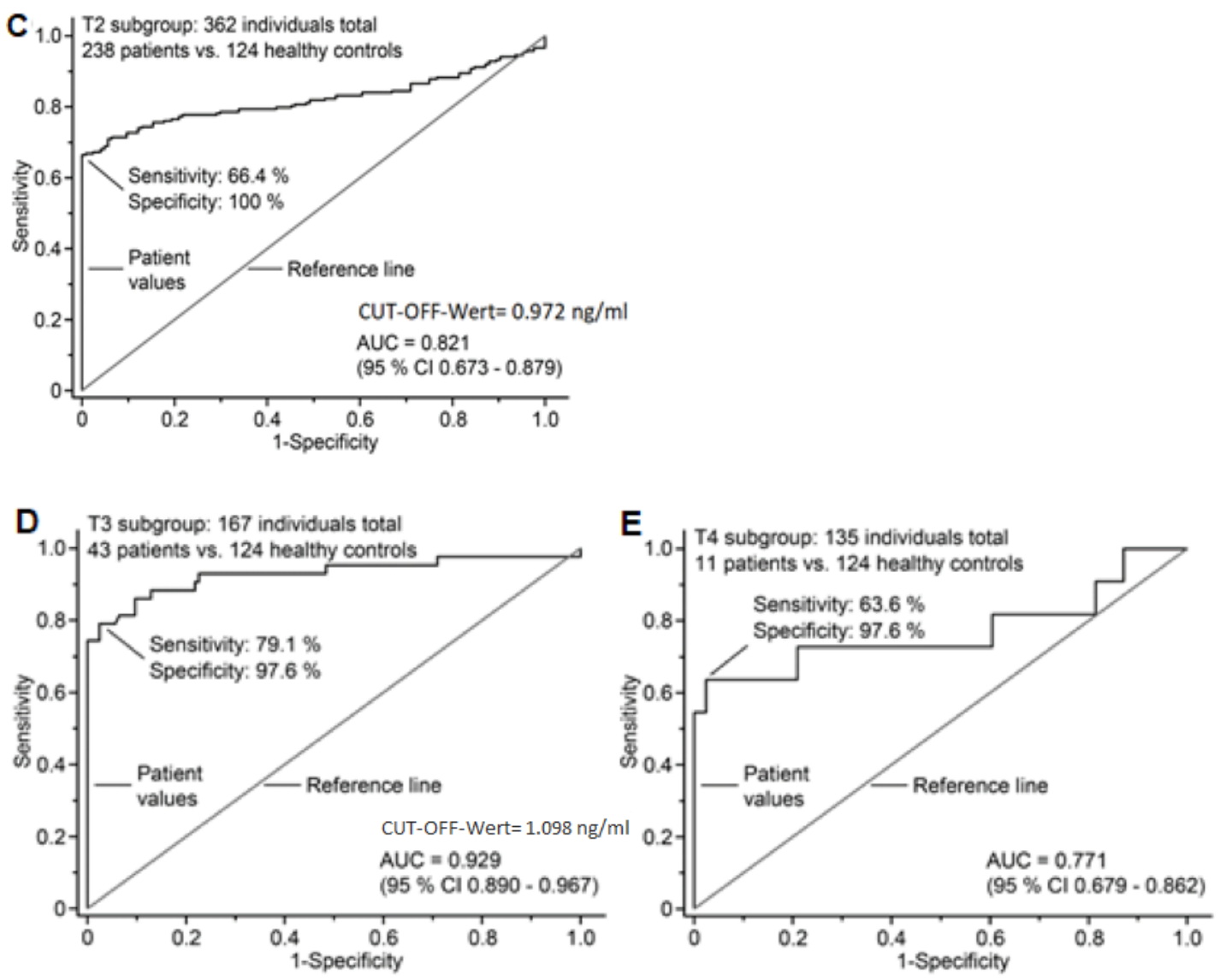

\begin{abstract}
Abbildung 22: ROC-Kurve zur diagnostischen Wertigkeit der CYR61-Konzentration im Blut von Mammakarzinompatientinnen (Tumorstadien T2-T4). Analysiert wurden Patientinnen mit Tumorstadium T2 bis T4 (C-E). Blutplasma von Mammakarzinompatientinnen wurde mit Blutplasma von weiblichen gesunden Kontrollpersonen (Alter 50+) verglichen. Der Cut-off-Wert in der Kohorte T2 (C) betrug 0,972 ng/mL. Der Cut-off-Wert in der Kohorte T3 (D) betrug 1,098 ng/mL. Für die Kohorte T4 ( $\mathrm{n}=11$ ) wurde aufgrund der geringen Größe kein Cut-off-Wert ermittelt. Auf der Abszisse ist die Spezifität und auf der Ordinate die Sensitivität angegeben. AUC: Fläche unter der Kurve; CI: Konfidenzintervall.
\end{abstract}


Bei den 238 Patientinnen mit invasivem Mammakarzinom im Stadium T2 (Abb. 22 C) betrug die Sensitivität 66,4 \% bei einer Spezifität von ebenfalls 100 \%. Die Fläche unter der Kurve betrug 0,821 mit einem 95-\%-Konfidenzintervall von 0,673 bis 0,879. Der Cut-off-Wert in der Kohorte T2 betrug $0,972 \mathrm{ng} / \mathrm{mL}$.

Bei 43 Patientinnen mit dem Tumorstadium T3 (Abb. 22 D) wies der Test eine Sensitivität von 79,1 \% und eine Spezifität von 97,6 \% auf, mit einer Fläche unter der Kurve von 0,929. Der Cut-off-Wert in dieser Kohorte betrug 1.098 ng/mL. Bei den elf Patientinnen mit einem Tumorstadium von T4 (Abb. 22 E) zeigte der Test ELICYR eine Sensitivität von 63,6 \% bei einer Spezifität von 97,6\%. Das Areal unter der Kurve betrug hier 0,771. Zur Bestimmung der ROCKurve wurden auch hier nach wie vor die 124 gesunden Kontrollen genutzt.

Zusammenfassend lässt sich also sagen, dass die Subgruppen der Tumorstadien T3 bis T4 eine Sensitivität zwischen 63,6 \% (T4) bis 79,1 \% (T3), bei einer Spezifität von 97,6 \%, aufwiesen. Hier ist aber zu betonen, dass die geringen Anzahlen der krebskranken Individuen in den Tumorstadien T3 bis T4 im Kollektiv von 43 auf elf Patientinnen sanken, weshalb in der Gruppe mit Tumorstadium T4 kein Cut-off-Wert ermittelt wurde.

Frühe Tumorstadien wie T1 und T2 stachen also mit besonders hohen Sensitivitäten von 66,4 $\%$ (T2) bis 71, $5 \%$ (T1), bei einer Spezifität von $100 \%$, heraus.

\subsection{Analyse der Assoziation des CYR61-Spiegels im Blutplasma von Mammakarzinompatientinnen mit klinisch-pathologischen Eigenschaften}

In diesem Kapitel sollten Korrelationen der CYR61-Kozentrationen mit Erkrankungsparametern, die für das Mammakarzinom relevant sind, ermittelt werden (1. Spalte). Dazu gehören der Tumorstatus (Primär oder Rezidiv), das Tumorstadium (T1 bis T4), das Grading (G1-G3), der histologische Typ, der Lymphknotenstatus, die Invasion des Lymp systems, ie Invasion der Blutgefäße, der Hormonrezeptorstatus (Östrogenrezeptor, Progesteronrezeptor 
und HER2-Status) und die Art der Therapie (neoadjuvante Therapie, adjuvante Therapie, Bestrahlung, und weitere).

Tabelle 10: Assoziation des CYR61-Spiegels im Blutplasma von Mammakarzinompatientinnen mit klinisch-pathologischen Eigenschaften

\begin{tabular}{|c|c|c|c|c|c|c|c|c|c|c|c|}
\hline \multirow{2}{*}{$\begin{array}{l}\text { Brustkrebs } \\
\text { Gesamt }\end{array}$} & \multirow{2}{*}{$\begin{array}{c}n \\
786\end{array}$} & \multirow{2}{*}{$\begin{array}{c}\begin{array}{c}\mathrm{c}(\mathrm{Cy} / 61) \\
{[\mathrm{ng} / \mathrm{m} /]^{2}}\end{array} \\
25.6 \pm 41.3\end{array}$} & \multicolumn{2}{|c|}{$\begin{array}{l}\mathrm{c}(\text { Cyr61) } \\
<1 \mathrm{ng} / \mathrm{ml}\end{array}$} & \multicolumn{2}{|c|}{$\begin{array}{c}c(\text { Cyr61) } \\
1<10 \mathrm{ng} / \mathrm{ml}\end{array}$} & \multicolumn{2}{|c|}{$\begin{array}{c}\mathrm{c}(\mathrm{Cy} r 61) \\
10<100 \\
\mathrm{ng} / \mathrm{ml}\end{array}$} & \multicolumn{2}{|c|}{$\begin{array}{c}c(\text { Cyr61) } \\
<100 \mathrm{ng} / \mathrm{ml}\end{array}$} & \multirow{2}{*}{ p-value } \\
\hline & & & $\begin{array}{c}n \\
228\end{array}$ & $\stackrel{\%}{29.0}$ & $\begin{array}{c}n \\
237\end{array}$ & $\begin{array}{r}\% \\
30.2\end{array}$ & $\underset{237}{n}$ & 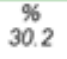 & $\begin{array}{l}n \\
74\end{array}$ & $\%$ & \\
\hline Diagnose & & & & & & & & & & & 0.253 \\
\hline $\begin{array}{l}\text { Karzinom } \\
\text { DCIS }\end{array}$ & $\begin{array}{c}708 \\
74\end{array}$ & $\begin{array}{l}25.1 \pm 40.9 \\
31.8 \pm 45.8\end{array}$ & $\begin{array}{l}226 \\
19\end{array}$ & $\begin{array}{l}31.9 \\
25.7\end{array}$ & $\begin{array}{l}204 \\
23\end{array}$ & $\begin{array}{l}28.8 \\
31.1\end{array}$ & $\begin{array}{c}211 \\
25\end{array}$ & $\begin{array}{l}29.8 \\
33.8\end{array}$ & $\begin{array}{c}67 \\
7\end{array}$ & $\begin{array}{l}9.5 \\
9.5\end{array}$ & \\
\hline $\begin{array}{l}\text { Detektion } \\
\text { Primärtumor } \\
\text { Rezidiv }\end{array}$ & $\begin{array}{c}680 \\
80\end{array}$ & $\begin{array}{l}26.5 \pm 42.1 \\
15.6 \pm 30.5\end{array}$ & $\begin{array}{r}212 \\
30\end{array}$ & $\begin{array}{l}31.2 \\
37.5\end{array}$ & $\begin{array}{r}193 \\
26\end{array}$ & $\begin{array}{l}28.4 \\
32.5\end{array}$ & $\begin{array}{l}208 \\
21\end{array}$ & $\begin{array}{l}30.6 \\
26.3\end{array}$ & $\begin{array}{c}67 \\
3\end{array}$ & $\begin{array}{l}9.9 \\
3.8\end{array}$ & 0.150 \\
\hline $\begin{array}{l}\text { Tumorstadium } \\
\mathrm{CT}_{1} \\
\mathrm{CT}_{2} \\
\mathrm{CT}_{3} \\
\mathrm{cT}_{4}\end{array}$ & $\begin{array}{c}387 \\
238 \\
43 \\
11\end{array}$ & $\begin{array}{l}29.0 \pm 44.3 \\
20.6 \pm 36.5 \\
22.8 \pm 36.2 \\
30.2 \pm 36.9\end{array}$ & $\begin{array}{r}115 \\
83 \\
13 \\
5\end{array}$ & $\begin{array}{l}29.7 \\
34.9 \\
30.2 \\
45.5\end{array}$ & $\begin{array}{r}106 \\
74 \\
11 \\
1\end{array}$ & $\begin{array}{r}27.4 \\
31.1 \\
25.6 \\
9.1\end{array}$ & $\begin{array}{c}121 \\
16 \\
4 \\
1\end{array}$ & $\begin{array}{l}31.3 \\
6.7 \\
9.3 \\
9.1\end{array}$ & $\begin{array}{c}45 \\
67 \\
10 \\
1\end{array}$ & $\begin{array}{c}11.6 \\
28.2 \\
23.3 \\
9.1\end{array}$ & 0.737 \\
\hline $\begin{array}{l}\text { Grading } \\
\text { G1 } \\
\text { G2 } \\
\text { G3 }\end{array}$ & $\begin{array}{l}114 \\
339 \\
287\end{array}$ & $\begin{array}{l}29.5 \pm 43.3 \\
26.4 \pm 42.6 \\
23.4 \pm 39.5\end{array}$ & $\begin{array}{l}30.7 \\
29.8 \\
33.8\end{array}$ & $\begin{array}{r}30 \\
100 \\
87\end{array}$ & $\begin{array}{l}26.3 \\
29.5 \\
30.3\end{array}$ & $\begin{array}{l}32.5 \\
30.4 \\
27.5\end{array}$ & $\begin{array}{c}37 \\
103 \\
79\end{array}$ & $\begin{array}{l}32.5 \\
30.4 \\
27.5\end{array}$ & $\begin{array}{l}12 \\
35 \\
24\end{array}$ & $\begin{array}{l}10.5 \\
10.3 \\
8.4\end{array}$ & 0.678 \\
\hline $\begin{array}{l}\text { Histologie } \\
\text { duktal } \\
\text { papillär } \\
\text { lobulär } \\
\text { nicht spezifisch } \\
\text { sonstige } \\
\text { Lymphknotenstatus }\end{array}$ & $\begin{array}{c}177 \\
90 \\
8 \\
298 \\
42\end{array}$ & $\begin{array}{l}29.4 \pm 41.0 \\
24.2 \pm 38.6 \\
11.9 \pm 18.2 \\
23.9 \pm 42.1 \\
19.3 \pm 37.9\end{array}$ & $\begin{array}{l}14.7 \\
31.1 \\
12.5 \\
36.6 \\
40.5\end{array}$ & $\begin{array}{r}64 \\
25 \\
5 \\
88 \\
10\end{array}$ & $\begin{array}{l}36.2 \\
27.8 \\
62.5 \\
29.5 \\
23.8\end{array}$ & $\begin{array}{r}71 \\
28 \\
2 \\
73 \\
12\end{array}$ & $\begin{array}{l}71 \\
28 \\
2 \\
73 \\
12\end{array}$ & $\begin{array}{l}40.1 \\
31.1 \\
25.0 \\
24.5 \\
28.6\end{array}$ & $\begin{array}{c}16 \\
9 \\
0 \\
28 \\
3\end{array}$ & $\begin{array}{l}9.0 \\
10.0 \\
0.0 \\
9.4 \\
7.1\end{array}$ & 0.131 \\
\hline $\begin{array}{l}\text { positiv } \\
\text { negativ }\end{array}$ & $\begin{array}{l}222 \\
481\end{array}$ & $\begin{array}{l}22.6 \pm 38.1 \\
27.2 \pm 42.5\end{array}$ & $\begin{array}{l}35.1 \\
28.5\end{array}$ & $\begin{array}{r}66 \\
141\end{array}$ & $\begin{array}{l}29.7 \\
29.3\end{array}$ & $\begin{array}{r}62 \\
151\end{array}$ & $\begin{array}{c}62 \\
151\end{array}$ & $\begin{array}{l}27.9 \\
31.4\end{array}$ & $\begin{array}{l}16 \\
52\end{array}$ & $\begin{array}{l}7.2 \\
10.8\end{array}$ & טיניט \\
\hline $\begin{array}{l}\text { Lymphinvasion } \\
\text { positiv } \\
\text { negativ }\end{array}$ & $\begin{array}{l}148 \\
478\end{array}$ & $\begin{array}{l}22.7 \pm 39.0 \\
26.9 \pm 42.3\end{array}$ & $\begin{array}{l}28.9 \\
41.2\end{array}$ & $\begin{array}{r}144 \\
37\end{array}$ & $\begin{array}{l}30.1 \\
25.0\end{array}$ & $\begin{array}{r}148 \\
37\end{array}$ & $\begin{array}{c}37 \\
148\end{array}$ & $\begin{array}{l}25.0 \\
31.0\end{array}$ & $\begin{array}{l}14 \\
48\end{array}$ & $\begin{array}{c}9.5 \\
10.0\end{array}$ & \\
\hline $\begin{array}{l}\text { Gefäßinvasion } \\
\text { positiv } \\
\text { negativ }\end{array}$ & $\begin{array}{c}10 \\
612\end{array}$ & $\begin{array}{l}31.0 \pm 41.6 \\
259 \pm 41.7\end{array}$ & $\begin{array}{l}30.0 \\
31.9\end{array}$ & $\begin{array}{r}3 \\
175\end{array}$ & $\begin{array}{l}30.0 \\
28.6\end{array}$ & $\begin{array}{r}3 \\
181\end{array}$ & $\begin{array}{c}3 \\
181\end{array}$ & $\begin{array}{l}30.0 \\
29.6\end{array}$ & $\begin{array}{c}1 \\
61\end{array}$ & $\begin{array}{l}10.0 \\
10.0\end{array}$ & \\
\hline $\begin{array}{l}\text { Hormonrezeptorstatus } \\
\text { ER/PR positiv } \\
\text { EnbB2 positiv } \\
\text { Triple negativ }\end{array}$ & $\begin{array}{c}526 \\
85 \\
106\end{array}$ & $\begin{array}{l}26.0 \pm 41.6 \\
24.8 \pm 41.3 \\
24.4 \pm 40.9\end{array}$ & $\begin{array}{l}30.6 \\
35.3 \\
33.0\end{array}$ & $\begin{array}{r}158 \\
20 \\
30\end{array}$ & $\begin{array}{l}30.0 \\
23.5 \\
28.3\end{array}$ & $\begin{array}{r}155 \\
29 \\
31\end{array}$ & $\begin{array}{l}155 \\
29 \\
31\end{array}$ & $\begin{array}{l}29.5 \\
34.1 \\
29.2\end{array}$ & $\begin{array}{c}52 \\
6 \\
10\end{array}$ & $\begin{array}{l}9.9 \\
7.1 \\
9.4\end{array}$ & 0.556 \\
\hline $\begin{array}{l}\text { Therapie } \\
\text { neoadjuvant } \\
\text { adjuvant } \\
\text { Radiatio } \\
\text { sonstige }\end{array}$ & $\begin{array}{c}39 \\
499 \\
55 \\
43\end{array}$ & $\begin{array}{l}28.2 \pm 43.9 \\
24.5 \pm 40.3 \\
39.9 \pm 51.4 \\
19.4 \pm 40.0\end{array}$ & $\begin{array}{l}38.5 \\
32.5 \\
27.3 \\
44.2\end{array}$ & $\begin{array}{r}12 \\
139 \\
12 \\
12 \\
\end{array}$ & $\begin{array}{l}30.8 \\
27.9 \\
21.8 \\
27.9\end{array}$ & $\begin{array}{r}6 \\
156 \\
20 \\
8\end{array}$ & $\begin{array}{c}6 \\
156 \\
20 \\
8\end{array}$ & $\begin{array}{l}15.4 \\
31.3 \\
36.4 \\
18.6 \\
\end{array}$ & $\begin{array}{c}7 \\
42 \\
8 \\
4\end{array}$ & $\begin{array}{c}17.9 \\
8.4 \\
14.5 \\
9.3 \\
\end{array}$ & \\
\hline
\end{tabular}

In der ersten Zeile dieser Tabelle sind verschiedene CYR61-Konzentrationen angegeben, beginnend mit einer durchschnittlichen CYR61-Konzentration in $\mathrm{ng} / \mathrm{mL}$ für alle Patientinnenproben ohne Kategorisierung oder für alle Patientinnenproben innerhalb eines Erkrankungsparameters, gefolgt von Werten kleiner als $1 \mathrm{ng} / \mathrm{mL}$ bis hin zu ansteigenden Konzentrationen von mehr als $100 \mathrm{ng} / \mathrm{mL}$. Innerhalb dieser Spalten wird für die jeweilige klinisch-pathologische Kategorie zum einen die Anzahl (n) der Patientinnen, die diesen CYR61-Wert aufweisen angegeben und zum anderen, welchen Anteil am Gesamten in Prozent diese Anzahl ausmacht. In der letzten Spalte wird der p-Wert (p-Value) zu jeder klinisch pathologischen Kategorie angegeben. Bei der Analyse der klinisch-pathologischen Patientinnendaten und möglicher negativer oder positiver Korrelationen zu der CYR61-Konzentration [in ng], konnten keine signifikanten Zusammenhänge nachgewiesen werden. Der p-Wert befand sich daher im Rahmen von 0,131 (His- 
tologischer Typ) und 0,737 (Tumorstadium) bei einem Signifikanzniveau von 0,05. Dies bedeutet, dass der Test alle Subtypen des Krebses bezogen auf die Hormonrezeptoreigenschaften (ER/PgR +, HER2 neg., Triple neg.) gleich gut erkennen konnte, da er hier die gleiche Positivität aufwies. Zudem ergab die Testung keinen Unterschied zwischen den Altersgruppen, sodass er bei jungen prämenopausalen Patientinnen und älteren postmenopausalen Patientinnen anzuwenden ist.

\subsection{Erstellung und Analyse eines Früherkennungskollektivs}

Nachdem dieser Überblick über die gesamte Patientinnenkohorte gewonnen wurde, spezifizierte ich diese auf ein sogenanntes Früherkennungskollektiv. In dieses Kollektiv wurden nur Patientinnen eingeteilt, die primäre Tumore aufwiesen und zuvor in ihrer Anamnese keine Mammakarzinomerkrankung erlitten haben und die noch keinerlei Therapie erfahren haben und somit einen präoperativen Status aufwiesen. In diesem Kollektiv befinden sich insgesamt 443 Patientinnen. Zudem wurden die Plasmaproben gesunder Frauen über 50 Jahren auf 324 gesunde Kontrollen ergänzt. Auch hier wurde zunächst eine ROC-Kurve für das gesamte Früherkennungskollektiv und die erweiterte Anzahl an gesunden Kontrollen erstellt.

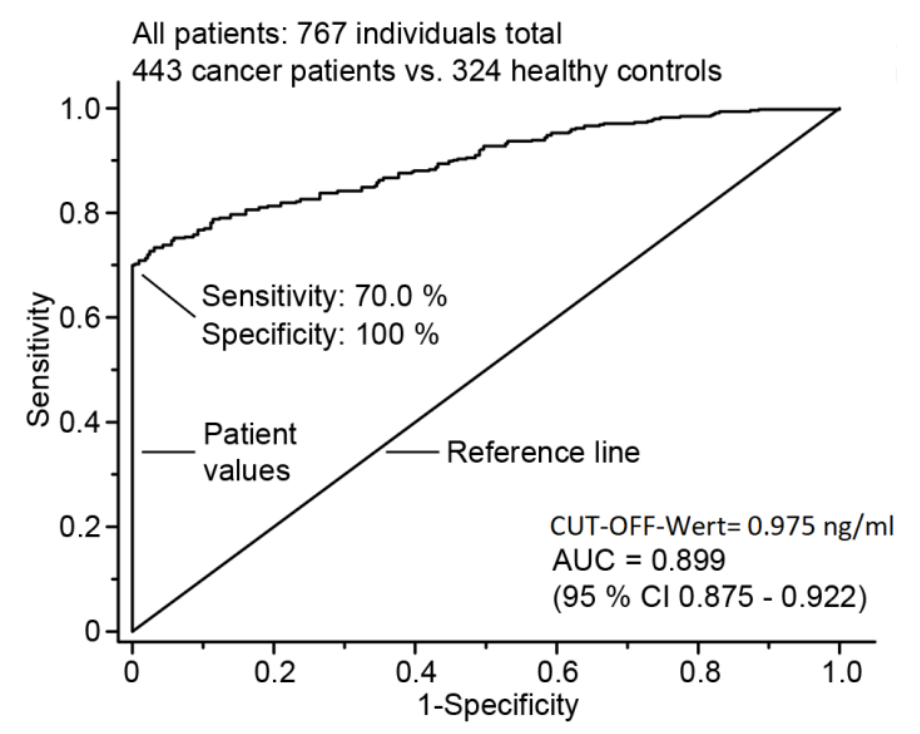

Abbildung 23: ROC-Kurve für alle analysierten Mammakarzinomfälle des Früherkennungskollektivs ( $n=443)$ im Vergleich zu gesunden Frauen als Kontrollgruppe $(n=324)$. Der Cut-off-Wert betrug $0,975 \mathrm{ng} / \mathrm{mL}$. Auf der Abszisse ist die Spezifität und auf der Ordinate die Sensitivität angegeben. AUC: Bereich unter Kurve; CI: Konfidenzintervall.

In der Abbildung 23 ist eine ROC-Kurve abgebildet, die Aussagen über Spezifität und Sensitivität macht, bezogen auf die Messwerte für die Detektion von Mammakarzinom, die mit unserem Test ELICYR von dem gesamten Früherkennungskollektivs gemessen wurden. Für die 
Gesamtgruppe von 443 Mammakarzinompatientinnen wurde eine Sensitivität von 70,0 \% bei einer Spezifität von $100 \%$ ermittelt. Es ergab sich daraus ein Cut-off Wert von $0.975 \mathrm{ng} / \mathrm{mL}$ und einer Fläche unter der Kurve von 0,899 mit einem 95-\%-Konfidenzintervall von 0,875 bis 0,922 .

Anschließend wurde die Sensitivität und Spezifität von CYR61 zum Nachweis von Brustkrebs in den Subgruppen DCIS (47 Patientinnen) und T1(243 Patientinnen) bis T2 (124 Patientinnen) des „Early Detection“-Kollektivs bestimmt, wobei ebenso die ROC-Kurvenanalyse für diese Subgruppen der Patientinnen verwendet wurde (Abbildung 24 und 25).
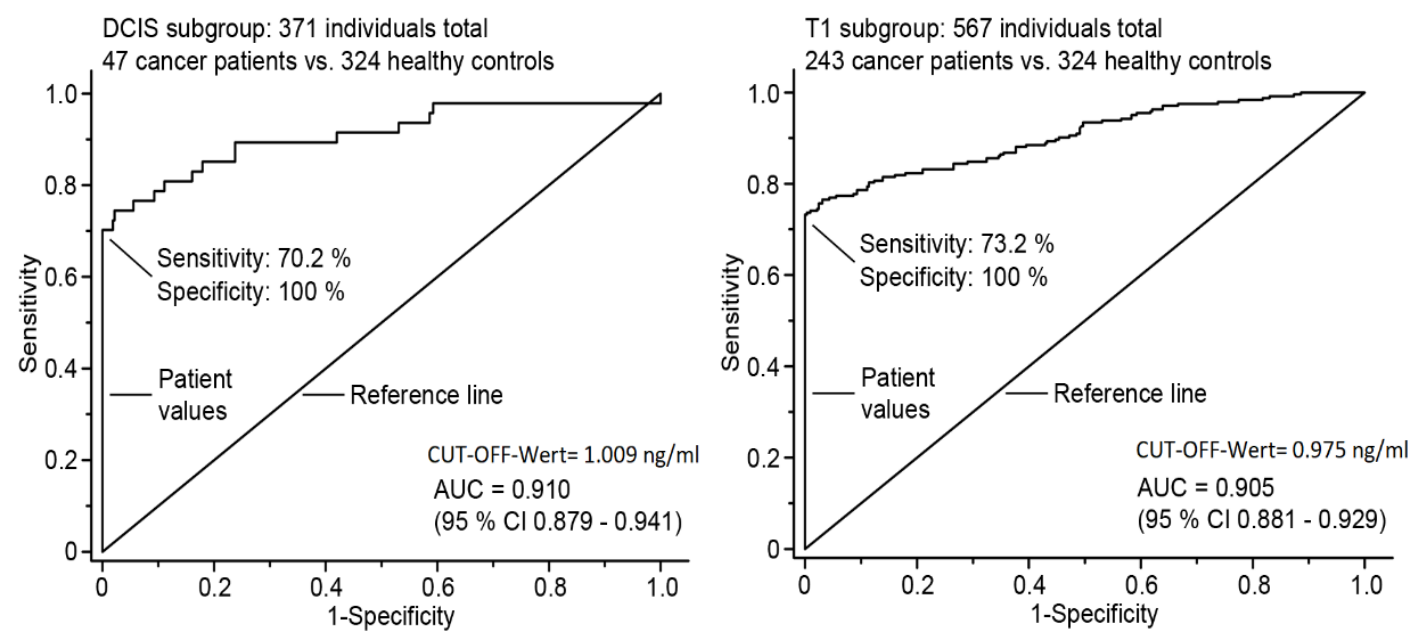

Abbildung 24: ROC-Kurve zur diagnostischen Wertigkeit der CYR61-Konzentration im Blut vom Mammakarzinompatientinnen (DCIS und Tumorstadium T1) des Früherkennungskollektivs. Analysiert wurde das Blut von Patientinnen mit DCIS und Tumorstadium T1. Blutplasma von Mammakarzinompatientinnen wurde mit Blutplasma von weiblichen gesunden Kontrollpersonen (Alter $50+$ ) verglichen. Der Cut-off-Wert betrug beim DCIS 1,009 ng/mL und beim Tumorstadium T1 0,975 $\mathrm{ng} / \mathrm{mL}$. Auf der Abszisse ist die Spezifität und auf der Ordinate die Sensitivität angegeben.AUC: Fläche unter der Kurve; CI: Konfidenzintervall.

In Abbildung 24 ist eine ROC-Kurve zur Bestimmung von Sensitivität (Ordinate) und Spezifität (Abszisse) des Bluttests ELICYR, in Bezug auf die Detektion von Mammakarzinom in den Stadien DCIS und Tumorstadium T1, dargestellt. Bei den 47 Patientinnen mit DCIS wurden eine Sensitivität von 70,2 \% und eine Spezifität von 100 \% erreicht. Das Areal unter der Kurve betrug hier 0,910 mit einem 95-\%-Konfidenzintervall von 0,879 bis 0,941. Der Cut-off-Wert betrug hier 1,009 ng/mL. Bei den 243 Patientinnen mit invasivem Mammakarzinom im Frühstadium T1 betrug die Sensitivität 73,2 \% bei einer Spezifität von ebenfalls $100 \%$. Das Areal 
unter der Kurve wies einen Wert von 0,905 mit einen 95\%-Konfidenzintervall von 0,881 bis 0,929 auf. Der Cut-off-Wert betrug im Kollektiv der T1-Erkrankungen 0,975 ng/mL.

Anschließend wurden die Sensitivität und Spezifität von CYR61 zum Nachweis von Mammakarzinom im Tumorstadium T2 bestimmt, wobei ebenso die ROC-Kurvenanalyse für diese Subgruppen der Patientinnen verwendet wurde (Abbildung 25).

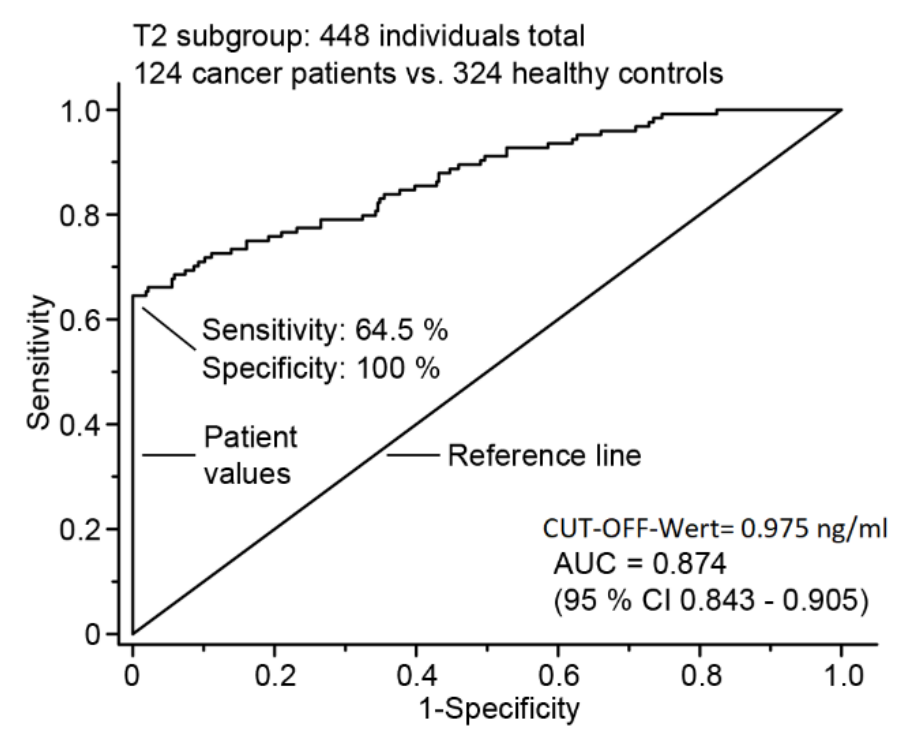

Abbildung 25: ROC-Kurve zur diagnostischen Wertigkeit der CYR61-Konzentration im Blut vom Mammakarzinompatientinnen (Tumorstadium T2) des Früherkennungskollektivs. Analysiert wurde das Blut von Patientinnen mit Tumorstadium T2. Blutplasma von Mammakarzinompatientinnen wurde mit Blutplasma von weiblichen gesunden Kontrollpersonen (Alter 50+) verglichen. Der Cut-off-Wert betrug beim Tumorstadium T2 0,975 ng/mL. Auf der Abszisse ist die Spezifität und auf der Ordinate die Sensitivität angegeben. AUC: Fläche unter der Kurve; CI: Konfidenzintervall.

In Abbildung 25 ist eine ROC-Kurve zur Bestimmung von Sensitivität (Ordinate) und Spezifität (Abszisse) des Bluttests ELICYR, in Bezug auf die Detektion von Mammakarzinom in dem Tumorstadium T2, dargestellt. Bei den insgesamt 124 Patientinnen in diesem Tumorstadium wurden eine Sensitivität von 64,5 \% und eine Spezifität von $100 \%$ erreicht. Das Areal unter der Kurve betrug hier 0,874 mit einem 95-\%-Konfidenzintervall von 0,843 bis 0,905. Der Cut-offWert betrug hier ebenso wie bei den Patintinnen mit Tumorstadium T1 und wie im Gesamtkollektiv $0,975 \mathrm{ng} / \mathrm{mL}$.

Es liegen nun alle Resultate meiner Arbeit vor, sodass ich diesen Teil mit einer Zusammenfassung der Haupterkenntnisse meiner Experimente abschließen möchte:

Ich konnte zeigen, dass CYR61 häufig in Mammakarzinomzelllinien vorkam und dort mit aggressiveren Zelllinien assoziiert war, die einen EMT-Phänotyp aufwiesen. 
Zudem zeigte sich, dass CYR61 bevorzugt durch Mammakarzinomzellen sekretiert wurde und das besonders homogen in Zelllinien mit EMT-Phänotyp.

Darüber hinaus ließ sich das Protein durch Induktion von Hypoxie und durch Gabe von Wachstumsfaktor, wie EGF induzieren, wobei bei Stimulation mit EGF schon eine frühe Sekretion ab 15 Minuten stattfand.

Weitere Erkenntnisse aus dem experimentellen und klinischen Teil sind zum einen, dass homogen niedrige CYR61-Konzentrationen im Blutplasma von Gesunden vorkommen und zum anderen, dass deutlich erhöhte CYR61-Konzentration in ca. 70 \% der analysierten Mammakarzinompatientinnen, schon in sehr frühen Stadien (DCIS, T1-T2 Karzinome) nachzuweisen sind.

Die angefertigten ROC-Kurvenanalysen zeigen das Potenzial von CYR61-Plasmamessungen mittels des Tests ELICYR für die Früherkennung von Mammakarzinom durch eine Sensitivität von ca. 70 \% Sensitivität bei einer Spezifität von $100 \%$, inbesondere bei der frühen Erkennung von Mammakarzinomen und einer Patientinnenkohorte, die bisher keine Therapie erfahren hat. 


\section{Diskussion}

\subsection{Zelltypabhängige Differenzen in der Expression von CYR61}

Die Arbeit begann damit, dass mithilfe von Westernblotanalysen vor allem Mammakarzinomzelllinien untersucht wurden. In diesen Experimenten sollten zelltypabhängige Differenzen in der Expression von CYR61 untersucht werden. Zudem wurden mesenchymale und epitheliale Marker detektiert, um eine Beziehung zu EMT-Phänotypen herzustellen. Ich konnte zeigen, dass zelltypabhängige Unterschiede in der Expression von CYR61 bestehen. Insbesondere stellte sich heraus, dass die verwendeten Mammakarzinomzelllinien, die überwiegend CYR61positiv waren, einen epithelial-mesenchymal gemischten Phänotyp oder einen rein mesenchymalen Phänotyp aufwiesen. Dies war daran zu erkennen, dass die Zelllinien MDA-MB-231, MDA-MB-231-BO2, MDA-MB-321-Br, LC-M1 und BC-M1, die CYR61-positiv waren, die Panzytokeratine als epithelialen Marker und ebenso das Vimentin als mesenchymalen Marker exprimierten. Der mesenchymale Phänotyp und der epithelial-mesenchymal gemischte (intermediäre) Phänotyp ist mit einer aggressiveren Form des Krebses assoziiert (Nieto et al. 2016). Man vermutet, dass sich gerade die Zellen mit diesen Phänotypen einer EMT unterziehen, was die Ablösung von Tumorzellen von einem Primarius und die Migration und Bildung von Metastasen ermöglicht (Bednarz-Knoll et al. 2012; Keller and Pantel 2019). Die EMT-assoziierten Mammakarzinomarten tragen einen großen Teil zu der Heterogenität des Mammakarzinomes bei. Vor allem der mesenchymale Phänotyp ist mit einer aggressiveren Form verbunden, was bedeutet, dass diese Zellen sich früh aus der soliden Masse des Tumors lösen und über die Blutgefäße in andere Organe oder das Knochenmark intra- und etxravasieren (Hanahan und Weinberg 2011; Nieto et al. 2016; Bardelli und Pantel 2017). Hier kann es dann, gut versteckt vor Therapiemaßnahmen, zunächst zu einem Tumorschlaf kommen (Kang und Pantel 2013), aus dem sie erwachen und Metastasen bilden können, die sich phänotypisch von dem Muttertumor unterscheiden. Bereits angewandte Chemotherapien können gegen diese Zellpopulation nicht wirken, sodass ein aggressiveres Rezidiv entstehen kann (Meng et al. 2004). Ich schlussfolgere daher, dass CYR61 mit Mammakarzinomzelllinien, die einen aggressiven EMT-Phänotyp aufweisen, assoziiert ist (Nieto et al. 2016).

In diesem Zusammenhang ist es zudem interessant, dass die CYR61-negativen Zelllinien wie MCF-7 und GI-101 einen rein epithelialen Phänotyp aufwiesen, so wie in den Northern-Analysen von Xie et al. (2011) beschrieben. Auch bei Xie et al. ergaben die Studien, dass CYR61 in 
den invasiven und EMT assoziierten Mammakarzinomzelllinien wie MDA-MB-231 stark exprimiert wurde und in Zelllinien mit weniger tumorerzeugender Wirkung, wie MCF-7- und BT20-Mammakarzinomzellen, in nur sehr geringen Mengen gefunden wurde.

Der Zusammenhang von EMT-Phänotypen in Krebszellen und einem hohen Expressionslevel an CYR61 bestätigten Haque et al. (2011) am Beispiel von aggressiven Pankreaskarzinomen. Die Autoren zeigten zum einen, dass die Stummschaltung von CYR61 / CCN1 in Panc-1-SPZellen, die EMT-Stammzellenmerkmale und die Tumorigenität aufhebt. Zum anderen, dass in den aggressiven Zelllinien, die EMT-Marker exprimieren, exorbitant erhöhte CYR61 / CCN1Expressionslevel vorlagen. Eine weitere Studie von Nguyen et al. (2016) besagt, dass die Expression von CYR61-mRNA positiv mit fortgeschrittenen Stadien bei Mammakarzinompatientinnen, wie z. B. der Tumorgröße und der Lymphknotenmetastasierung korreliert. Daher könnte die Suche nach Wirkstoffen, die die CYR61-Signalgebung abschwächen, ein möglicher zukünftiger Ansatz für die Krebsbehandlung sein. Eine Inhibierung des CYR61 nachgeschalteten Signalwegs Akt / GSK3 $\beta$ in MDA-MB-231-Zellen mittels Baicalein senkte die Expression von CYR61 sowie die EMT-assoziierte Migration und Invasion von humanen MDA-MB-231Mammakarzinomzellen signifikant. Der genaue Effekt auf die Signalkaskaden konnte in dieser Studie allerdings nicht genau festgestellt werden. Jedoch war ein Endeffekt in Form von Tumorreduzierung und von einer abgeschwächten EMT-assoziierter Migration unter CYR61-Inhibierung deutlich zu erkennen.

Meiner Meinung nach ist eine hohe Assoziation von CYR61-Expression mit aggressiven mesenchymalen Tumorzellen der Pankreas daher auch bei weiteren Tumorarten wie den Mammakarzinomen, die oft EMT-assoziierte Phänotypen aufweisen, denkbar. Gerade hier ist es wichtig, nicht bis auf die Entstehung eines soliden Tumors und seine Entdeckung mittels Mammographie zu warten, was den heutigen Goldstandard der Mammakarzinomvorsorge darstellt. Es sollte möglich sein, erste kleinste Tumorbestandteile und Biomarkerproteine zu detektieren, um darauf hingewiesen zu werden, dass ein Tumorgeschehen im Körper aktiv ist.

Um das Potenzial dieses Proteins zu untersuchen, wurde zunächst analysiert, wie das Protein bevorzugt vorliegt und von welchen Mengenverhältnissen ausgegangen werden muss.

Hier konnte gezeigt werden, dass CYR61 vorwiegend extrazellulär vorlag, was Brigstock (2002) in seiner Studie ebenso bestätigen konnte. Betrachtet man die Mammakarzinomzelllinie MDAMB-231 bestätigt sich die Aussage Brigstocks, denn nach meinen Berechnungen lagen hier 8,5 Mrd. Moleküle pro Zelle extrazellulär vor und im Vergleich dazu lagen 3,7 Mrd. Moleküle CYR61 pro Zelle im Zytoplasma vor. Somit war mehr als die doppelte Molekülanzahl pro Zelle extrazellulär vorhanden. Dieser Effekt oder ein noch größerer Faktor, war bei allen CYR61- 
positiven Mammakarzinomzelllinien, außer MDA-MB-231-BO2, die verwendet wurden, zu beobachten. Dies entspricht der biologischen Funktion des Proteins, da viele Interaktionen des Proteins über extrazellulär gelegene Integrinrezeptoren und HSPG-Domänen laufen. Das Protein hat hier die Möglichkeit die Rezeptoren zu binden und Wachstumsfaktoren und Angiogenese in Gang zu setzen (Schober et al. 2002, Bai et al. 2010). Darüber hinaus kann es sich autokrin stimulieren oder über Aktivierung von Wachstumsfaktoren seine eigene Stimulation initiieren. Zudem wird es sehr schnell transkribiert und translatiert, vor allem unter Stressbedingungen wie Hypoxie (Schober et al. 2002, Bai et al. 2010). Das CYR61-Protein ist sowohl mit Stressfaktoren wie Hypoxie assoziiert als auch mit wachstumstimulierende Faktoren, welche Mechanismen widerspiegeln, die im Tumorwachstum und Tumorüberleben eine große Rolle spielen. Zudem konnten Xie et al. (2001) zeigen, dass in gesunden Zelllinien von Brustgewebe und Hautgewebe kein CYR61 nachweisbar ist. Dies ist ein wichtiger Hinweis für das Potenzial der Spezifität des Proteins als möglicher Tumormarker.

Zusammengefasst kann man nach dem jetzigen Stand des Wissens über einen Zusammenhang von der CYR61-Bildung und CYR61-Ausschüttung mit Tumorwachstum, mit Tumorfaktorenaktivierung und mit einer Beeinflussung des Tumormikroenvironments, sprechen. Aufgrunddessen wurde zunächst die Reaktion von CYR61 auf Stress bedingte Faktoren wie Hypoxie und EGF-Stimulation in Mammakarzinomzellen in dieser Arbeit untersucht.

\subsection{Expression von CYR61 in Mammakarzinomzellen unter hypoxischen Bedingungen und unter EGF-Stimulation}

Oft kann die Bildung von Blutgefäßen in einem Tumor nicht mit dem Tumorwachstum mithalten, wodurch die Expression einer Vielzahl von Stressantwortproteinen, wie z.B. das CYR61Protein, induziert wird. In meinen Experimenten wurde in den Mammakarzinomzelllinien, die unter hypoxischen Bedingungen (1 \% Sauerstoff) kultiviert wurden, CYR61 verspätet sekretiert. Diesen Effekt konnte man gut im Vergleich mit nicht stimulierten Zelllinien unter atmosphärischer Luft (21\% Sauerstoff) erkennen. Bei unter Hypoxie stehenden Zelllinien fand die Ausschüttung ab Stunde 16 statt und stieg acht Stunden später weiter an. Dieses Ergebnis war unerwartet, da die Arbeitsgruppe um Dr. Bartkowiak nachweisen konnte, dass schon zu einem früheren Zeitraum die intrazelluläre CYR61-Konzentration sank. Man vermutete daher eine direkte Korrelation mit der Ausschüttung des Proteins zum selben Zeitpunkt. Da diese aber erst nach acht Stunden anfing, muss das CYR61 noch in der Zelle zurückgehalten worden sein. Eine weitere Theorie wäre, dass CYR61 über einen Vesikel-Transport zur Membran gebracht wird und dort als glykosylierte Kette an der Membran haftet, ehe es ganz ausgeschüttet würde. 
Ebenso könnte man die Hypothese aufstellen, dass die Zellen unter Hypoxie auf einen Überlebensmodus schalten, indem sie alle Funktionen so weit wie möglich herunterregulieren, um die restliche Energie für die überlebenswichtigen Stoffwechselvorgänge zu nutzen. Im Laufe dieses Prozesses könnte es dann erst verspätet zu einer CYR61-Exprimierung und CYR61-Sekretion kommen. Dies wäre nun für die Bildung von Endothelzellen, also für das Überleben des Tumors durch Angiogenese, ausschlaggebend. Zudem könnten Wachstumsfaktoren aktiviert werden, die nun, nach veränderter Einstellung der Stoffwechselvorgänge unter Hypoxie, aktiv werden können und die Proliferation des Tumorgewebes sichern. Dies sind Hypothesen, die im weiteren Verlauf experimentell untersucht werden müssten.

Bekannt ist, dass es einen Zusammenhang zwischen der Ausschüttung des HIF1aplha-Hypoxiefaktors und der vermehrten Expression von CYR61 geben soll. Überexpression von proangiogenem CYR61, bei eutopischer Endometrie und ektopischen endometriotischen Läsionen von Frauen mit Endometriose, wurde sowohl durch Hypoxie als auch durch Prostaglandine stimuliert. Hier kam es zu einer vermehrten Bildung von CYR61-mRNA, was aus der vermehrten Bildung von CYR61-Proteinen resultierte (Hsiao 2015). Eine weitere Arbeit, basierend auf der Untersuchung des Verhaltens von CYR61 unter hypoxischen Bedingungen in humanen Trophoblasten, weist darauf hin, dass die Expression der intrazellulären und sekretierten CYR61-Proteine auf wahrscheinlich zwei verschiedenen Signalwegen reguliert wird (Wolf 2010). Die Regulation von intrazellulärem CYR61 bei hypoxischen Bedingungen scheint durch den Hypoxiefaktor HIF-alpha-1 $\alpha$ zu erfolgen, während die Sekretion durch eine Kombination von Hypoxiefaktor und Beteiligung von TGF-beta3 (transforming grwoth factor- beta 3) gesteuert werden soll (Wolf 2010). Die Tatsache, dass intrazelluläres Vorkommen und Sekretion von CYR61 auf verschiedenem Wege gesteuert würde, wäre eine Erklärung dafür, dass das intrazelluläre CYR61 unter Hypoxie früher ansteigt und sich somit anders verhält, als das sekretierte CYR61, dass erst nach 16 Stunden reagiert. Generell sorgt ein hypoxisches Signal für eine Induktion der Angiogenese, welche überlebenswichtig für den Tumor ist und die CYR61-Proteinlevel erhöht, was wiederum über Chemotaxis und Bindung an Integrinrezeptoren zur Ausbildung von Blutgefäßen führt (Babic et al. 1998). Dies gewährleistet das Tumorüberleben. Brigstock et al. (2002) berichteten über CYR61-Knockout-Mäuse, die während der Embryogenese und der Entwicklung des Fötus Gefäßfehler aufwiesen. Sowohl CTGF als auch CYR61 seien intrinsisch in In-vivo-Assays bezüglich angiogener Aktivität aktiv. Sie können aber auch die Produktion und/oder Aktivität anderer angiogener Moleküle (z. B. bFGF, VEGF) regulieren, die die Integrität oder Stabilität der Extrazellulärmatrix beeinflussen (z. B. Kollagen, MatrixMetalloproteasen (MMPs)). Zudem wurde in Zellinien, die keine CYR61-mRNA (MCF-7Mammazelllinie, MCF-12A gesunde Brustzellen) exprimieren, CYR61 injiziert, was zur Bildung 
von großen Tumoren führte, die stark vaskularisiert waren. Neben der Angiogenese spielen demnach Wachstumsfaktoren im Zusammenhang mit CYR61 eine ebenso große Rolle. Gerade in einem Tumor mit abnormal hoher Teilungsrate sind dies wichtige Faktoren.

Meine Hypothese besagt, dass CYR61 durch EGF-Stimulation induziert werden kann und vermehrt sekretiert wird. Dies könnte sich in einem sinkenden zytoplasmatischen CYR61-Signal in der Westernblotanalyse, beispielsweise durch eine Entleerung von vesikulärem CYR61 und einer parallel ansteigenden Sekretion, zeigen. In diesem Experiment veränderte sich jedoch, trotz sinkendem intrazellulären Expressionslevel des EGFR-Signals im Laufe der Zeit, die Konzentration von CYR61 im Zytoplasma kaum. Ganz anders verhielt sich die Sekretion, die mittels Sandwich-ELISA gemessen wurde. Diese begann bereits ab 15 Minuten und stieg über 24 Stunden kontinuierlich an. Die Hypothese, dass zytoplasmatisches CYR61 in Vesikeln vorliegt und jeder Zeit durch Wachstumsfaktoren aktivierbar ist, um in Richtung Zellmembran transportiert und dort freigesetzt zu werden, kann in diesem Zusammenhang nicht erfüllt werden. Sowohl bei MDA-MB-231 und MDA-MB-231-BO2 veränderten sich die intrazellulären CYR61-Proteinlevel nicht. Dennoch kam es ab 15 Minuten zu einer erhöhten Sekretion von CYR61, die kontinuierlich anstieg. Somit ist anzunehmen, dass das sekretierte CYR61 aus anderen Quellen bezogen wird, als aus der Leerung der zytoplasmatischen Speicher.

Eine Hypothese wäre, dass CYR61 ein Protein ist, dessen mRNA früh transkribiert wird (Brigstock 2002). Es zählt zu den sogenannten „immediate early genes“, welche Gene sind, die nach einem Reiz, wie der Stimulation mit Wachstumsfaktoren, sofort exprimiert werden. Sie können für alle Klassen von Proteinen codieren, so auch für sekretorische Proteine (Babic et al. 1998; Lexikon der Neurowissenschaft 2005).

Allerdings bleibt es fraglich, ob innerhalb von 15 Minuten eine komplette Proteinbiosynthese mit extrazellulärer Ausschüttung stattfinden kann. Es gäbe die Möglichkeit, dass bereits in der Zelle alle notwendigen Proteine, wie auch Transkriptionsfaktoren vorlagen, sodass die Proteinsynthese von CYR61 sofort beginnen konnte. So könnten anfänglich CYR61-Speicher ausgeschüttet worden sein, was die schnelle Sekretion von CYR61 im Überstand erklärt. Die Neuproduktion des Proteins funktionierte jedoch zeitlich fast genauso schnell, sodass diese das Fließgleichgewicht zwischen zytoplasmatischem CYR61, das sekretiert wird und zytoplasmatischem CYR61, das neu gebildet wird, konstant erhielt. So bliebe es innerhalb der Zelle bei einem gleichen Signal, trotz zytoplasmatischer Dynamik. Zudem könnte das Protein auch als glykosylierte Kette an der Zellmembran befestigt gewesen sein, um enzymatisch schnell aktiviert zu werden und so in der EZM aktiv autokrine Signalwege zu induzieren. Auch Brigstock (2002) vermutet, dass CYR61 seine eigene Signalkaskade initiieren kann und es genauso gut, durch 
andere Integrinkontakte und Wachstumsfaktoren beeinflusst werden kann. Dies wäre eine mögliche Erklärung für den stetigen Anstieg der Sekretion, da die Synthese als auch Ausschüttung autokrin oder durch Wachstumsfaktoren ständig angetrieben wird. Die Bindung von CYR61 an HSPGs und Zelloberflächenintegrine kann, so Brigstock, ein Mittel zur Verfügung stellen, um beträchtliche Plastizität zu erreichen, denn Wachstumsfaktoren und CCN-Proteine seien in dynamischem Fluss miteinander. Eine Großzahl dieser Effekte werden durch Zelloberflächenintegrine vermittelt, darunter Integrin $\alpha v \beta 3$ in Endothelzellen, $\alpha 6 \beta 1$ und HSPGs in Fibroblasten und glatten Muskelzellen $\alpha \operatorname{IIb} \beta 3$ in aktivierten Plättchen, $\alpha \mathrm{M} \beta 2$ in Monozyten und Makrophagen und $\alpha \mathrm{D} \beta 2$ in Makrophagenschaumzellen (Jedsadayanmata et al. 1999; Grzeszkiewicz et al. 2002; Schober et al. 2002; Bai et al. 2010). So scheint das Protein auch einen Einfluss auf das Immunsystem zu haben, da es mit Monozyten und Makrophagen in Kontakt stehen kann. Zudem wurde im Jahr 2000 von Xu et al. festgestellt, dass WISP-1, ein weiteres Mitglied der CNNFamilie und eng verwandt mit CYR61, ein auf Wnt-1- und $\beta$ b-Catenin reagierendes Onkogen darstellt. Transfiziertes und überexprimiertes WISP-1 in normalen Ratten-Nierenfibroblasten (NRK-49F) induzierte deren morphologische Transformation, beschleunigte das Zellwachstum, erhöhte die Sättigungsdichte in vitro und ermöglichte die Bildung von Tumoren in Nacktmäusen. In Anbetracht der Tatsache, dass CYR61 vier identische strukturelle Domänen aufweist und eng mit WISP-1 zusammenhängt (Xie et al. 2001), könnte es auch an den Wnt-1- und $\beta b-C a t e n i n-W e g e n$ beteiligt sein, insbesondere an denjenigen, die die Tumorentwicklung und progression fördert.

Somit scheint es einen Einfluss von Wachstumsfaktoren auf das CYR61-Protein zu geben, was zu einer schnellen und stetig ansteigenden Sekretion dieses Proteins führt. Die Ausschüttung kann dann wiederum einen Synergismus von Autostimulation des Proteins und Anregung weiterer Wachstumsfaktoren bewirken. Die Wachstumsfaktoren induzieren weiterhin das CYR61Protein, was zur Stimulierung von Mitogenese in Fibroblasten und Endothelzellen mit resultierender Angiogenese führt (Grzeszkiewicz et al. 2002).

All das sind Vorgänge, die in einem Tumorgeschehen dafür sorgen, dass der Tumor destruktiv wachsen kann und über Anbindung an Blutgefäße Tumorbestandteile in Form von zirkulierenden Tumorzellen, Tumor-DNA oder Proteinen an seine Umgebung und somit in den Körperkreislauf abgeben kann. Dies sichert sein Tumorüberleben, birgt aber auch Chancen für den Untersuchenden diese Tumorbestandteile über eine Blutanalyse zu detektieren. 


\subsection{Eignung von CYR61 als neuer Tumormarker in der Mammakarzinom-früherkennung}

Im nächsten Schritt wollte ich durch Sandwich-ELISA Messungen von Mammakarzinompatientinnen, mittels des Tests ELICYR (entwickelt von Prof. Pantel und Dr. Bartkowiak) erfahren, in welchen Mengen CYR61 im Blut von Mammakarzinompatientinnen vorkommt und ob sich die CYR61-Messung im Blut zur Erkennung von Mammakarzinomen eignen könnte. Dazu sollte vergleichend das Blut gesunder Frauen ab 50 Jahren untersucht werden, um dies in Bezug zu der Menge an CYR61 im Blut krebskranker Frauen zu setzen, und um anschließend Sensitivitäten und Spezifitäten des Tests berechnen zu können. Die Wahl einer gesunden Kontrollgruppe, deren Alter in etwa das Alter der Karzinompatientinnen widerspiegelt ist wichtig, um ein altersabhängiges Bias auszuschließen, und wird in vielen Publikationen zur Krebsfrüherkennung nicht berücksichtigt. Die Analyse ergab zunächst bei Mammakarzinompatientinnen einer unselektionierten Kohorte aus der UKE-Biobank $(\mathrm{n}=786)$ eine mittlere CYR61-Konzentration von 25,1 $\pm 40,9 \mathrm{ng} / \mathrm{mL}\left(\mathrm{p}<2 \times 10^{6}\right)$. Diese Konzentration war nahezu signifikant $(\mathrm{p}=0,05)$ höher als bei gesunden Frauen, die lediglich eine mittlere CYR61-Konzentration von 0,59 \pm $0,19 \mathrm{ng} / \mathrm{mL}$ zeigten. In ähnlicher Weise war die mittlere CYR61-Konzentration von Patientinnen mit DCIS $(\mathrm{n}=74) \mathrm{im}$ Vergleich zu den gesunden Kontrollen mit 31,8 \pm 45,8 ng/mL ( $\mathrm{p}<2$ $\times 10^{6}$ ) ebenfalls signifikant erhöht. Interessanterweise war die Standardabweichung der Werte bei den gesunden Frauen im Vergleich zu den Karzinompatientinnen $( \pm 0,19$ ng/mL vs. $\pm 40,1$ ng/mL) sehr gering. Zur Ermittlung eines Cut-off-Wertes für karzinomspezifisch erhöhte CYR61-Werte, wurde anschließend eine ROC-Kurve für das gesamte Kollektiv ( $\mathrm{n}=786$ ) erstellt und ein Cut-off-Wert von 0,962 ng/mL errechnet, der sicherstellte, dass die CYR61-Werte von gesunden Frauen allesamt unter diesem Wert lagen. Mithilfe des nun errechneten Cut-offWertes ließ sich ebenso die Zahl an CYR61-positiven und CYR61-negativen Plasmaproben ermitteln.

Unter Anwendung des Cut-off-Wertes waren 71 \% der Plasmaproben von Mammakarzinompatientinnen CYR61-positiv und 29 \% waren CYR61-negativ. Aus der ROC-Kurvenanalyse ergab sich bei einer Spezifität von $100 \%$ eine Sensitivität um die $70 \%$ für das Gesamtkollektiv. Diese Messungen zeigten bereits das Potenzial des CYR61-Proteins, da es anscheinend in gesunden Frauen nur in sehr geringen Mengen und mit geringer Streuung der Werte auftrat und die mittlere CYR61-Konzentration bei Mammakarzinompatientinnen um den Faktor von ca. 42 erhöht war. Dennoch konnte man auch die Limitation erkennen, dass knapp 30 \% der Karzinome übersehen wurden. 
Im nächsten Schritt sollten Korrelationen zwischen der CYR61-Konzentration und Tumorgröße ermittelt werden. Erwartet wurde, dass die CYR61-Konzentrationen mit der Tumorgröße, also dem T-Stadium aus der TNM-Klassifikation, korrelieren (Xie et al. 2001; Grzeszkiewicz et al. 2002). Je größer der Tumor ist, desto höher sollte auch der CYR61-Konzentration im Blut ansteigen. Zudem wurde vermutet, dass womöglich ein Zusammenhang zwischen der CYR61-Konzentration im Blut und dem Hormonrezeptorstatus im Tumorgewebe bestünde, da die CYR61-Expression von Gestagenen induziert werden konnte (Xie et al. 2001; Sampath et al. 2002, S. 61; Hsiao 2015). Überraschenderweise konnten wir solche Korrelationen in meiner Studie nicht messen. Für die Korrelation zum Tumorstadium ergab sich ein $\mathrm{p}$-Wert von $\mathrm{p}=$ 0,737 ( $\alpha=0,05)$ und für die Hormonrezeptorstatus-Subtypen (ER/PR/HER2) ein ebenso nicht signifikanter $\mathrm{p}$-Wert von $0,556(\alpha=0,05)$.

In der Literatur gibt es nur begrenzt Informationen zu CYR61-Messungen an klinischen Proben beim Mammakarzinom. In der Studie von Xie et al. (2001) zeigte die Arbeistgruppe, dass sich die Expression von CYR61-mRNA in einer gesunden Brustdrüsenzelllinie MCF-12A um das acht bis Zwölffache und in der normalerweise CYR61-negativen Karzinomzelllinie MCF-7 um das drei- bis Fünffache, nach 24- bzw. 48-stündiger Exposition von Östrogenen, erhöhte. Da die Autoren kein Östrogen-Response-Element in der Promotorregion des menschlichen CYR61 gefunden haben, spekulierte man, dass Östrogen indirekt durch ein oder mehrere auf Östrogen reagierende Gene wirkt, deren Produkt die Expression von CYR61 reguliert. In Übereinstimmung mit dieser Hypothese ist ihr Befund, dass Östradiol eine Verzögerung von acht bis 16 Stunden benötigt, um die sichtbare Anhäufung von CYR61-mRNA in den Brustzellen zu stimulieren. Allerdings blieb es hier bei dem Östrogen-Effekt letztlich bei einer Vermutung und müsste in weiteren Mammakarzinomzelllinien und im Blut und Tumorgewebe von Mammakarzinompatientinnen validiert werden. Da CYR61, laut dieser Studie, indirekt durch Östrogene induziert werden kann, müsste man annehmen, dass bei positivem Hormonrezeptorstatus $(\mathrm{ER}+)$, ein ebenso signifikanter $\mathrm{p}$-Wert für eine Korrelation mit erhöhten CYR61Konzentrationen ermittelt werden konnte. Solche Korrelationen beschrieben Xie et al. (2001) in Bezug auf den ER-Hormonrezeptorstatus und dem HER2-Status. Beides sind wichtige Faktoren für die Tumorprogression und Therapieentscheidung beim Mammakarzinom. In der Studie von Xie et al. (2001) zeigte eine univariate Analyse von 44 Patientinnen (Alterspanne zwischen 34 und 81 Jahren) mit invasivem Mammakarzinom, von Stadium T1 bis T3b, einen signifikanten oder grenzwertigen signifikanten Zusammenhang zwischen der Expression von CYR61-mRNA und dem Östrogenrezeptorstatus und dem HER2-Status. Insgesamt waren aber nur 16 Patientinnen der insgesamt 44 Patientinnen mit primärem Brustkrebs CYR61-positiv. 
Nun wurde in diesen „CYR61-positiven“ und „CYR61-negativen“ Kohorten der Hormonrezeptorstatus für HER2 und die mittleren ER-Scores ermittelt. Tumoren, die Cyr61-negativ waren, wiesen einen mittleren ER-Score von $40 \mathrm{fmol} / \mathrm{g}$ ( \pm 69 S. D.) auf, während diejenigen, die Cyr61-positiv waren, einen mittleren ER-Score von $102 \mathrm{fmol} / \mathrm{g}( \pm 110$ S. D.) ( $p=0,03)$ aufwiesen. Dies gab den Autoren den Anlass, eine Korrelation zwischen CYR61 und dem ERRezeptorstatus herzustellen. Der HER2-mRNA-Status wurde durch Echtzeit-PCR mit Her2/neu-spezifischen Primern bestimmt. Her2/neu war in 7 von 16 (44\%) CYR61-positiven Plasmaproben exprimiert. Vergleichend dazu war HER2/neu in nur 6 von 28 (21\%) CYR61negativen Plasmaproben stark exprimiert, was darauf schließen ließ, dass die Expression von CYR61-mRNA, also ein positiver CYR61-Status, ebenso positiv mit Her2/neuexpression korrelierte.

Auch hier konnte ich, im Gegensatz zu Xie et al. (2001), in meiner Studie mit einem p-Wert von $0,556(\alpha=0,05)$ für den Hormonrezeptorstatus keine signifikanten Korrelationen messen. Ein erhöhter CYR61-Wert umfasst somit, in meiner Arbeit, all diese verschiedenen Subtypen des Mammakarzinoms, unabhängig von Grading, Tumorgröße oder Hormonrezeptorstatus. Dies kann für einen breiten Einsatz in der Früherkennung von verschiedenen Mammakarzinomsubtypen sprechen, da es nicht zwischen Hormonrezeptoren, Gradings oder Tumorgrößen unterscheidet, sondern diese absolut gleich gut detektiert. Zudem entspricht die HER2-Bestimmung am Tumor von Xie et al. nicht dem Standard der HER2-Bestimmung (ICC und eventuell FISH) wie in meinen Daten und kann aufgrund der niedrigen Kohortenanzahl $(\mathrm{n}=44)$ und der univariaten Analyse nur schwer mit meiner statistischen Analyse verglichen werden. CYR61-positiv bedeutete in der Studie von Xie et al., dass diese Tumorgewebeproben CYR61-mRNA exprimierten. In meiner Studie wurde, aufgrund des Bezugs zu Plasmaproben gesunder Frauen, ein Cut-off-Wert bestimmt, an dem sich die Aussage „CYR61 -positiv“ orientierte.

Die univariate Analyse von Xie et al. (2001) zeigte zudem entweder einen signifikanten oder grenzwertigen signifikanten Zusammenhang zwischen CYR61-mRNA-Expression im Blut und der Tumorgröße. Diese Aussage entstand daraus, dass nur 6 von 28 (21\%) der Individuen mit einer primären Mammakarzinomgröße von 1A ( $\leq 2 \mathrm{~cm}$ Durchmesser) oder $2 \mathrm{~A}(\leq 5 \mathrm{~cm}) \mathrm{Tu}-$ moren, CYR61-positiv waren. Im Vergleich dazu hatten 10 von 16 (63\%) der Individuen mit einem Stadium von entweder 3A oder 4B ( $\geq 5 \mathrm{~cm}$ ) CYR61 positive Mammakarzinome ( $\mathrm{p}=$ 0,006). Daraus wurde geschlussfolgert, dass mit zunehmender Tumorgröße mehr CYR61 exprimiert würde.

Anders als bei Xie et al. (2001) beobachtet, konnte ich in meiner wesentlich umfangreicheren Studie, keine signifikanten Korrelationen zwischen dem Blutplasmawerten von CYR61 und der 
Tumorgröße beobachten $(\mathrm{p}=0,737)$. Dazu passend verweise ich auf die Dynamik in meiner Studie, dass in ansteigenden Tumorstadien, die Sensitivität ab T3 stark abnahm. Hier muss allerdings betont werden, dass die geringe Anzahl von Patientinnen (T3 = 46 Patientinnen, T4 = elf Patientinnen) noch nicht aussagekräftig genug ist, um diesen Befund sicher zu untermauern. Eine Erklärung für diesen überraschenden Befund könnte sein, dass CYR61 ein Gen ist, das früh abgelesen wird (Brigstock 2002), getriggert durch Stresssituationen und Wachstumsfaktoren, so wie es in einem entstehenden Tumor vorkommt. Womöglich findet bei Tumorentstehung demnach eine vermehrte Proteinbiosynthese statt, die sich in früheren Stadien des Tumors und noch bei kleiner Größe zu seinem Maximum entwickelt, um somit das Tumorwachstum und Überleben, gerade zu Beginn, zu gewährleisten. So werden optimale Bedingungen für den Tumor geschaffen. Je weiter dieser dann wächst, könnte sich ein Optimum des Proteins einstellen, sodass es pro Zelle weniger stark sekretiert oder produziert wird. Somit könnten keine erhöhten CYR61-Werte im Blut von Patientinnen mit größeren Tumoren im Vergleich zu kleineren Tumoren auftreten. Zudem können sich im Inneren von größeren Tumoren Nekrosen befinden, was für eine schlechtere Blutversorgung spricht und wodurch CYR61 schwieriger in den Blutkreislauf des Körpers abgegeben werden kann. Ebenso könnte sekretiertes CYR61 durch Integrinrezeptoren an den Stromazellen des wachsenden Tumors abgefangen werden, ehe es in das Blut gelangt. Insgesamt bleiben dies aber nur Hypothesen, die in zukünftigen Studien untersucht werden müssten.

Zusammenfassend stand in der Arbeit von Xie et al. (2001) die Expression von CYR61-mRNA und die Menge an zytoplasmatischem CYR61-RNA im Mittelpunkt. Es wurden keine gesunden Kontrollpersonen untersucht und kein Grenzwert bestimmt. Eine Analyse des sekretierten CYR61 mit knapp 700 Blutproben, wie in unserer Studie, hat es in der Literatur noch nicht gegeben.

Ein weiteres Ergebnis meiner Arbeit, ergab sich zudem aus der ROC-Kurvenanalyse, wenn man das Kollektiv auf die Tumorgrößen von DCIS bis T4 aufschlüsselte. Hier stach besonders das Kollektiv der DCIS und der frühen invasiven T1- und T2-Stadien hervor. Die Analyse im Vergleich zu gesunden Proben ergab signifikant erhöhte Werte mit 31,8 \pm 45,8 ng/mL ( $\mathrm{p}<2 \times$ $10^{16}$ ) für DCIS und 25,1 \pm 40,9 ng/mL für T1 Tumore. Der Unterschied in der CYR61-Konzentration zwischen den Karzinompatientinnen und der DCIS-Gruppe war statistisch jedoch nicht signifikant ( $p=0$,253), was darauf hinweist, dass die CYR61-Spiegel bereits in sehr frühen Stadien des Mammakarzinoms hochreguliert und sezerniert werden und sich deshalb besonders für die Früherkennung eignen könnten. Bei einer vorgegebenen Spezifität von 100 \% ergab sich 
für den Nachweis von DCIS und den kleinen T1-Tumoren eine Sensitivität von 71,5 \% -74,3 $\%$.

Um die Eignung des Proteins für eine frühe Detektion zu prüfen, wurde das große Gesamtkollektiv von 786 Proben auf ein sogenanntes Früherkennungskollektiv reduziert. Es wurden ausschließlich 443 Patientinnen zum Zeitpunkt der Primärdiagnose DCIS/invasives Mammakarziom ausgewählt. Die Patientinnen hatten vor der Blutanalyse somit im Gegensatz zu der Gesamtkohorte, keine Therapien erhalten, die den CYR61-Blutwert verfälschen könnte. Zudem wurde die Kontrollkohorte gesunder Frauen ab 50 Jahren um 200 Plasmaproben ergänzt und die ROC-Kurvenanalysen erneut durchgeführt. Die Sensitivitäten bei 100\%iger Spezifität betrug für den Nachweis von DCIS und den frühen T1 bis T2 Läsionen 64,5 \%- 73,2 \%, wobei die T1-Läsionen wiederum mit der höchsten Sensitivität von 73,2 \% erkannt wurden. Im Vergleich zur Gesamtkohorte unterscheiden sich die Ergebnisse nicht im Wesentlichen. Das Früherkennungskollektiv weist eine etwas höhere Sensitivität für T1- und T2-Tumore auf und eine geringere Sensitivität für die relativ kleine DCIS Gruppe $(n=43)$. Aus klinischer Sicht und im Hinblick auf die Gefahr der Übertherapie ist diese erniedrigte Sensitivität im Vergleich zu frühen T1-Tumoren sogar positiv. Überdiagnoseraten und daraus resultierender Übertherapie werden auf bis zu $30 \%$ geschätzt, wobei die statistische Erfassung herausfordernd ist und eine große Dunkelziffer vermutet wird (IARC 2014). Die Schwierigkeit liegt darin, diejenigen Tumore früh zu detektieren, die potenziell lebensgefährlich sind und dessen Behandlung Frauen vor einem langen Leidensweg bewahrt und sie von solchen zu unterscheiden, die auch ohne Behandlung die Lebenserwartung einer Frau nicht beeinflussen.

Die AUC für T1-Tumore in dieser Arbeit wies einen Wert von 0,905 auf und ist mit der AUC von mammographisch festgestellten Läsionen mit einer AUC von 0,803-0,907 (AminololamaShakeri et al. 2017) vergleichbar.

Nach diesen ermutigenden Ergebnissen stellt sich die Frage, ob der ELYCYR-Test das Potenzial hat mit den jetzigen Diagnosestandards mitzuhalten.

Die Mammographie ist die einzige von der Europäischen Kommission anerkannte Methode zur Frühdiagnose von Brustkrebs für Frauen zwischen 50 und 69 Jahren. Ihre Spezifität ist allerdings durch die Dichte der Brust, die Technik und den auswertenden Radiologen, stark beeinflusst (Altobelli und Lattanzi 2014). Darüber hinaus ist die Biolgie des Mammakarzinoms sehr heterogen, was die starren Präventionsvorschriften, die in Deutschland in der Krebsvorsorge vorgesehen sind, nicht ausreichend berücksichtigen. Eine starre zweijährliche Kontrolle bei einer Frau ab 50 Jahren, kann einen Tumor dennoch zu spät erkennen lassen, wenn er in der 
Zwischenzeit entsteht. Häufigere Screenings sind aber teuer und es kommt zu einer Strahlenbelastung, die bei häufigeren Abständen akkumulieren würde. In diesem Fall muss Nutzen und Risiko miteinander abgewogen werden.

In einer schwedischen Studie von Blamey et al. (2000) wurde untersucht, ob jährliche Screenings eine Auswirkung auf die Senkung der Mortalitätsrate haben. 7.350 Frauen im Alter zwischen 50 und 62 Jahren wurden über drei Jahre zu jährlichen Mammographien-Screenings eingeladen und mit 38.492 Frauen verglichen, bei denen nur ein Mammographien-Screening alle drei Jahre durchgeführt wurde. Es ergab sich aufgrund von prognostischen Abschätzungen allerdings keine signifikante Senkung des Mortalitätsrisikos (5\%-11\%), was laut der Autoren sowohl nicht den Aufwand und die Kosten als auch die zusätzliche Strahlenbelastung der Frauen rechtfertigen würde.

Von 4.300.000 Frauen, die jährlich in Deutschland gescreent werden, bekommen $3 \%$, also 129.000 Frauen, eine erneute Einladung aufgrund eines auffälligen Befunds (Kooperationsgemeinschaft Mammographie 2018). 17.430 Frauen davon haben tatsächlich einen Tumorbefund, sodass mehr als $85 \%$ dieser Frauen weiteren nicht notwendigen Untersuchungen und emotionalen Sorgen ausgesetzt werden. Dies ist eine große psychische Belastung für die Frauen, die invasive Verfahren erhielten, welche jedoch vermeidbar gewesen wären. Genau an diesem Punkt könnte man Blutanalysen gut mit solchen bildgebenden Verfahren kombinieren, um unnötige und teure Zusatzuntersuchungen und emotionale Belastungen zu reduzieren.

Neben falsch-positiven Befunden spielen falsch-negative Befunde bei der Mammographie ebenso eine Rolle. Eine Analyse der Breast Screening Frequency Trial Group (2002) von 320 Mammakarzinomen, die zwischen August 1985 und Mai 1990 in einer untersuchten Population gefunden wurden, ergab, dass 77 Krebserkrankungen beim Mammographie-Screening übersehen wurden. Die übersehenen Läsionen wurden als falsch-negative Ergebnisse falsch diagnostiziert oder zu spät diagnostiziert, weil man diese Läsionen schon auf früheren Mammographiebildern hätte detektieren müssen, oder sie wurden bei der Auswertung der Bilder vom ersten von insgesamt zwei Lesern nicht erkannt. Die übersehenen Läsionen wurden mit 121 Krebserkrankungen verglichen, die bei der Mammographie im Screening richtig diagnostiziert wurden. Die falsch-negativen Befunde traten nach diesem Vergleich vor allem bei Frauen mit dichterem Brustgewebe auf $(p=0,046)$ und sie zeigten in der Regel weniger wahrscheinlich maligne Mikroverkalkungen, sondern eher eine sich entwickelnde Trübung als Indikation für das Mammakarzinom $(\mathrm{p}=0,005)$.

Im heutigen medizinischen Alltag werden diagnostische Verfahren auch einer strikten ökonomischen Analyse unterzogen. Die gesamten Gesundheitsausgaben von Krebserkrankungen in 
den Jahren 2002 bis 2015 betrugen rund 340 Mrd. € pro Jahr. Innerhalb dieser Gruppe der Neubildungen macht das Mammakarzinom an zweiter Stelle, nach Leukämien und Lymphomen, rund 2,2 Mrd. €, also 9,4 \%, aus (Bick 2006; Kooperationsgemeinschaft Mammographie 2018). Hier noch nicht miteingerechnet sind die indirekten Kosten durch sogenannte Produktivitätsausfälle, die sich zusammensetzen aus Versterben, den krankheitsbedingten Ausfall oder die unentgeltlich geleistete Pflege durch Angehörige. Die indirekten Kosten weisen in Bezug auf die direkten medizinischen Kosten eine vergleichbare Höhe auf. Die Autoren betonen hier dennoch, dass sich, trotz der medizinischen Fortschritte und des Effekts der demographischen Entwicklung, für den Zeitraum von 2004 bis 2015 kein überproportionaler Anstieg der Kosten der Krebsmedizin an den gesamten Gesundheitsausgaben nachweisen lässt (Schlander et al. 2018; Bick 2006; Kooperationsgemeinschaft Mammographie 2018). Die Kosten speziell für das Mammographie-Screening sind mit rund 250 Millionen Euro jährlich sehr hoch (Bick 2006).

Die oben genannten Analysen unterstreichen die Bedeutung der Entwicklung neuer Methoden zur präventiven und frühen Diagnostik von Mammakarzinomen als Ergänzung der Mammographie deutlich. Solch eine Methode könnte im Prinzip eine einfache Blutanalyse wie unser ELICYR-Test darstellen. Die Kosten unseres CYR61- Sandwich-ELISAs (ca. $50 €$ pro Messung) und die einer Blutabnahme sind erheblich niedriger als die einer Mammographie. Zudem kann die Blutentnahme von jedem Arzt durchgeführt werden. Sicherlich muss noch das Problem der ca. $30 \%$ falsch-negativen Ergebnisse angegangen werden. So ist es notwendig weitere Biomarker hinzuzuziehen, um die Sensitivität zu steigern. Zudem besteht die Möglichkeit, Biomarker, wie das CYR61, mit einer Mammographie oder anderen bildgebenden Verfahren zu kombinieren. So könnte den bereits erwähnten starren Präventionsvorschriften einer zweijährigen Mammographie und der bestimmten Altersvorgabe entgegengewirkt und die Heterogenität des Tumors besser berücksichtigt werden. In Bezug auf die falsch-positiven Werte ist der ELICYR-Test besonders spezifisch, gerade im Vergleich zur Mammographie, da er bisher eine vorgegebene Spezifität von 100 \% aufwies. Eine gesunde Frau wird daher als gesund diagnostiziert und keinen unnötig emotionalen Ängsten und teilweise invasiven Folgeuntersuchungen ausgesetzt. Da diese Arbeit aber eine Case-Control-Studie ist, sollte man hier anmerken, dass sie nicht direkt mit den Werten von Mammographiekohortenstudien verglichen werden kann. Solche wesentlich umfangreicheren Kohortenstudien beziehen sich stets auf ein Gesamtkollektiv gescreenter Frauen, die in einem Risikoalter sind, während wir in unserer Case-Control-Studie ein ausgewähltes Kollektiv von Frauen mit bekannter Diagnose untersucht haben.

Eine frühe Erkennung von Brustkrebs führt zu einem frühen Einsatz von therapeutischen Maßnahmen wie der frühzeitigen operativen Resektion des Karzinoms, die das Risiko von Rezidiven 
und Todesfällen senken können (Puliti et al. 2008; Basu et al. 2018, Pantel und Hayes 2017; Pantel und Alix-Panabieres 2019 ). Pan et al. (2017) beschrieben in ihrer Studie, dass nach fünf Jahren adjuvanter endokriner Therapie, während des gesamten Untersuchungszeitraums von fünf bis 20 Jahren, immer wieder Mammakarzinomrezidive auftraten. Das Risiko eines Rezidivs korrelierte stark mit dem ursprünglichen TN-Status, wobei die Risiken zwischen $10 \%$ und 41 \% lagen, abhängig vom TN-Status und dem Grading. Je größer der Tumor, desto höher waren auch die Rezidivraten. Kam zusätzlich ein Lymphknotenbefall hinzu, stieg das Risiko noch weiter an.

Doch selbst bei sehr früher Tumorerkennung würde man bei einigen Patientinnen schon zu spät kommen, da bereits Tumorzellen gestreut sind. Man vermutet, dass bereits bei früher Tumorentstehung der solide Primärtumor Zellen ins Blut abgibt, die dort zirkulieren und in andere Organe oder das Knochenmark extravasieren (Bidard et al. 2016; Mohme et al. 2016). Hierbei können diese Tumorzellen eine EMT durchlaufen, die zu Metastasen mit unterschiedlichen Eigenschaften als der Primärtumor führt. Diese Metastasen entgehen im Frühstadium zum einen der Detektion, da es bisher keine Blutanalyse als präventive Diagnostik in der Brustkrebsvorsorge gibt und zum anderen entgehen sie der auf den Primärtumor abgestimmten Therapie und stellen einen Grund für Therapieresistenzen und Tumorrezidive dar. Um die Bedeutung einer einfachen Blutuntersuchung für die frühe Detektion von Mammakarzinomen und deren Rezidive zu untersuchen, muss diese Methodik in Form von prospektiven Studien in die Klinik validiert werden.

Wir haben bisher gezeigt, dass der Nachweis von CYR61 durch ELSIA als unkomplizierter Bluttest angewendet werden kann. Dieser Test benötigt weniger als $0,5 \mathrm{~mL}$ Blut, ist sehr kostengünstig und erlaubt einen hohen Durchsatz, der zu jeder Zeit in einer Praxis und im klinischen Setting nicht invasiv stattfinden kann. Unser Bluttest ist daher in der Lage, Mammakarzinome im Frühstadium mit hoher Präzision, jedoch ohne Strahlenbelastung oder aufwendige Instrumente zu identifizieren. Die Sensitivität unseres Tests muss jedoch noch verbessert werden.

Trotz der vielversprechenden Ergebnisse weist die vorliegende Studie einige Limitationen auf. Es scheint eine Untergruppe von etwa $30 \%$ der Mammakarzinompatientinnen ohne erhöhte CYR61-Spiegel im Blut zu geben, wodurch die Sensitivität für alle Tumorgrößen derzeit bei 70 \% liegt. Die Kombinationen von CYR61-Messungen mit zusätzlichen Protein- oder DNA-Markern können dazu beitragen die Empfindlichkeit des aktuellen Bluttests zu erhöhen. Einen ersten Ansatz über das Potenzial solcher Bluttests, in denen eine Kombination verschiedener Biomarker eingesetzt wird, konnten Cohen et al. (2018) mit dem Cancer-Seek-Test demonstrieren. 
Sie kombinierten Proteinbiomarker mit genetischen Biomarkern, um die Sensitivität ihres Tests zu erhöhen, ohne die Spezifität wesentlich zu senken. Durch den Cancer-SEEK-Test waren im Durchschnitt 70 \% der acht Krebstypen (Eierstock, Leber, Magen, Pankreas, Ösophagus, Colorektum, Lunge und Brust) positiv und reichten von $98 \%$ bei Ovarialkarzinomen bis $33 \%$ bei Mammakarzinomen. Die Sensitivität lag zwischen $69 \%$ und $98 \%$ für die Erkennung von fünf Krebsarten (Eierstock, Leber, Magen, Pankreas und Ösophagus), für die es keine Screeningtests für Patientinnen mit mittlerem Risiko gibt. Die Spezifität vom Cancer-SEEK-Test betrug bei allen Krebsarten mehr als 99 \%. Andere Krebsbiomarker, wie Metaboliten, mRNA-Transkripte, miRNAs oder methyliert DNA-Sequenzen könnten auf ähnliche Weise kombiniert werden, um zunehmende Senistivitäten und Lokalisierung des Tumors zu detektieren.

Zudem wären Kombinationen aus dem ELICYR-Test mit einer Mammographie oder anderen bildgebenden Verfahren eine Möglichkeit frühe Tumore rechtzeitig zu entdecken. Außerdem wäre es interessant zu untersuchen, wie sich das Protein bei benignem Mammakarzinom verhält und ob es die Möglichkeit besitzt zwischen malignem und benignem Typ des Tumors zu unterscheiden. Zudem zeigten Studien, dass das Protein auch in Entzündungsvorgängen und an nicht tumorösen Krankheiten beteiligt sein kann. Daher wäre es interessant zu erforschen, wie sich das Protein bei generellen weit verbreiteten Erkrankungen wie Diabetes oder Herz-KreislaufErkrankungen verhält. Diese Ansätze werden im Rahmen des Früherkennungsprojekts derzeit untersucht. Zudem zeigt die Datenlage deutlich, dass Sekretions- und Signalwege des CYR61Proteins noch einige Fragen offenlassen. Zu diesen Fragen zählen die Klärung der genauen Sekretionsvorgänge in der Zelle bei Stimulation durch EGF oder durch Autostimulation an Integrinen und HSPGs. Zudem wäre es interessant herauszufinden, welche indirekten Faktoren in Wechselwirkung mit der Auschüttung von CYR61 stehen und welche Zellprozesse und Zellfaktoren diese Wechselwirkungen anstoßen. Diese Forschung hat das Projekt, um die EGFStimulation und Hypoxie-Induktion bereits angestoßen, was in Zukunft auf interessante Erkenntnisse hoffen lässt.

In Zukunft müssen noch Patientinnen mit gutartigen Brusttumoren (oder anderen NichtKrebserkrankungen) in die vorliegende Analyse einbezogen werden. Schließlich muss der klinische Nutzen von CYR61 als diagnostischer Marker in einer prospektiven Kohortenstudie von Personen mit unbekanntem Krankheitsstatus, die das Risiko haben, Krebs zu entwickeln, validiert werden. Diese Personen müssen vom Zeitpunkt der ersten Blutentnahme bis zur Diagnose von Krebs und über die anfängliche Therapie (z. B. chirurgische Eingriffe) hinaus verfolgt werden, um zu beweisen, dass die Früherkennung von Krebs aufgrund unseres Bluttests Leben retten kann. Neben umfangreichen populationsbasierten Screeningstudien, die zehntausende 
von Testpersonen erfordern, kann die Analyse von Personen mit bekanntem Mammakarzinom und Keimbahnmutation (z. B. Keimbahnmutationen in BRCA-Genen), die ein sehr hohes Risiko für die Entwicklung von Krebs haben, ebenso Daten zum Nutzen des CYR61-basierten Bluttests in der Klinik (clinical utility) liefern. Der vorgestellte Bluttest (ELICYR) könnte in der Zukunft verwendet werden, um den besten Zeitpunkt der Mammographie und anderer bildgebender Verfahren bei Frauen mit Risiko zu bestimmen. Aktuelle Screeningprogramme, die feste Zeitpunkte für Mammographie-Scans verwenden, ignorieren die komplexe Variabilität der Mammakarzinombiologie. Die günstigen Auswirkungen des organisierten Screenings sind jedoch gut etabliert. Trotz einiger möglicher Vorurteile in Bezug auf die Verringerung der Sterblichkeit haben alle Untersuchungen zu Mammakarzinom-Screeningprogrammen in Europa konsequent gezeigt, dass Früherkennung einen positiven Einfluss auf die Reduktion der Mortalität besitzt, der aber durch verbesserte Ansätze noch optimierbar ist (Altobelli und Lattanzi 2014; Basu et al. 2018). Eine flexible, auf Biomarkern basierende Strategie könnte dazu beitragen, die derzeitigen Konzepte des Mammakarzinom-Screenings weiter zu verbessern. 


\section{$5 \quad$ Zusammenfassung}

Die Idee, eine Krebserkrankung anhand von bestimmten Proteinen im Blut feststellen zu können, bevor der Tumor disseminiert ist und Metastasen bilden kann, beschäftigt die angewandte Krebsforschung schon seit Jahrzehnten. Bisher gelingt dies, wenn auch mit sehr eingeschränkter Genauigkeit, nur beim Prostatakarzinom. Bei allen anderen Karzinomarten gibt es derzeit keinen Bluttest, der in der Klinik etabliert ist.

Der Fokus dieser Arbeit sollte deshalb auf das Potenzial des Cystein-rich-angiogenic 61 Proteins (CYR61) für die frühe Erkennung vom Mammakarzinom gelegt werden. Mittels Westernblotanalyse wurde in zwölf Zelllinien, die bevorzugt Mammakarzinomzelllinien waren, das Maß der CYR61-Expression und seine Assoziation mit einem Epithelialen-Mesenchymalen-Transitions(EMT)-Phänotyp untersucht. Darüber hinaus konnten Schlüsse über das Vorliegen und die Mengenverhältnisse des Proteins und über den Einfluss von Wachstumsfaktoren wie dem epidermal growth factor (EGF) und Stressfaktoren, wie Hypoxie, gezogen und mittels SandwichELISA und Westernblotanalyse untersucht werden. Anschließend wurden Plasmaproben von Patientinnen mit Mammakarzinom aus einer bestehenden Biobank gesammelt und die klinischpathologischen Parameter mittels Datenrecherche erhoben. Die CYR61-Konzentration wurde im Blutplasma von Mammakarzinompatientinnen bestimmt. Die ermittelten CYR61-Konzentrationen wurden mit den klinischen Parametern korreliert. Zudem wurden receiver-operating-characteristic(ROC)-Kurvenanalysen erstellt, um die Aussagen von Sensitivität und Spezifität für das Protein und einen Cut-off-Wert zu analysieren. Dazu wurden ebenso Plasmaproben gesunder Frauen (+50 Jahre) analysiert und in Bezug gesetzt.

Die Ergebnisse zeigten, dass CYR61 insbesondere in Mammakarzinomzellen mit einem EMTPhänotyp in größeren Mengen sekretiert wird und daher mit einer aggressiveren Form des Krebses assoziiert ist. Zudem wurde CYR61 in Mammakarzinomzelllinien unter Hypoxie verzögert ab der 16. bis zur 24. Stunde ansteigend sekretiert. Bei Stimulation mit EGF wurde eine bemerkenswert schnelle Sekretion von CYR61 nach 15 Minuten ab Beginn der Stimulation im Vergleich zu unstimulierten Kontrollen beobachtet. Diese stieg bis zur 24. Stunde der Stimulation kontinuierlich an. Es besteht also ein deutlicher Einfluss zwischen Eigenschaften des Tumormilieus wie Hypoxie und Wachstumsfaktoren und der Sekretion von CYR61.

Im klinischen Teil der Arbeit konnte gezeigt werden, dass das Protein zu früher Erkennung von Brustkrebs ein großes Potenzial aufweist, da es eine hohe Sensitivität von 70 \% für frühe Tumoren (DCIS bis T2) bei einer Spezifität von $100 \%$ aufweist. Zum anderen gab es keine signi- 
fikanten Korrelationen mit dem Fortschreiten einer Erkrankung, sodass das Signal eines erhöhten CYR61-Spiegels bei einem Tumor unabhängig von dessen Status oder Grading in gleicher Weise gut anspricht, aber keine Information über das Stadium der Erkrankung gibt.

Das CYR61-Protein weist somit eine interessante Biologie und ein großes Potenzial für die Früherkennung von Mammakarzinomen mittels einer Blutanalyse auf, was in weiteren Studien näher untersucht und validiert werden muss. Die Kombinationen von CYR61-Messungen mit zusätzlichen Protein- oder DNA-Markern können dazu beitragen, die Empfindlichkeit des aktuellen Bluttests zu erhöhen und das Mammographie-Screening zu ergänzen. 


\section{$6 \quad$ Anhang}

Diagramme über die CYR61-Proteinmengen und CYR61-Konzentrationen pro Tumorzelle und Zelllinien.

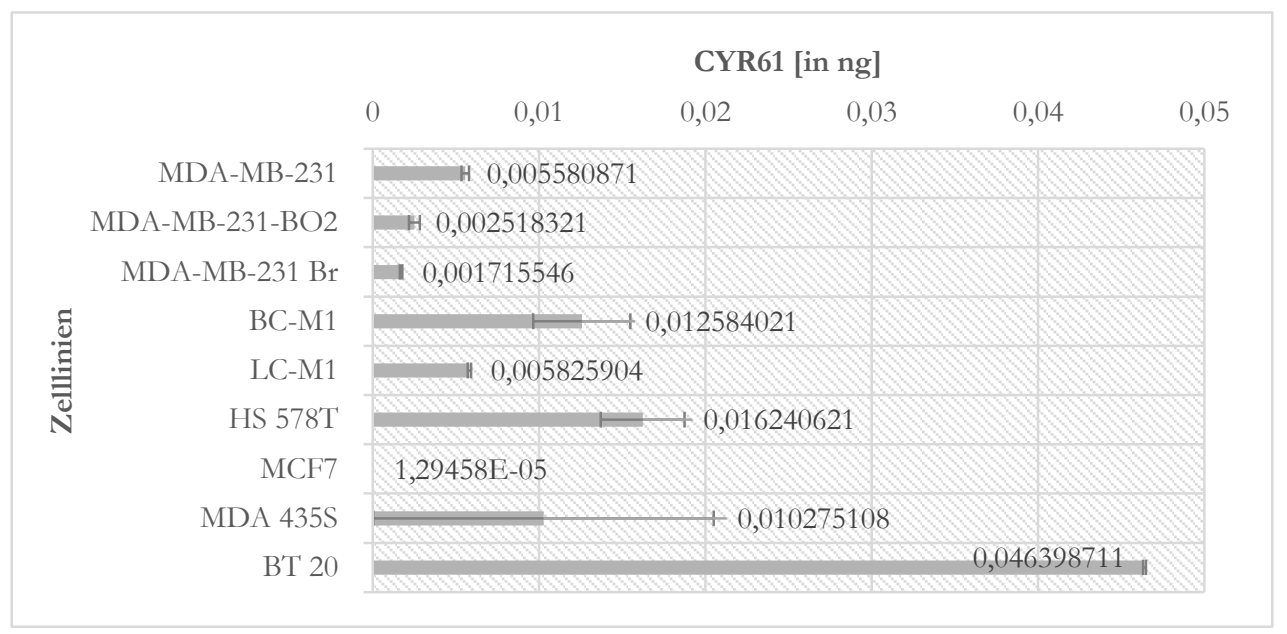

Abbildung A1: Menge an rekombinantem CYR61 [in ng] pro Zelle im Überstand. MDA-MB231, MDA-MB-231-BO2, MDA-MB-231-Br, BC-M1, BT-20, HS 578T und MCF-7 sind Mammakarzinomzelllinien. MDA-435S wurde ursprünglich auch in der Literatur als Mammakarzinomzelllinie geführt, hat sich aber in der Zwischenzeit als Melanomzelllinie offenbart. LC-M1 wurde aus DTCs im Knochenmark an einem Lungenkarzinompatienten etabliert. MCF-7 dient als Negativkontrolle. Die Messwerte sind der Mittelwert von Messungen aus biologischen Triplikaten und die Fehlerbalken entsprechen der Standardabweichung.

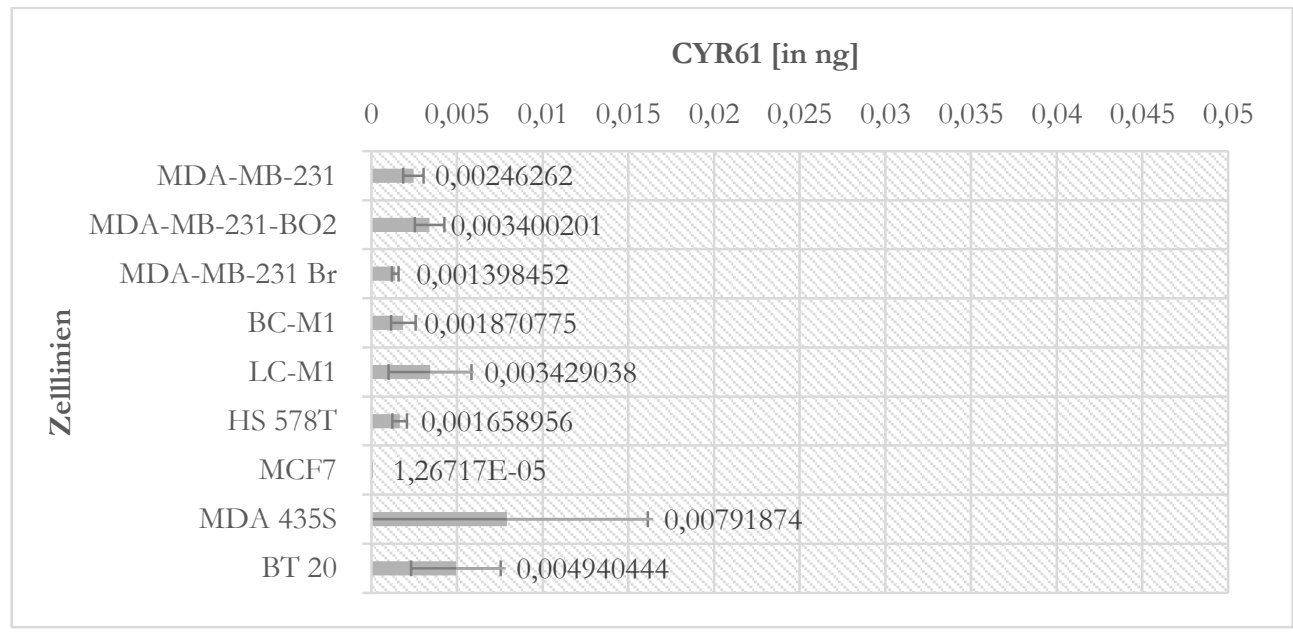

Abbildung A2: Menge an rekombinantem CYR61 [in ng] pro Zelle im Lysat. MDA-MB-231,
MDA-MB-231-BO2, MDA-MB-231-Br, BC-M1, BT-20, HS 578T und MCF-7 sind Mammakarzinom-
zellinien. MDA-435S wurde ursprünglich auch in der Literatur als Mammakarzinomzelllinie geführt, hat
sich aber in der Zwischenzeit als Melanomzellinie offenbart. LC-M1 wurde aus DTCs im Knochenmark
an einem Lungenkarzinompatienten etabliert. MCF-7 dient als Negativkontrolle. Die Messwerte sind
der Mittelwert von Messungen aus biologischen Triplikaten und die Fehlerbalken entsprechen der Stan-
dardabweichung. 


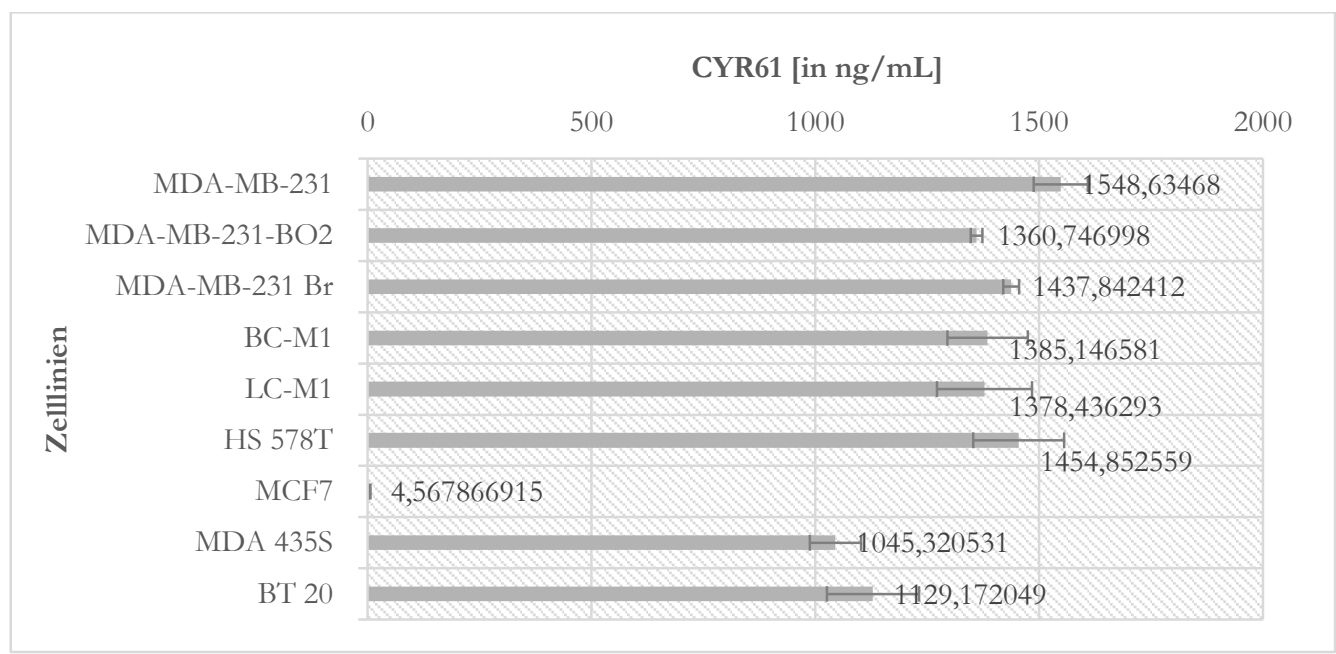

Abbildung A3: Menge an rekombinantem CYR61 [in $\mathrm{ng} / \mathrm{mL}$ ] pro Zelllinie im Überstand. MDAMB-231, MDA-MB-231-BO2, MDA-MB-231-Br, BC-M1, BT-20, HS 578T und MCF-7 sind Mammakarzinomzellinien. MDA-435S wurde ursprünglich auch in der Literatur als Mammakarzinomzelllinie geführt, hat sich aber in der Zwischenzeit als Melanomzelllinie offenbart. LC-M1 wurde aus DTCs im Knochenmark an einem Lungenkarzinompatienten etabliert. MCF-7 dient als Negativkontrolle. Die Messwerte sind der Mittelwert von Messungen aus biologischen Triplikaten und die Fehlerbalken entsprechen der Standardabweichung.



Abbildung A4: Menge an rekombinantem CYR61 [in ng/mL] pro Zelllinie im Lysat. MDA-MB-
231, MDA-MB-231-BO2, MDA-MB-231-Br, BC-M1, BT-20, HS 578T und MCF-7 sind Mammakarzi-
nomzelllinien. MDA-435S wurde ursprünglich auch in der Literatur als Mammakarzinomzelllinie ge-
führt, hat sich aber in der Zwischenzeit als Melanomzellinie offenbart. LC-M1 wurde aus DTCs im
Knochenmark an einem Lungenkarzinompatienten etabliert. MCF-7 dient als Negativkontrolle. Die
Messwerte sind der Mittelwert von Messungen aus biologischen Triplikaten und die Fehlerbalken ent-
sprechen der Standardabweichung. 


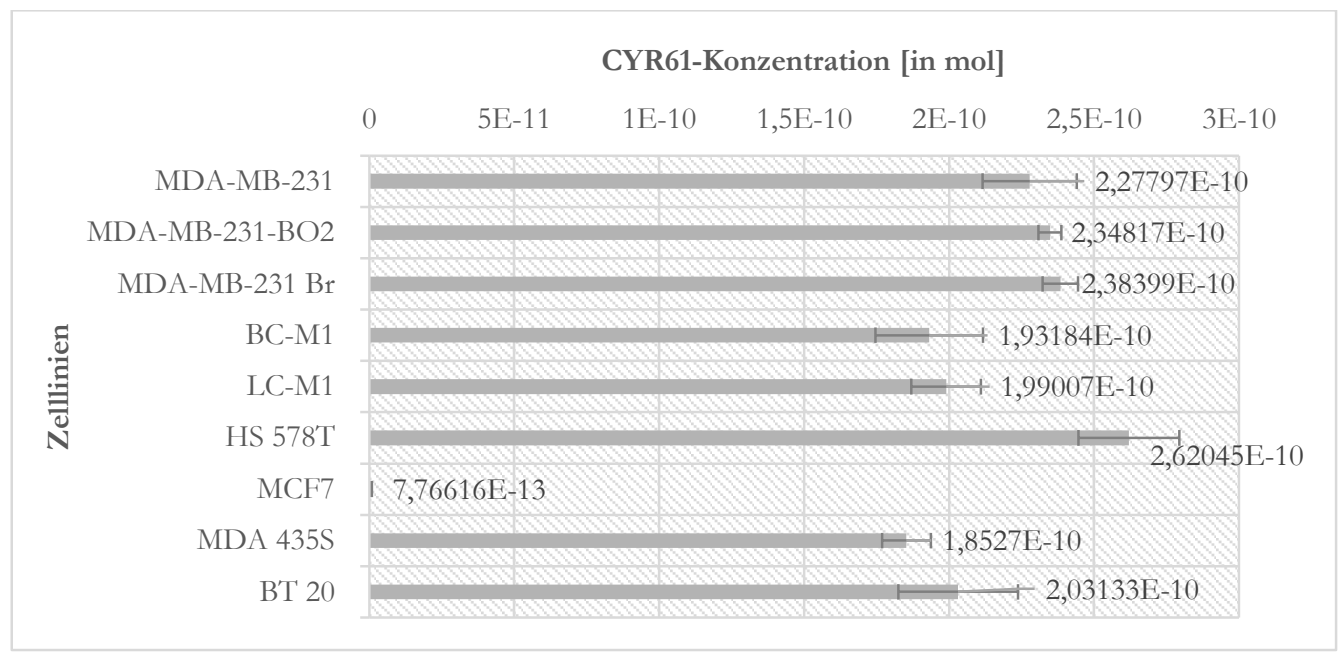

Abbildung A5: Menge an rekombinantem CYR61 [in mol] pro Zelllinie im Überstand. MDAMB-231, MDA-MB-231-BO2, MDA-MB-231-Br, BC-M1, BT-20, HS 578T und MCF-7 sind Mammakarzinomzellinien. MDA-435S wurde ursprünglich auch in der Literatur als Mammakarzinomzelllinie geführt, hat sich aber in der Zwischenzeit als Melanomzelllinie offenbart. LC-M1 wurde aus DTCs im Knochenmark an einem Lungenkarzinompatienten etabliert. MCF-7 dient als Negativkontrolle. Die Messwerte sind der Mittelwert von Messungen aus biologischen Triplikaten und die Fehlerbalken entsprechen der Standardabweichung.

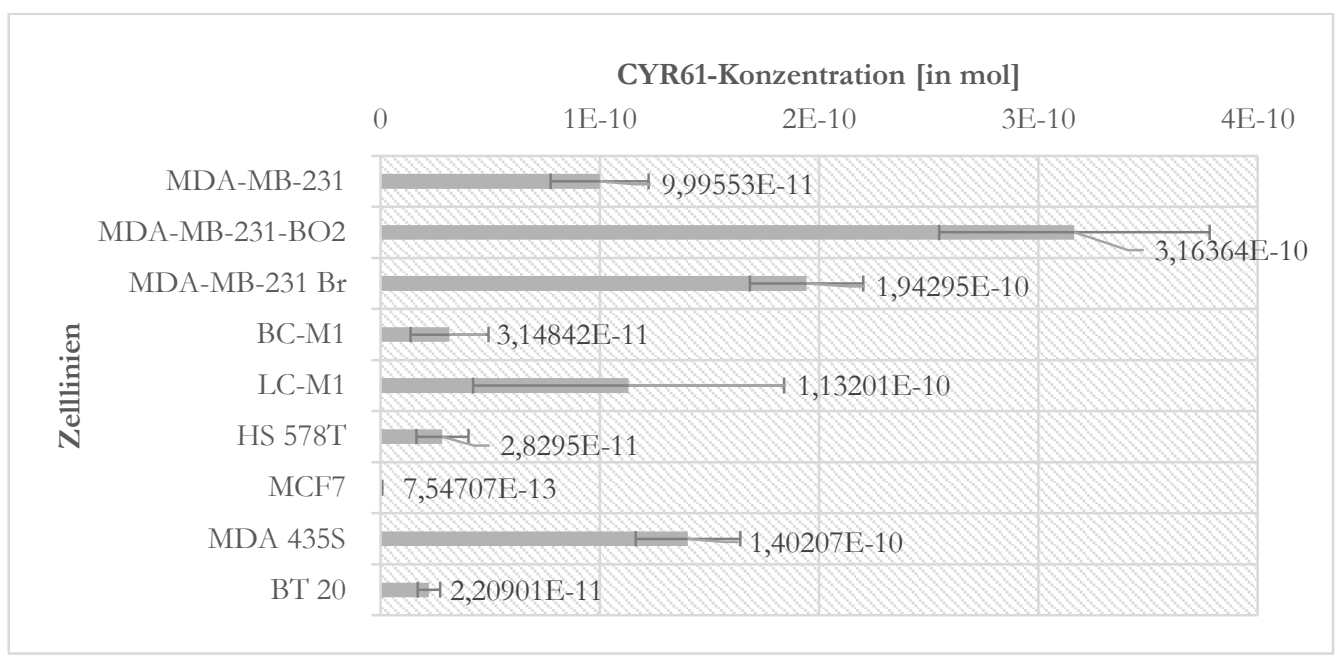

Abbildung A6: Menge an rekombinantem CYR61 [in mol] pro Zelllinie im Lysat. MDA-MB231, MDA-MB-231-BO2, MDA-MB-231-Br, BC-M1, BT-20, HS 578T und MCF-7 sind Mammakarzinomzelllinien. MDA-435S wurde ursprünglich auch in der Literatur als Mammakarzinomzelllinie geführt, hat sich aber in der Zwischenzeit als Melanomzelllinie offenbart. LC-M1 wurde aus DTCs im Knochenmark an einem Lungenkarzinompatienten etabliert. MCF-7 dient als Negativkontrolle. Die Messwerte sind der Mittelwert von Messungen aus biologischen Triplikaten und die Fehlerbalken entsprechen der Standardabweichung. 


\begin{abstract}
"WCERANGEN
09. Dez. 2015

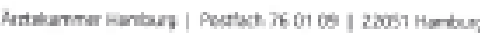

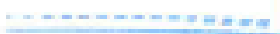

Herm

Prof. Dr. med. Klaus Pantel

Institut fur Tumorbiologie

Universitatsklinikum Hamburg-Eppendort

Martinistr. 52

20246 Hamburg

Q6. 12.2016

Bearb.-Nr.: PV5392 (Bitte stets angeben!)

Studientitel: Identifizierung und Charakterisierung von zirkulierenden und disseminierten Tumorzellen und Tumor-assoziierten Nukleinsăuren in Blut, Knochenmark und anderen Organen: Bestimmung von Biomarkern in Blut, Knochenmark und anderen Organen bei Tumorpatienten Aufbau einer Biobank zur Erforschung von Tumorerkrankungen
\end{abstract}

Sehr geehrter Herr Kolloge Pantel.

Ober Ihr oben bezeichnetes, zur Primarberatung vorgelegtes Projekt hat die EthikKommission in ihrer Sitzung am 29.11.2016 ausführlich beraten.

Das Vorhaben entspricht den ethischen und fachrechtlichen Anforderungen. Dic Ethik-Kommission stimmt dem Vorhaben zu.

Die Kommission weist darauf hin, dass die Verantwortung des Versuchsleiters fúr das Forschungsvorhaben und seine Durchfuhrung durch das obige Votum der Kommission nicht beruhrt wird.

Für den Fall der Durchfuhrung der Studie in Zentren anderer Kammerbereiche geht die Kommission won der Einbindung der lokal zuständigen Ethik-Kommission aus

Dis Ethik-Kommission bittet um Unterrichtung uber ale schwerwiegenden oder unerwarteten Ereignisse, die wăhrend der Studie auftreten und die die Sicherheit der Studienteilnehmer gefahrden, in Verbindung mit lhrer Stelungnahme.

Die Kommission geht davon aus, dass die personenbezogenen Daten der Probanden' Patienten den datenschutzrechtlichen Vorschriften entsprechend behandelt werden.

Zudem erlaubt sich die Kommission den unten folgenden Hirweis und emptiehit eine entsprechende Oberarbeitung der Dokumente. Ggf, im Nachgang vorgelegte, revidierte Unterlagen werden nicht erneut geprift, da die Beratung der Kommission mill desem Schreben beendet ist.

- Die Versendung von Proben und Daten zur Untersuchung und Auswertung in andere Länder undioder an andere Einrichtungen sollte anonymisiert erfolgen bzw. die Textstelen inhaitlich harmonisiert werden ivgl. Datenschutzpassus der Patienteninformationen und Eirwiligungserklarungen).

Bankwekindung Deutsche Apocheirer und Arztehank IBAN: DE713006 0601 0001345113 | BC: DAAFDECOXOXX
Weidestrabe $122 \mathrm{~b}$ | 22063 Harbum Telefon: $040 / 202299.240$ | Fax. 040/20 22 99-410 ethixeaskhnde | www aercekammer-hamburg de 
Bearb.-Nr.: PV5392

$-2-$

Die Ethik-Kommission erwartet, dass ihr nach Abschluss des Projektes unaufgefordert ein Abschluss-Bericht übersandt wird (unter Angabe der Bearb.-Nr.), aus dem der Erfolg/ Misserfolg der Studie sowie Angaben darüber, ob die Studie abgebrochen oder geändert bzw. ob Regressansprüche geltend gemacht wurden, ersichtlich sind.

Mit verbindlicher Empfehlung

im Auftrage der Kommission

Prof. Dr. med. R. Stahl

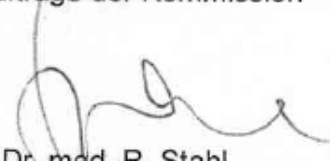

- Vorsitzender -

P.S. Die Ethik-Kommission arbeitet auf der Grundlage deutschen Rechts und Berufsrechts sowie in Anlehnung an die ICH-GCP. 


\section{$7 \quad$ Literaturverzeichnis}

Aguirre-Ghiso JA (2007): Models, mechanisms and clinical evidence for cancer dormancy. Nat Rev Cancer , 834-846

Alix-Panabières C, Pantel K (2016): Clinical Applications of Circulating Tumor Cells and Circulating Tumor DNA as Liquid Biopsy. Cancer Discov $\underline{6}$, 479-491

Alix-Panabières C, Bartkowiak K, Pantel K (2016): Functional studies on circulating and disseminated tumor cells in carcinoma patients. Mol Oncol 10, 443-449

Altobelli E, Lattanzi A (2014): Breast cancer in European Union: an update of screening programmes as of March 2014 (review). Int J Oncol 45, 1785-1792

Aminololama-Shakeri S, Flowers CI, McLaren CE, Wisner DJ, de Guzman J, Campbell JE, Bassett LW, Ojeda-Fournier H, Gerlach K, Hargreaves J, et al. (2017): Can Radiologists Predict the Presence of Ductal Carcinoma In Situ and Invasive Breast Cancer. Am J Roentgenol 208, 933-939

AWMF Leitlinienprogramm Onkologie (2018): Früherkennung, Diagnostik, Therapie und Nach-sorge des Mammakarzinoms. Interdisziplinäre S3-Leitlinie für die Kurzversion 4.1 in Zusam-menarbeit mit DKG und Deutsche Kresbhilfe. AWMF-Registernummer: 032045OL. https://www.awmf.org/uploads/tx_szleitlinien/032-045OLk_S3_Mammakarzinom_2018-09.pdf; Zugriff am 12.02.2019

Babic AM, Kireeva ML, Kolesnikova TV, Lau LF (1998): CYR61, a product of a growth factorinducible immediate early gene, promotes angiogenesis and tumor growth. Proc Natl Acad Sci USA $\underline{95}, 6355-6360$

Bai T, Chen C-C, Lau LF (2010): Matricellular protein CCN1 activates a proinflammatory genetic program in murine macrophages. J Immunol 1950 184, 3223-3232

Bardelli A, Pantel K (2017): Liquid Biopsies, What We Do Not Know (Yet). Cancer Cell $\underline{31}$, 172-179

Basu P, Ponti A, Anttila A, Ronco G, Senore C, Vale DB, Segnan N, Tomatis M, Soerjomataram I, Primic Žakelj M, et al. (2018): Status of implementation and organization of cancer screening in The European Union Member States-Summary results from the second European screening report: Cancer Screening in European Union. Int J Cancer 142, 44-56

Bedi U, Mishra VK, Wasilewski D, Scheel C, Johnsen SA (2014): Epigenetic plasticity: a central regulator of epithelial-to-mesenchymal transition in cancer. Oncotarget $\underline{5}$, 2016-2029

Bednarz-Knoll N, Alix-Panabieres C, Pantel K (2012): Plasticity of disseminating cancer cells in pa-tients with epithelial malignancies. Cancer and Metastasis Reviews $\underline{31}$, 673-687

Bick U (2006): Mammographie-Screening in Deutschland:Wie, wann und warum? RöFo $\underline{178}$, 957-969 
Bidard F-C, Proudhon C, Pierga J-Y (2016): Circulating tumor cells in breast cancer. Mol Oncol $\underline{10}, 418-430$

Blamey RW, Wilson ARM, Patnick J (2000): Screening for breast cancer. BMJ 321, 689

Botha JL, Bray F, Sankila R, Parkin DM (2003): Breast cancer incidence and mortality trends in 16 European countries. Eur J Cancer 39, 1718-1729

Breast Screening Frequency Trial Group (2002): The frequency of breast cancer screening: results from the UKCCCR Randomised Trial. United Kingdom Co-ordinating Committee on Can-cer Research. Eur J Cancer $\underline{38}, 1458-1464$

Brigstock DR (2002): Regulation of angiogenesis and endothelial cell function by connective tissue growth factor (CTGF) and cysteine-rich 61 (CYR61). Angiogenesis $\underline{5}, 153-165$

Chang HY, Sneddon JB, Alizadeh AA, Sood R, West RB, Montgomery K, Chi J-T, van de Rijn M, Botstein D, Brown PO (2004): Gene Expression Signature of Fibroblast Serum Response Predicts Human Cancer Progression: Similarities between Tumors and Wounds. PLoS Biol 2, E7

Chu D, Paoletti C, Gersch C, VanDenBerg DA, Zabransky DJ, Cochran RL, Wong HY, Toro PV, Cidado J, Croessmann S, et al. (2016): ESR1 Mutations in Circulating Plasma Tumor DNA from Metastatic Breast Cancer Patients. Clin Cancer Res 22, 993-999

Cohen JD, Li L, Wang Y, Thoburn C, Afsari B, Danilova L, Douville C, Javed AA, Wong F, Mattox A, et al. (2018): Detection and localization of surgically resectable cancers with a multi-analyte blood test. Science $\underline{359}, 926-930$

Coussens LM, Werb Z (2002): Inflammation and cancer. Nature $\underline{420}$, 860-867

dkfz-Deutsches Krebsforschungszentrum (2014): Tumormarker: Hintergründe. https://www.krebsinformationsdienst.de/untersuchung/tumormarker-hintergrund.php; Zugriff am 09.04.2019

DKG- Deutsche Kresbgesellschaft (2018): Brustkrebs-Früherkennung. https://www.krebsgesellschaft.de/onko-internetportal/basisinformationen-krebs/krebsarten/brust-

krebs/frueherkennung.html; Zugriff am 09.04.2019

Fehm T, Hoffmann O, Aktas B, Becker S, Solomayer EF, Wallwiener D, Kimmig R, KasimirBauer S (2009): Detection and characterization of circulating tumor cells in blood of primary breast cancer patients by RT-PCR and comparison to status of bone marrow disseminated cells. Breast Cancer Res $\underline{11}, \mathrm{R} 59$

Fischer KR, Durrans A, Lee S, Sheng J, Li F, Wong S, Choi H, El Rayes T, Ryu S, Troeger J, et al. (2015): EMT is not required for lung metastasis but contributes to chemoresistance. Nature $\underline{527}, 472-476$

Fitzmaurice C, Akinyemiju TF, Lami FHA, Alam T, Alizadeh-Navaei R, Allen C, Alsharif U, Alvis-Guzman N, Amini E, Anderson BO, et al. (2018): Global, Regional, and National 
Cancer Incidence, Mortality, Years of Life Lost, Years Lived With Disability, and DisabilityAdjusted Life-Years for 29 Cancer Groups, 1990 to 2016: A Systematic Analysis for the Global Burden of Disease Study. JAMA Oncol 4, 1553-1568

Gerlinger M, Rowan AJ, Horswell S, Math M, Larkin J, Endesfelder D, Gronroos E, Martinez P, Matthews N, Stewart A, et al. (2012): Intratumor Heterogeneity and Branched Evolution Revealed by Multiregion Sequencing. N Engl J Med 366, 883-892

Grzeszkiewicz TM, Lindner V, Chen N, Lam SC-T, Lau LF (2002): The Angiogenic Factor Cyste-ine-Rich 61 (CYR61, CCN1) Supports Vascular Smooth Muscle Cell Adhesion and Stimu-lates Chemotaxis through Integrin $\alpha 6 \beta 1$ and Cell Surface Heparan Sulfate Proteoglycans. Endocrinology 143, 1441-1450

Hanahan D, Weinberg RA (2011): Hallmarks of Cancer: The Next Generation. Cell $\underline{144}$, 646674

Hellinger JW, Hüchel S, Goetz L, Bauerschmitz G, Emons G, Gründker C (2019): Inhibition of CYR61-S100A4 Axis Limits Breast Cancer Invasion. Front Oncol. ㅁ, 1074

Hohensee I, Chuang H-N, Grottke A, Werner S, Schulte A, Horn S, Lamszus K, Bartkowiak K, Witzel I, Westphal M, et al. (2016): PTEN mediates the cross talk between breast and glial cells in brain metastases leading to rapid disease progression. Oncotarget $\underline{8}$, 6155-6168

Hsiao K-Y (2015): Pathological functions of hypoxia in endometriosis. Front Biosci 7, 352-366 Huang AC, Postow MA, Orlowski RJ, Mick R, Bengsch B, Manne S, Xu W, Harmon S, Giles JR, Wenz B, et al. (2017): T-cell invigoration to tumour burden ratio associated with antiPD-1 response. Nature $\underline{545}, 60-65$

IARC- International Agency for Research on Cancer (2014) : Relaunch of the IARC Handbooks of Cancer Prevention . https://www.iarc.fr/news-events/relaunch-of-the-iarc-handbooksof-cancer-prevention; Zugriff am 21.02.2019

Jedsadayanmata A, Chen C-C, Kireeva ML, Lau LF, Lam SC-T (1999): Activation-dependent Adhe-sion of Human Platelets to Cyr61 and Fisp12/Mouse Connective Tissue Growth Factor Is Mediated through Integrin $\alpha$ IIb $\beta 3$. J Biol Chem 274, 24321-24327

Jordan NV, Bardia A, Wittner BS, Benes C, Ligorio M, Zheng Y, Yu M, Sundaresan TK, Licausi JA, Desai R, et al. (2016): HER2 expression identifies dynamic functional states within circulat-ing breast cancer cells. Nature $\underline{537}, 102-106$

Kang Y, Pantel K (2013): Tumor cell dissemination: emerging biological insights from animal models and cancer patients. Cancer Cell $\underline{23}, 573-581$

Keller L, Pantel K (2019): Unravelling tumour heterogeneity by single-cell profiling of circulating tumour cells. Nat Rev Cancer 19, 553-567

Kooperationsgemeinschaft Mammographie GbR (2018): Mammoreport- Daten und Fakten zum deutschen Mammographie-Screening-Programm. Die Kooperationsgemeinschaft 
Mammog-raphie wird getragen von der Kassenärztlichen Bundesvereinigung und dem GKV-Spitzenverband. Mammoreport, 28-34

Laemmli UK (1970): Cleavage of Structural Proteins during the Assembly of the Head of Bacterio-phage T4. Nature 227, 680-685

Lam H-M, Vessella RL, Morrissey C (2014): The Role of the Microenvironment - Dormant Prostate Disseminated Tumor Cells in the Bone Marrow. Drug Discov Today Technol 11 , $41-47$

Lau LF, Nathans D (1985): Identification of a set of genes expressed during the G0/G1 transition of cultured mouse cells. EMBO J 4 , 3145-3151

Leitline Mammakarzinom : siehe AWMF Leitlinienprogramm Onkologie (2018)

Lexikon der Neurowissenschaft (2005): immediate early genes. https://www.spektrum.de/lexikon/neurowissenschaft/immediate-early-genes/5987; Zugriff am 05.06.2019

Menendez JA, Vellon L, Mehmi I, Teng PK, Griggs DW, Lupu R (2005): A novel CYR61triggered 'CYR61- $\alpha \mathrm{v} \beta 3$ integrin loop' regulates breast cancer cell survival and chemosensitivity through activation of ERK1/ERK2 MAPK signaling pathway. Oncogene $\underline{24}$, 761779

Meng S, Tripathy D, Frenkel EP, Shete S, Naftalis EZ, Huth JF, Beitsch PD, Leitch M, Hoover S, Euhus D, et al. (2004): Circulating Tumor Cells in Patients with Breast Cancer Dormancy. Clin Cancer Res $\underline{10}, 8152-8162$

Merker JD, Oxnard GR, Compton C, Diehn M, Hurley P, Lazar AJ, Lindeman N, Lockwood CM, Rai AJ, Schilsky RL, et al. (2018): Circulating Tumor DNA Analysis in Patients With Cancer: American Society of Clinical Oncology and College of American Pathologists Joint Review. J Clin Oncol 36, 1631-1641

Mohme M, Riethdorf S, Pantel K (2016): Circulating and disseminated tumour cells — mechanisms of immune surveillance and escape. Nat Rev Clin Oncol 14, 155-167

Nguyen TN, Song YW, Cho SK (2016): Baicalein inhibits epithelial to mesenchymal transition via downregulation of CYR61 and LOXL-2 in MDA-MB-231 breast cancer cells. Molecules and cells $\underline{39}$, 909-914

Nieto MA, Huang RY-J, Jackson RA, Thiery JP (2016): EMT: 2016. Cell 166, 21-45

O’Brien TP, Yang GP, Sanders L, Lau LF (1990): Expression of cyr61, a growth factor-inducible immediate-early gene. Mol Cell Biol 10, 3569-3577

Pan H, Gray R, Braybrooke J, Davies C, Taylor C, McGale P, Peto R, Pritchard KI, Bergh J, Dowsett M, Hayes DF (2017): 20-Year Risks of Breast-Cancer Recurrence after Stopping Endocrine Therapy at 5 Years. N Engl J Med 377, 1836-1846 
Pantel K, Hayes DF (2017): Disseminated breast tumour cells: biological and clinical meaning. Nat Rev Clin Oncol 15, 129-131

Pantel K, Alix-Panabières C (2019): Liquid biopsy and minimal residual disease - latest advances and implications for cure. Nat Rev Clin Oncol 16, 409-424

Paoletti C, Muñiz MC, Thomas DG, Griffith KA, Kidwell KM, Tokudome N, Brown ME, Aung K, Miller MC, Blossom DL, et al. (2015): Development of Circulating Tumor CellEndocrine Therapy Index in Patients with Hormone Receptor Positive Breast Cancer. Clin Cancer Res $\underline{21}, 2487-2498$

Peyruchaud O, Winding B, Pécheur I, Serre C-M, Delmas P, Clézardin P (2001): Early Detection of Bone Metastases in a Murine Model Using Fluorescent Human Breast Cancer Cells: Appli-cation to the Use of the Bisphosphonate Zoledronic Acid in the Treatment of Osteolytic Lesions. J Bone Miner Res 16, 2027-2034

Pschyrembel Online (2016): HER2. https://www.pschyrembel.de/HER2/K00UQ/doc; Zugriff am 31.05.2019

Psychrembel Online (2016): Mammatumoren. https://www.pschyrembel.de/ Mammakar-zinom/K0DMW/doc; Zugriff am 31.05.2019

Puliti D, Miccinesi G, Collina N, De Lisi V, Federico M, Ferretti S, Finarelli AC, Foca F, Mangone L, Naldoni C, et al. (2008): Effectiveness of service screening: a case-control study to as-sess breast cancer mortality reduction. Br J Cancer $\underline{99}$, 423-427

Putz E, Witter K, Offner S, Stosiek P, Zippelius A, Johnson J, Zahn R, Riethmüller G, Pantel K (1999): Phenotypic Characteristics of Cell Lines Derived from Disseminated Cancer Cells in Bone Marrow of Patients with Solid Epithelial Tumors: Establishment of Working Models for Human Micrometastases. Cancer Res $\underline{59}$, 241-248

Sampath D, Winneker RC, Zhang Z (2002): The Angiogenic Factor Cyr61 Is Induced by the Proges-tin R5020 and Is Necessary for Mammary Adenocarcinoma Cell Growth. Endocrine $\underline{18}, 147-160$

Schlander M, Hernandez-Villafuerte K, Thielscher C (2018): Kosten der Onkologie in Deutschland. FORUM $\underline{33}, 330-337$

Schober JM, Chen N, Grzeszkiewicz TM, Jovanovic I, Emeson EE, Ugarova TP, Ye RD, Lau LF, Lam SC-T (2002): Identification of integrin $\alpha \mathrm{M} \beta 2$ as an adhesion receptor on peripheral blood monocytes for Cyr61 (CCN1) and connective tissue growth factor (CCN2): immediate-early gene products expressed in atherosclerotic lesions. Blood $\underline{99}, 4457-4465$

Thomas ET, Del Mar C, Glasziou P, Wright G, Barratt A, Bell KJL (2017): Prevalence of incidental breast cancer and precursor lesions in autopsy studies: a systematic review and metaanalysis. BMC Cancer $\underline{17}, 808$ 
Toy W, Shen Y, Won H, Green B, Sakr RA, Will M, Li Z, Gala K, Fanning S, King TA, et al. (2013): ESR1 ligand binding domain mutations in hormone-resistant breast cancer. Nat Genet $\underline{45}, 1439-1445$

Vogelstein B, Kinzler KW (2015): The Path to Cancer — Three Strikes and You're Out. N Engl $\mathrm{J}$ Med $\underline{373}, 1895-1898$

Vogelstein B, Papadopoulos N, Velculescu VE, Zhou S, Diaz LA, Kinzler KW (2013): Cancer Ge-nome Landscapes. Science $\underline{339}, 1546-1558$

Wetterwald A, van der Pluijm G, Que I, Sijmons B, Buijs J, Karperien M, Löwik CWGM, Gautschi E, Thalmann GN, Cecchini MG (2002): Optical Imaging of Cancer Metastasis to Bone Mar-row. Am J Pathol 160, 1143-1153

Wolf N: Hypoxische Regulation der matrizellulären CCN-Proteine CYR61 (CCN1) und NOV (CCN3) durch HIF-1alpha und TGF-beta3 im humanen Trophoblasten. Naturwissenschaft-liche Dissertation Duisburg-Essen 2010

Xie D, Miller CW, O’Kelly J, Nakachi K, Sakashita A, Said JW, Gornbein J, Koeffler HP (2001): Breast cancer. Cyr61 is overexpressed, estrogen-inducible, and associated with more advanced disease. J Biol Chem 276, 14187-14194

Xu L, Corcoran RB, Welsh JW, Pennica D, Levine AJ (2000): WISP-1 is a Wnt-1- and $\beta$-cateninresponsive oncogene. Genes Dev $\underline{14}, 585-595$

ZfKD- Zentrum für Krebsregisterdaten (2017): Krebs in Deutschland für 2013/2014. Robert Koch-Institut (Hrsg) in Zusammenarbeit mit der Gesellschaft der epidemiologischen Krebsregister in Deutschland e.V. 11. Ausgabe, 72-75 


\section{Danksagung}

Mein besonderer Dank gilt meinem wissenschaftlichen Betreuer Dr. rer. nat. K. Bartkowiak und Prof. Dr. med. K. Pantel, Leiter des Instituts für Tumorbiologie (ITB) des Universitätsklinikums Hamburg-Eppendorf (UKE), für die Möglichkeit an den spannenden Projekten mitwirken zu dürfen sowie für die hervorragende und umfassende Betreuung über die gesamte Zeit des Projekts und darüber hinaus. Zudem danke ich meinem Doktorvater Herrn Prof. Dr. S. Johnsen sehr herzlich für eine tolle und mittlerweile auch interkontinentale Betreuung und Unterstützung bei meiner Arbeit. Ich möchte ebenso Prof. Dr. rer. nat. C. Gründker für die Unterstützung und Mithilfe während des Verfassungsprozesses der Dissertation danken. Für die kompetente Beratung bei statistischen Fragestellungen gilt mein Dank Herrn Dr. S. Joosse (PhD B.A.Sc. MASt) aus dem ITB. Des Weiteren danke ich Prof. Dr. med. T. Müller, Stellvertretender Klinikdirektor und Facharzt für Frauenheilkunde und Geburtshilfe, und Priv.-Doz. Dr. rer. nat. L. Oliveira-Ferrer, wissenschaftliche Laborleitung aus selbiger Abteilung, und ihren Mitarbeiterinnen sowie Herrn Dr. med. S. Peine, Leitung des Instituts für Transfusionsmedizin, für die freundliche Kooperation in allen Fragestellungen und die Bereitstellung der Plasmaproben. Ich danke zudem den Mitarbeiterinnen und Mitarbeitern des Instituts für Tumorbiologie für die stets freundliche Hilfsbereitschaft und außerordentlich nette Zusammenarbeit. Dankend hervorheben möchte ich hiermit die folgenden Mitglieder der Arbeitsgruppe, die mich sehr unterstützt haben, bestehend aus Antje Andreas (MTA), Parinas Mossahebi (Ph.D.- Studentin) und Sebastian Gärtner (Ph.D.Student). Zuallerletzt möchte ich B. Pantel, K. Pantel, A. Pantel und F. Heidrich von Herzen für das unterstützende Mitwirken bei dieser Dissertation danken. 